\title{
Eine Zosimosquelle.
}

Inhalt.

I. Nachweis der Zosimosquelle S. 88. - II. Bestand der Zosimosquelle von der Regierung des Philippus Arabs bis zum SchluB S. 99. - III. Die Zosimosquelle und Eunapios S. 112. - IV. Dexippos von Philippus Arabs bis zum SchluB S. 118. - V. Zosimos und Julius Capitolinus S. 125. - VI. Verhältnis der Quellen zueinander S. 142. - SchluB S. 156.

Die folgende Untersuchung entstand in ihren Grundzügen als Vorarbeit zur Lösung einer von der philosophischen Fakultät der Universität Berlin gestellten Preisaufgabe: Die Einfälle der Goten in das römische Reich bis auf Konstantin. ${ }^{1}$ ) Wenn ich damals in der Lösung der eigentlichen Aufgabe keine rechten Fortschritte machte, so lag das außer dem Dazwischentreten anderer Tätigkeit auch an der unverhältnismäBigen Ausdehnung der Vorarbeit. Und doch schien mir eine eingehende Untersuchung notwendig, auf welchen Urquell die verschiedenen Berichte über die Goteneinfälle, besonders die wichtigsten, weil zusammenhängendsten, des Zosimos, zurïckgehen. Historische Daten haben für uns nur dann Wert, wenn sie aus annähernd zeitgenössischer Feder stammen, und wieder unterliegen sie ganz verschiedener Schätzung, je nachdem sie dem einen oder anderen Autor angehören; so hat denn auch die fast allgemeine Anschauung, dab die grobe Masse unserer Berichte auf Dexippos zurückgeht ${ }^{2}$ ), das Urteil darüber unzweifelhaft stark beeinflußt. Eine nähere Prüfung dieser Frage scheint mir daher angebracht, und ich hoffe, wenn auch nicht volle Klarheit über ein schwieriges Problem geschaffen, so doch eine erneute Erörterung der Quellenbeziehungen unvermeidlich gemacht zu haben.

Aus dem eben Gesagten geht schon hervor, $\mathrm{daB}$ es mir im wesentlichen nur auf die Primärquellen der einzelnen Berichte ankam, so daB mir nichts ferner lag, als mich etwa in das Gewirr der späteren byzantinischen Historiographie und ihrer Probleme zu stürzen, ein Gebiet,

1) Die Preisarbeit gleichen Titels von B. Rappaport ist 1899 erschienen. Die Quellenverhältnisse behandelt sie wesentlich referierend.

2) Selbst Mendelssohn in der Einleitung seiner Zosimos-Ausgabe hat sich doch nur gegen die direkte Benutzung der Chronika durch Zos. ausgesprochen. 
auf dem trotz erfolgreichster Arbeit der letzten anderthalb Jahrzehnte noch so unendlich viel dunkel und schwankend ist. Vermeiden mußte ich natürlich den Fehler, aus einer Parallele, die möglicherweise auf Abhängigkeit der einen Quelle von der andern beruht, schwerwiegende Schlubfolgerungen zu ziehen; dieser Anforderung glaube ich um so mehr entsprochen zu haben, als in der Arbeit auf die einzelne Parallele in der Regel wenig ankommt, die überwiegende Mehrzahl aber durch innere und äußere Merkmale gut gesichert erscheint. Was ich selbst von dem Beurteiler erwarten muB, ist nichts weiter als ein Verzicht aut das Vorurteil: Die Autorschaft des Dexipp sei von rornherein wahrscheinlich, weil er der einzige, uns bekannte, zeitgenössische Geschichtschreiber ist, der die fraglichen Ereignisse behandelte.

\section{Nachweis der Zosimosquelle.}

Bei direktem Vergleich zwischen Zosimos und den dürftigen sicheren Dexippos-Fragmenten müBten wir entweder aus geringfügigen Berührungspunkten einen Schluß ziehen oder ein "non liquet“ aussprechen. Ein einwandfreies Ergebnis läBt sich nur erwarten, wenn wir durch Vergleich des Zosimos mit anderen Quellen festzustellen vermögen, was er der einen oder andern Vorlage entnahm, und dann erst fragen, ob diese oder eine dieser Vorlagen mit Dexipp identisch ist beziehungsweise ihn ausgeschrieben hat. - Zweifellos mit Zosimos irgendwie verwandt sind für diese Zeit die Chroniken des Zonaras und Synkellos; ich gebe als Beispiel die Berichte über den Goteneinfall unter Valerian:

\begin{tabular}{|c|c|c|}
\hline Zos. & Zon. XI & Synk. $P$ \\
\hline 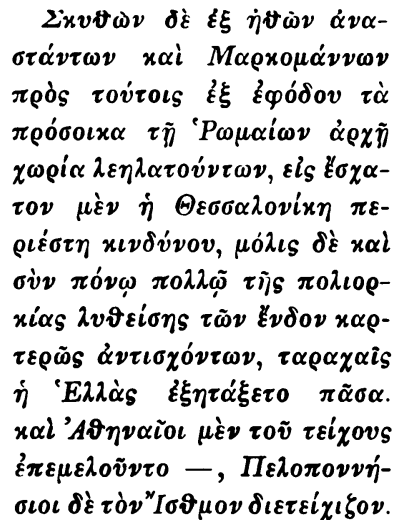 & 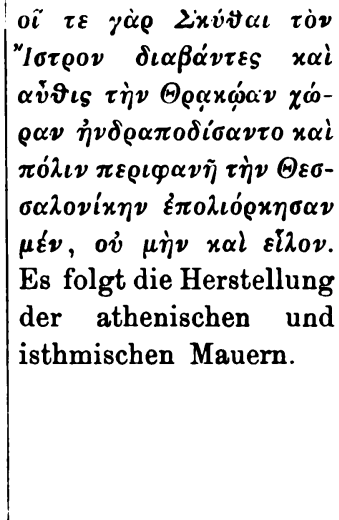 & 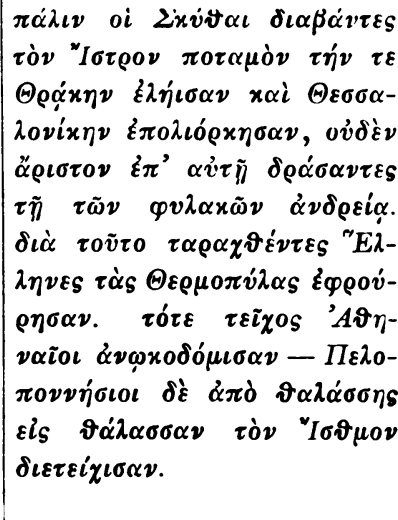 \\
\hline
\end{tabular}

Die Übereinstimmung ist unverkennbar. Daß Zon. und Synk. im Anfang gegen Zos. übereinstimmen, schlieBt ein direktes Zurückgehen auf diesen 
aus, wie denn Synk. auch am SchluB mehr gibt als Zos. Und daB Zon. hier am SchluB mit Zos. geht, macht es zum mindesten höchst unwahrscheinlich, daB er Synk. selbst ausgeschrieben habe. Wir werden außerdem später sehen, daß er noch eine zweite Quelle mit Synk. gemeinsam hat, daB aber an vielen Stellen, wo Synk. die eine dieser beiden Vorlagen benutzte, Zon. gerade auf die andere zurückgeht, und daB er, wo er Synk. parallel geht, die Quelle oft genauer als dieser wiedergibt. Der SchluB ist, daB Zosimos, Synkellos und Zonaras ihre gemeinsamen Nachrichten unabhängig voneinander aus derselben Vorlage erhielten. ${ }^{1}$ )

Um die Untersuchung auf eine breitere Basis stellen zu können, bietet sich als Wegweiser auffallenderweise einer der allerdürftigsten Geschichtsabrisse, die Epitome, die früher dem Aurelius Victor zugeschrieben wurde. Nachdem festgestellt worden war, daB die Schrift De Caesaribus und die Epitome nicht einem Verfasser angehören, sowie daB beide und außerdem Eutrop mit einem gemeinsamen Stamme andere Elemente selbständig verknüpften ${ }^{2}$ ), konnte Enmann ${ }^{3}$ ) für Eutrop

1) Ich muB hier gleich erklären, daB ich mich nicht an jeder einzelnen Stelle mit den scharfsinnigen Untersuchungen Patzigs (C̈ber einige Quellen des Zonaras, B. Z. V $24 \mathrm{ff}$.) auseinandersetzen kann. Sicher ist, daB die Synopsis ebenfalls der gleichen Quellenfamilie wie Zonaras angehört, nicht sicher, daB sie den Zosimos selbst benutzt habe, und von P. selbst p. 52 in Abrede gestellt, daB Zonaras auf sie direkt zurückgehe. $\mathrm{Zu}$ bedenken ist ferner, daB P. sich genötigt sieht, nicht nur den Zosimosstoff dem Zonaras durch zwei Quellen zukommen zu lassen, sondern p. 43 doch außerdem noch auf die Zosimosquelle zu recurrieren. Wenn sich endlich mit Hilfe der Synopsis und des Synkellos die Leoquelle rein ausscheiden lassen soll, so sind doch wieder einige Daten Gemeingut, wie z. B. die Notiz über die Körpergröße des Sapor bei Zonaras-Kedrenos und Synkellos. Für die Begründung einer anderen Scheidung der Quellen verweise ich, was Zonaras anbetrifft, vor allem auf Kap. V, wo sich für lange Strecken eine so reinliche Scheidung des Zonaras zwischen Zosimos und Dexippos vollziehen läBt, daß mir die Annahme einer derartig weitgehenden „Quellenpantscherei“, wie sie P. feststellen will, nicht notwendig erscheint. Der Kern meiner Arbeit würde sich übrigens selbst dann nicht wesentlich ändern, wenn Zonaras, wie P. annimmt, an gewissen Stellen auf Zosimos selbst zurückginge, da die weitaus meisten Parallelen außer durch Zonaras und die Leosippe noch durch ältere Quellen für die gemeinsame Vorlage gesichert sind.

2) Vgl. L. Jeep in Rivista di Filologia I p. $505 \mathrm{ff}$. A. Cohn „Quibus e fontibus Sexti Aurelii Victoris libri fluxerint". Berlin 1884. Wölfflin "Aurel. Victor". Rhein. Mus. N. F. 29, p. 283-308.

3) Philologus IV. Ergbd. p. $338 \mathrm{ff}$. Am nächsten kommt dem Enmannschen Ergebnis von den übrigen Forschern Cohn (vgl. z. B. das Schema auf S. 59). Das Verhältnis der Epitome zu Eutrop ist bei ihm sogar in einer Hinsicht richtiger und, sein kompliziertes System einmal angenommen, ziemlich einwandfrei. Nach- 
und die Caesares eine gemeinsame Quelle nachweisen, die, jetzt verloren, in ihrem ersten Teile die Geschichte der Kaiser bis zum Regierungsantritt Diokletians in biographischer Form nach einem bestimmten Schema behandelte, und die auch, in sehr verschiedenem Umfange, von mehreren der Scriptores historiae Augustae benutzt wurde. Der Verfasser der Epitome hätte nach ihm die Schrift De Caesaribus und den Eutrop unmittelbar ausgeschrieben. Auf das Verhältnis zu Eutrop komme ich noch zurück. Zunächst wende ich mich den Angaben zu, durch die sich die Epitome von der gemeinsamen Vorlage der beiden anderen unterscheidet. Ein nicht geringer Teil davon findet nämlich seine Parallelen bei Zosimos.

Ich beginne mit dem, wovon Enmann ausgeht; Eutrop und die Caesares kennen nur zwei Gordiane, die Epitome drei, ebenso wie Zos. und die verwandten Quellen. Schon vorher gibt er allein von den dreien die Zos. und Zon. gemeinsame (von Herodian stammende) Begründung des Hasses gegen Maximin: „Is dum persequitur pecuniosos,

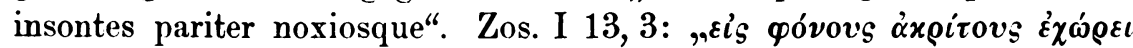

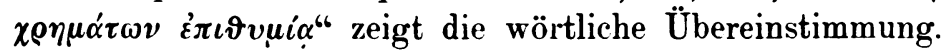

Wichtig ist die Erzählung rom Tode des Decius, wo zu Zos., Zon. und der Epit. als neuer Verwandter der Gewährsmann des Kedrenos und der sogenannten Chronik des Leo Grammaticus hinzutritt ${ }^{1}$ ):

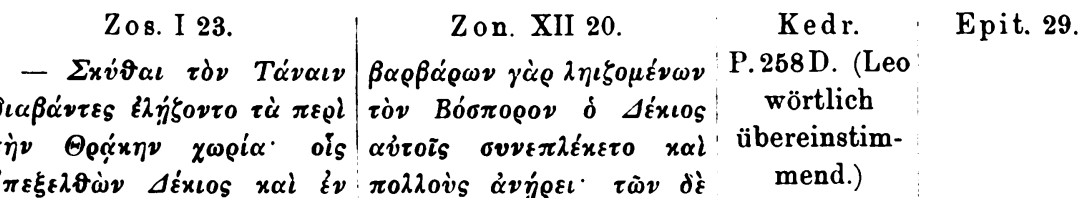

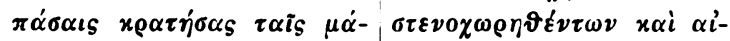

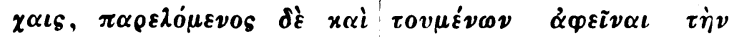

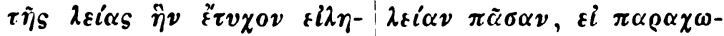

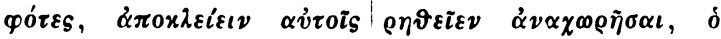

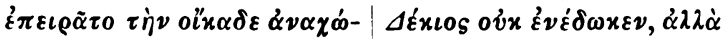

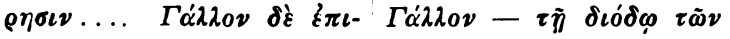

dem aber E. die Existenz der „Kaisergeschichte“ mindestens bis auf Diokletian und ihr Fortleben auch in den Scriptores historiae Augustae nachgewiesen hat, wird wohl für die frühere Zeit ebenfalls an Stelle des "Suetonius auctus" die „Kaisergeschichte" zu treten haben.

1) Ich führe in der Regel Kedrenos an, weil er mir die Quelle im ganzen vollständiger wiederzugeben scheint. Georgios Monachos, den Wiener und Pariser Codex habe ich ganz beiseite gelassen, weil sie nur in unzureichenden Drucken oder Auszügen zugänglich sind, weil ihre Stellung trotz der Studien von De Boor und Praechter noch nicht klar ist und deshalb die Ausscheidung des in ihnen enthaltenen heterogenen Materials - wie z. B. der Codex Paris. augenscheinlich Ausflüsse nicht nur der Zosimosquelle, sondern des Zos. selbst aufweist - nicht ohne große Mühe möglich ist. 


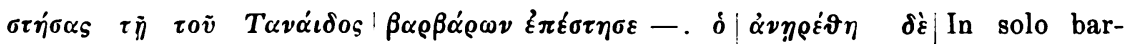
ö $\chi \vartheta \vartheta$

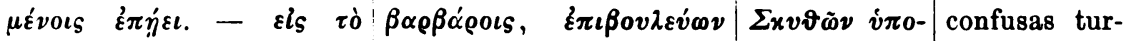

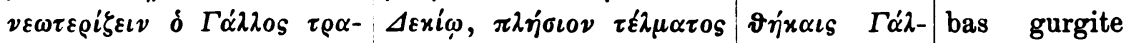

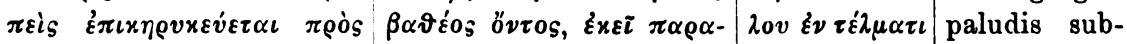

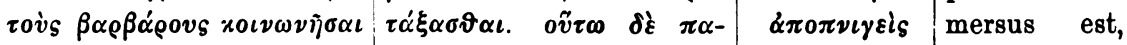

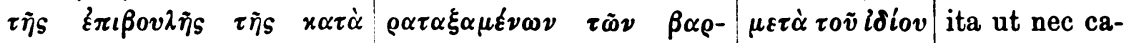

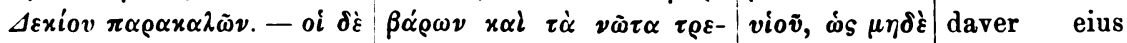

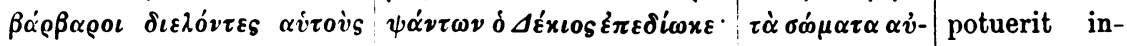

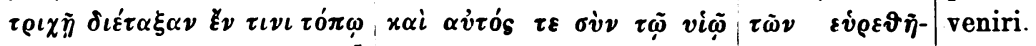

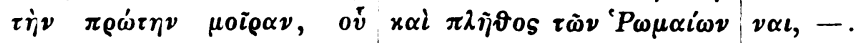

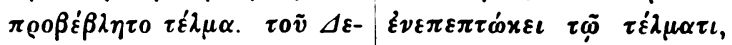

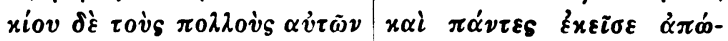

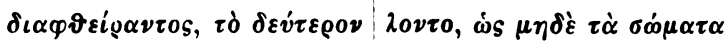

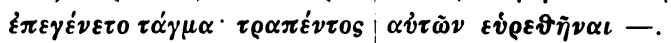
$\delta \grave{\varepsilon} x \alpha i \tau 0 \dot{\tau} \tau 0 v-\dot{\alpha} \gamma \nu 0 i \alpha \tilde{\alpha} \boldsymbol{\omega} \nu$

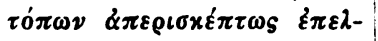
$\vartheta \dot{v} v, \quad \dot{\mu} \mu \pi \alpha \gamma \varepsilon i^{\prime} \xi \varepsilon \quad \tilde{\alpha} \mu \alpha \quad \tau \tilde{\eta}$ $\sigma \grave{v} \nu \alpha \dot{v} \tau \tilde{\omega} \delta \boldsymbol{v} \nu \alpha \dot{\mu} \mu \varepsilon \iota \tau \tilde{\omega} \pi \eta \lambda \hat{\omega}$

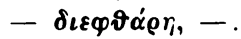

Auffallend ist hier die Übereinstimmung zwischen Zon., Kedr. und der Epit., deutlich aber weiter, daB Zon. nicht den Kedr. und beide natürlich nicht den Synk. ausgeschrieben haben können, da dieser hier einen ganz anderen Bericht bringt, der seinerseits mit dem bei Victor zusammengeht und, wie wir gleich bemerken können, von Dexippos stammt.

Im nächsten Kapitel der Epit. (Kap. 30) findet sich eine merkwürdige Abweichung von Eutrop-Victor. Während diese schlichtweg Gallus und Hostilianus zu Augusti, den Sohn des Gallus, Volusianus, zum Caesar erhoben werden lassen, schreibt die Epit.: „Vibius Gallus cum Volusiano filio imperaverunt annos duos. Horum temporibus Hostilianus Perpenna a Senatu Imperator creatus, nec multo post pestilentia consumptus est." Von Zos. können wir sonst nicht die Nennung jedes Gegenkaisers erwarten; hier erhalten wir von ihm allein Aufklärung: er berichtet, daB Gallus, der allgemeinen Anhänglichkeit an Decius nachgebend, dessen Sohn (eben Hostilian) zum Mitregenten angenommen, dann aber aus Furcht, durch ihn gestürzt zu werden, ihm nach dem Leben getrachtet habe. Bei Zon. und Kedr. endlich ist unter den Gegenkaisern des Philippus - was uns bei diesen beiden Schriftstellern nicht irre machen darf - ein sonst gänzlich unbekannter Hostilian (Justilian bei Kedr.) erwähnt, sicherlich unser Hostilian. Nach ihnen war er krank - auch Zos. erwähnt die damals wütende Pest und starb an einem AderlaB, den man als Kur anwandte.

Ich werde noch näher darauf einzugehen haben, daB Zonaras bis- 
weilen die Berichte mehrerer Autoren nebeneinander anführt. Das geschieht unter anderm bei Valerians Ende; nach der einen Nachricht wurde der Kaiser von Sapor gefangen und bis an sein Lebensende in Knechtschaft gehalten, nach der andern floh er selbst, da seine in Edessa hungernden Soldaten sich zu empören drohten. Eine dritte Version bietet Victor, diesmal mit Kedr.; auch bei ihnen wird Valerian gefangen, aber von Sapor grausam getötet. Die Epit. geht wieder mit Zon. zusammen.

Zon. XII 23, I $629 \mathrm{D}-630 \mathrm{~A}$.

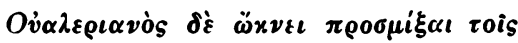
$\pi 0 \lambda \varepsilon \mu i o \iota s-\dot{\alpha} \nu \varepsilon \vartheta \dot{\alpha} \rho \sigma \eta \sigma \varepsilon-\sigma v \nu \varepsilon \pi \lambda \dot{\alpha} x \eta$

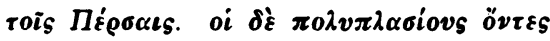

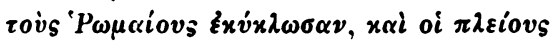

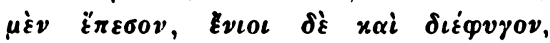

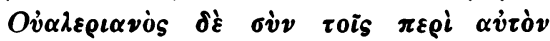

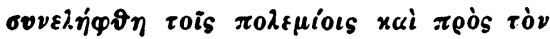

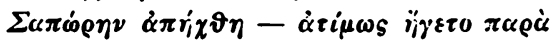

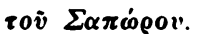

\section{Epit. 33.}

Valerianus rero in Mesopotamia bellum gerens, a Sapore Persarum rege superatus, mox etiam captus, apud Parthos ignobili servitute consenuit. Nam quamdiu vixit rex ciusdem provinciae, incurvato eo pedem cervicibus eius imponens, equum conscendere solitus erat.

Die Erzählung bei Zos. I 36 scheint auf den ersten Blick nicht unbeträchtlich abzuweichen, da nach ihm Valerian nicht in der Schlacht gefangen wird, sondern den Frieden durch Geld zu erkaufen versucht, worauf Sapor eine persönliche Zusammenkunft vorschlägt und ihn dabei ïberrumpelt. Bei näherer Betrachtung ergibt sich, daB der Bericht der Epit. von dem des Zos. nicht abweicht, da das "superatus" ausdrücklich von dem "captus" getrennt wird, also nicht andeutet, daß Valerian in der Schlacht gefangen worden sei. Der Text bei Zos. hat

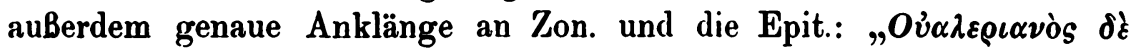

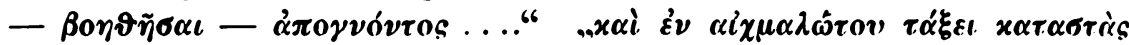

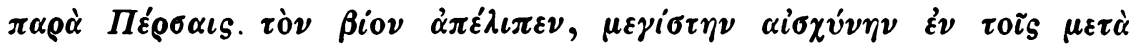

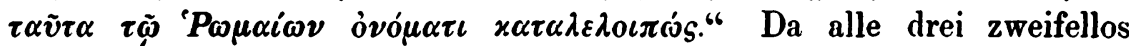
einen Gegensatz bilden gegen die beiden andern Versionen, so erklärt sich die Abweichung des Zon. am besten so, daß er einerseits aus der Niederlage des Kaisers auf eine Schlacht schloB, in der er gefangen worden sei $^{1}$ ), andrerseits, wie die Erwähnung von Edessa zeigt, ihm hier schon der Bericht seiner anderen Vorlage hineinfloB.

Die Epitome nennt Salonian als Sohn des Gallienus; Zos. I 38

1) Wie ersichtlich, komme ich mit De Boor „Röm. Kaiserg. in byzantin. Fassung", Byz. Z. 122 f., gut darin überein, daB sich Zon. ganz wohl mit Petr. Patr. fr. 9 verträgt, nur nicht gegen, sondern mit Zos. Der SchluB freilich ist ein anderer, nämlich da der Anonymus zur Zosimosquelle keine Beziehungen zeigt, daB nicht die vorliegende, sondern die andere Version bei Zonaras dem Anonymus angehört. 
berichtet, daB Postumus Galliens Sohn Salonin in Köln belagerte. Victor erwähnt des Claudius Bruder Quintillus nicht; die Epit. gibt seine kurze Regierung mit Zos. und den verwandten Quellen:

\section{\begin{tabular}{l|c|c|c|c} 
& Zon. XII 26 & Synk. & \\
Zos. I 47. & I 636 A B. & Kedr. P. 259 B. & P. 384 C. & Epit. 34.
\end{tabular}}

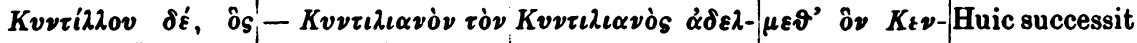

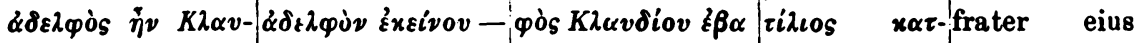

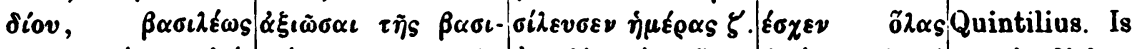

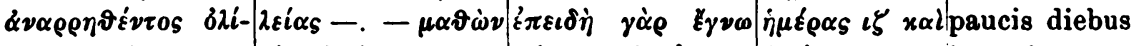

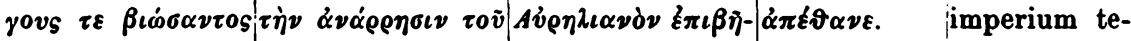

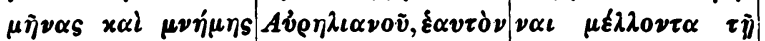

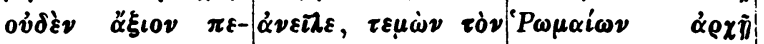

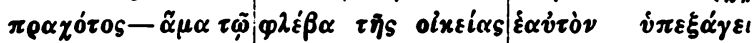

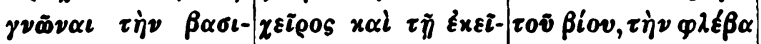

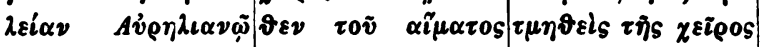

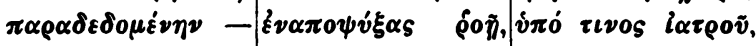

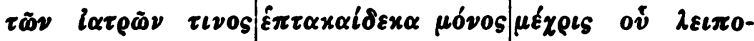

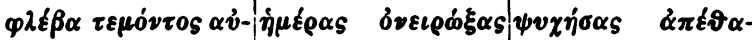

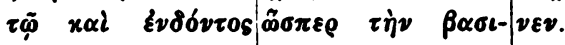
$\hat{\rho} \varepsilon \tilde{v} \sigma \alpha \iota$ to $\alpha i \mu \alpha, \lambda \varepsilon i \alpha v$.

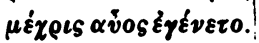
nens interemptus est.

Scheinbar weicht die Epit. dadurch ab, daB sie Quintilius getötet werden läßt. Doch hat sie mit den übrigen gegenüber Zos. den Fehler „paucis diebus" (die übrigen „17 Tage", wie auch sicher bei Kedr. zu emendieren ist). Da sich obnehin ergeben wird, daB die Epit. nicht die ganze Gesamtquelle, sondern einen Auszug benutzte, so dürfte sie eben darin die Todesart nicht angegeben gefunden haben, wie ja auch

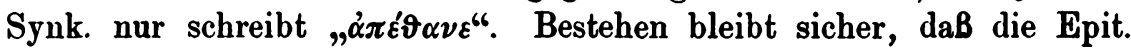
abweichend von Victor den Quintillus überhaupt erwähnt. Leo geht im übrigen Wort für Wort mit Kedrenos, hat aber einen Zusatz, der ihn von allen Quellen dem Zos. am nächsten bringt: $K$. - $\eta_{\mu \varepsilon \rho \alpha s}$

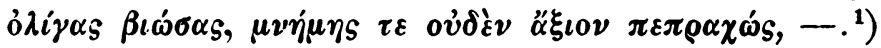

$\mathrm{Ob}$ die Angabe einer Alemannenschlacht des Claudius oder der drei Siege des Aurelian bei Placentia, an Metaurus und am Ticin mit dem Alemannenkampf bei Zos. I 49 etwas zu tun hat, lasse ich noch dahingestellt. Auffallen muB hingegen wieder, daB nur die Epit. und Zos. einen Septimius (Septiminus Ep.) als Gegenkaiser des Aurelian kennen.

1) Sotiriadis „Zur Kritik d. Joh. v. Ant.“ Jahrb. f. klass. Philol. XVI. Supplbd. p. 13 lïBt die Quelle des Zon. und Leo, wie an andern Stellen, so auch hier aus Zos. selbst schöpfen. Ich beschränke mich darauf, da die Unrichtigkeit dieser Ansicht in den gegebenen Parallelen zur Genüge hervortritt, für den vorliegenden Fall auf die tobereinstimmung mit Eutr. und Synk. gegen Zos. in bezug auf die Regierungszeit des Quintillus hinzuweisen. 
Damit haben wir eine ganze Reihe von Fällen kennen gelernt, in denen die Epitome im Gegensatz zu der Hauptquelle der Caesares und des Eutrop mit Zos. übereinstimmt, und bei einigen dieser Fälle lieB sich zeigen, daB auch Zon., Kedr. und Synk. der gemeinsamen Vorlage folgten. Nun benutzt aber auch Eutrop nicht immer die mit Victor gemeinsame Quelle, sondern geht bisweilen ihm gegenüber mit der Epit. zusammen; so ist nach beiden Decius „e Pannonia inferiore $\mathrm{Bu}$ baliae natus", beide erwähnen den Gegenkaiser des Probus Proculus und lassen Probus „in turri ferrata“ getötet werden. Eutrop sagt von den beiden Decii: "uterque in barbarico interfecti sunt"; trotzdem er die Einzelheiten übergeht, zeigt die wörtliche Übereinstimmung deutlich die Verwandtschaft mit der Epit. Und ebenso sind die Worte über die Gefangennahme Valerians bis auf den Buchstaben gleich. Deshalb werden auch diese Stellen des Eutr. auf unsere Gesamtquelle zurückgehen, und wir dürfen weitere Parallelen erwarten, wenn wir wieder die Angaben des Autors durchmustern, in denen er von Victor abweicht: Zos. I 37 spricht von einer Plünderung Italiens durch die Barbaren, Eutrop läBt die Alemannen bis Italien vordringen. Wichtiger ist der Bericht über Odenathos:

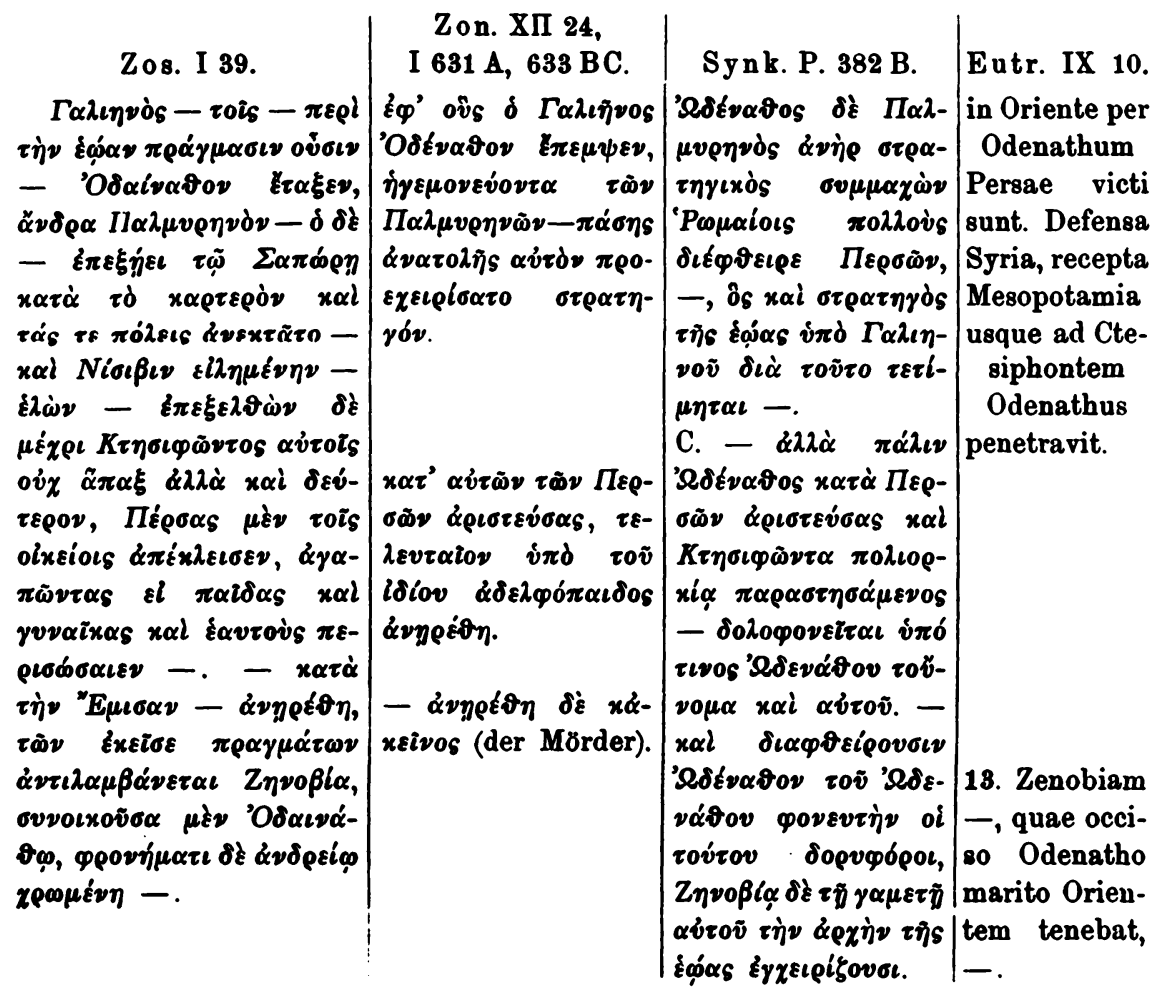


Die zum Teil wörtliche Übereinstimnung ist unverkennbar, trotzdem Zon. und Synk. das mit Zos. Gemeinsame bis zur Unkenntlichkeit mit Nachrichten fremder Quellen vermischen. Die Fortsetzung bildet die Geschichte der Zenobia, und wieder fordert Eutrop, da Victors Schrift Zenobia nicht erwähnt, zum Vergleich mit Zos. heraus: Zos. I 50-60 erzählt die Unterwerfung der Palmyrener bis ins kleinste ausführlich; der allgemeine Gang ist trotzdem sichtlich derselbe:
Zos. I.
Zon. XII 27.
Synk. P. 384-85.
Eutr. IX 13.

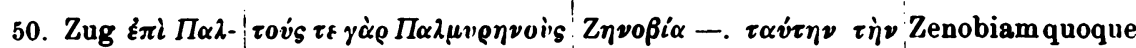

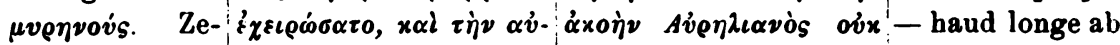

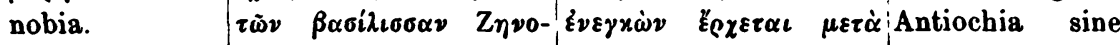

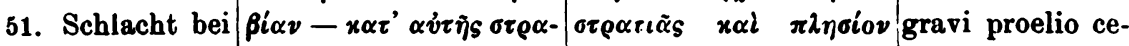

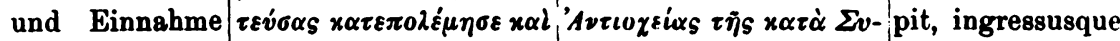

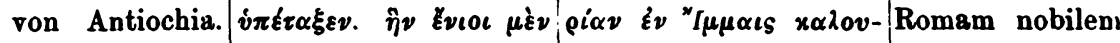

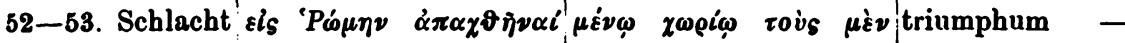

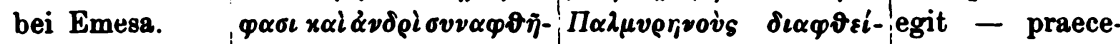

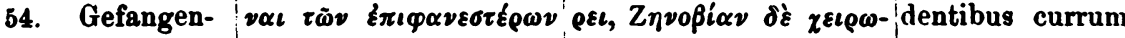

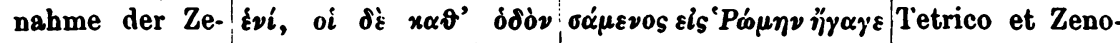

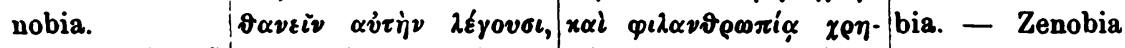

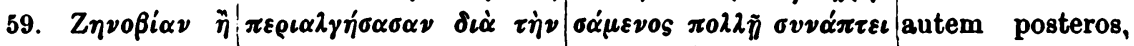

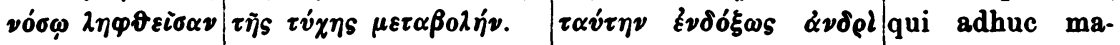

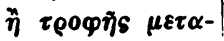
$\lambda \alpha \beta \varepsilon \tau \nu$ ov่ $\alpha \nu \alpha-$

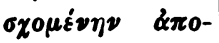

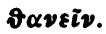

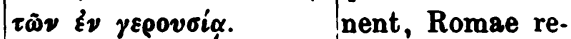

$$
\begin{aligned}
& \text { liquit. }
\end{aligned}
$$

Von den beiden Versionen über Zenobias Tod, wie Zos. und Zon. sie geben, bringt Eutrop nur die eine, Synk. hat dementsprechend wenigstens die Nachricht, daB sie nach Rom gebracht worden sei. Eutrop erwähnt Nachkommen der Zenobia, Zos. wenigsteus (Kap. 59) einell überlebenden Sohn.

Zum SchluB sei noch bemerkt, daB Eutrop genauer als die Epit. die Regierungsdauer des Quintillus mit den ülbrigen kleinen Quellen auf 17 Tage angibt.

Sicher erscheint, daB die dem Eutrop und der Epit. mit Zos. und den verwandten Chroniken gemeinsamen Nachrichten auf eine Quelle zurückgehen; und da die Epit. diese Vorlage, wie ein Vergleich zeigt, bisweilen vollständiger wiedergibt als Eutr., so ist klar, daB der Epitomator sie wenigstens ohne Vermittlung des Eutr. benutzte. Dagegen ergibt die oft wörtliche Übereinstimmung ganzer Sätze, mit denen die Ausführungen der Gesamtqualle ganz in nuce wiedergegeben werden, daB sie nicht diese direkt ausschrieben, sondern schon eine Art Epitome davon, und zweitens, daB dieser Auszug, wie sie ihn vorfanden, lateinisch geschrieben war.

Nachdem wir nunmehr einen gewissen sicheren Bestand von Nach- 
richten für die in Frage stehende Vorlage festgestellt haben, können wir uns an der Hand dieses Führers in das Labyrinth der Scriptores historiae Augustae wagen, und zwar an die Viten, die der bekannten großen Lücke folgen: Haben Trebellius Pollio und Vopiscus unsere Gesamtquelle benutzt?

Der Tod des Decius und die Stellung Hostilians fallen in die verlorenen Teile der Viten. Dem von Zos., Zon. und Synk. berichteten Skytheneinfall unter Valerian könnte die verstümmelte Stelle Gall. duo c. 5, 6 entsprechen: "Gothori clodius - a quo dictum est superius, Gothis inditum est, occupatis Thraciis Macedoniam vastaverunt, Thessalonicam obsederunt -." Das Ende des Valerian entspricht, soweit ersichtlich, Eutr.-Epit.: „Sed Valeriano apud Persas consenescente -“, seine Gefangenschaft wird mehrfach erwähnt. Über Odenath heißt es Trig. tyr. 15: „Odenathus - contra Persas profectus est. Nisibin primum et orientis pleraque cum omni Mesopotamia in potestatem recepit, deinde ipsum regem victum fugere coëgit. Postremo Ctesifonta usque Saporem et eius liberos persecutus captis concubinis, capta etiam magna praeda ad orientem vertit. - composito igitur magna ex parte orientis statu a consobrino suo Maeonio - interemptus est -“. c. 17: „Maeonius - brevi a militibus - interemptus est". c. 30: „Zenobia - post Odenathum maritum - imperavit." Gall. duo c. 12, 1: „Gallienus - (auf die Nachricht von Odenaths Siegen) Odenatum participato imperio Augustum vocavit eiusque monetam - cudi iussit." In den mehrfachen Erzählungen und Erwähnungen der Taten des Palmyreners ist der oben gegebene Text, hier und da mit verschiedenen $\mathrm{Zu}$ taten versetzt, die materia subsistens, und, wie ersichtlich, stimmt er durchans mit dem Bericht der Zosimosquelle, wobei es nicht auffallen kann, wenn Treb. Pollio die Weiber des Sapor wirklich gefangen nehmen läßt. In der Nennung von Nisibis sowie der Anspielung auf die persischen Weiber und Kinder steht er Zos. näher als irgendein anderer Autor. Den Namen des Saloninus, des Sohnes Galliens, erwähnt Treb. nicht nur (Gall. duo c. 19 u. Trig. tyr. 3), sondern er läßt ihn, wie Zos., durch Postumus umkommen. - Endlich geht Trebellius auch in dem Abschnitt über Quintillus den verwandten Chroniken parallel; Claud. c. 12, 3-5: „Quintillus frater eiusdem - suscepit imperium -. Quintillus autem ob brevitatem temporis nihil dignum imperio gerere potuit, nam septima decima die - interemptus est." Die Stelle „ob brevit. - potuit" stimmt wörtlich zu Zos., die 17 Tage zu Zon. (Kedr.) Synk. Eutr., das „interemptus est“ zur Epit. und Eutr. Gehen wir zu Vopiscus über; der Prüfstein ist Aurelians Kampf gegen Zenobia. Das Ergebnis entspricht den kühnsten Erwartungen: 
Zos. I 50.

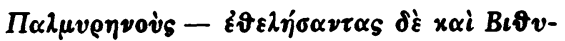

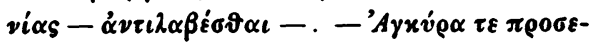

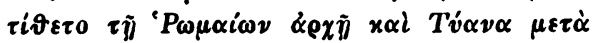

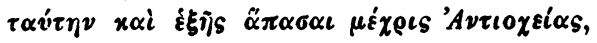

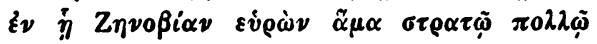

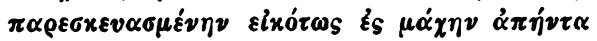

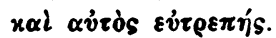

Antiochia wird ron den Palmyrenern verlassen, von $A$. besetzt.

Zos. I 52.

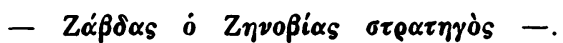

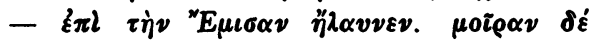

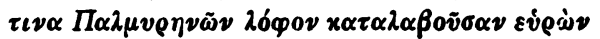

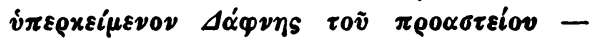

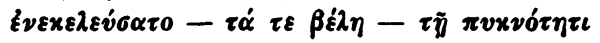

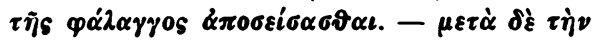

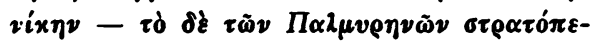

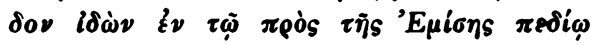

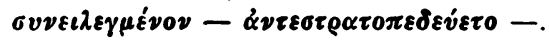

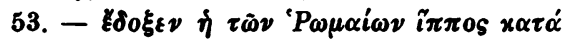

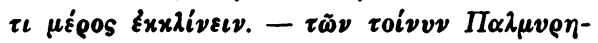

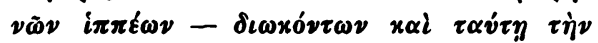

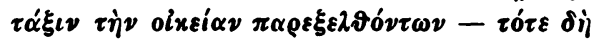

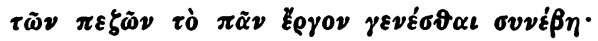

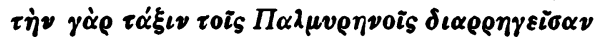

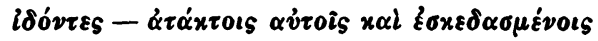
$\varepsilon \pi \xi \theta \varepsilon v \tau 0$ -

Sieg der Römer.

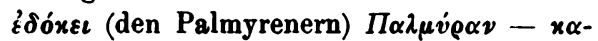

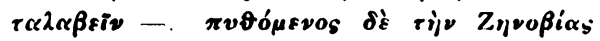

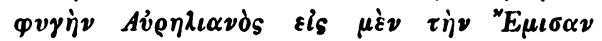

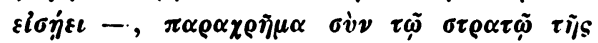

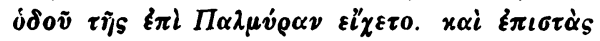

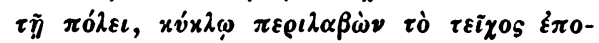

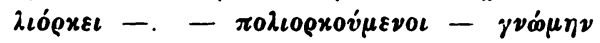

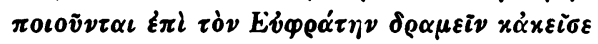

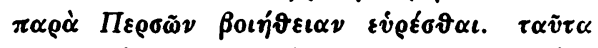

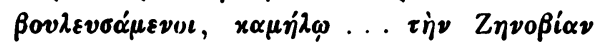

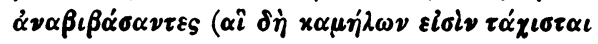

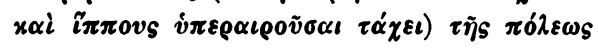

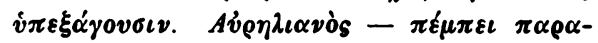

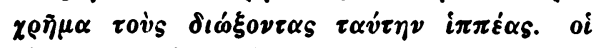

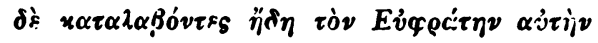

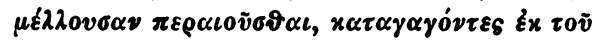

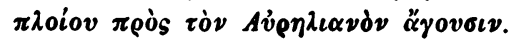

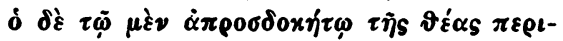

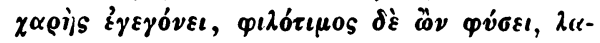

Byæant. \%itschrift XIV 1 u. 2.
Aurel. c. 22, 3.

- in Bithyniam transitum fecit eamque nullo certamine obtinuit. Multa eius magna - facta - omnia libro innectere nou possumus -. Nam cum Tyanam venisset - Recepta Tyana Antiochiam -.

A urel. c. 25.

- brevi apud Dafnem certamine optinuit. - Pugnatum est post haec de summa rerum contra Zenobiam et Zabam eius socium apud Emesam magno certamine. Cumque Aureliani equites fatigati iam paene discederent ac terga darent, - per pedites etiam equites restituti sunt. Fugata est Zenobia cum Zaba, et plenissime parta victoria. - Fmesam victor Aurelianus ingressus est - .

26. Post haec Palmyram iter flexit, ut ca oppugnata laborum terminus fieret -.

28. -- victa igitur Zenobia cum fugeret camellis, quos dromedas vocitant, atque ad Persas iter tenderet, equitibus missis est capta atque in Aureliani potestateu deducta.

Aurelianus - superbior atque insolentior egit ea, quae ratio temporis postulabat.

Bei Vop. verteidigt sich Aur. r. 26, 2 gegen den Vorwurf, dil $B$ er ; 


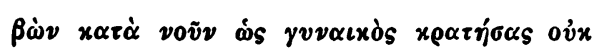

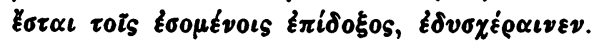
Palmyra ergibt sich.

\section{Zos. I 56, 2.}

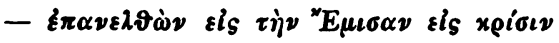

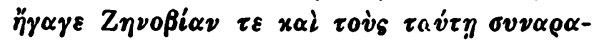

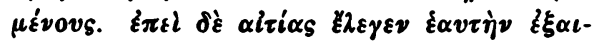

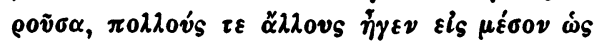

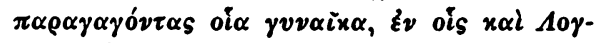

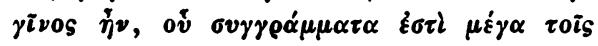

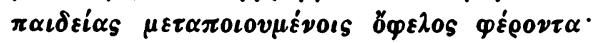

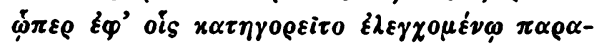

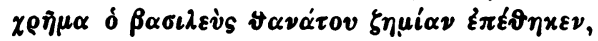

Zos. I 60.

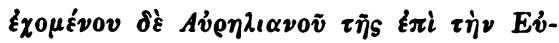

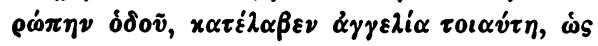

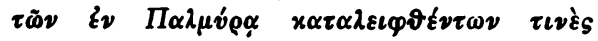

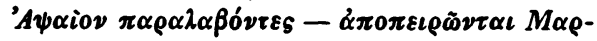

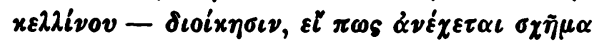

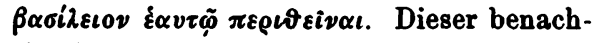

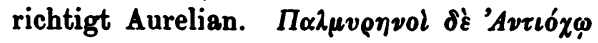

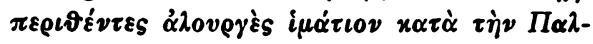

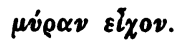

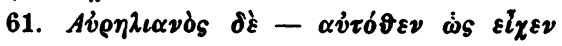

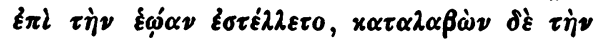

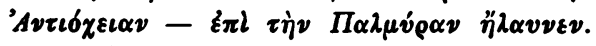

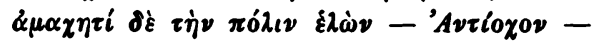

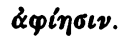

Vopiscus erzählt um vieles kürzer, hat manches mißverstanden (so die beiden Namen im letzten Abschnitt), augenscheinlich, weil er aus einem griechischen Text ausschrieb. Trotzdem ist auf den ersten Blick klar, daB hier ein und dieselbe Erzählung beiden zugrunde liegt. Die völlige Identität ist so groß, daB man die verdorbene Stelle Zos. I 55, 2 wohl trotz allem aus Vop. in $\delta \rho o \mu \alpha ́ \delta c$ verbessern kann, da der Relativ-

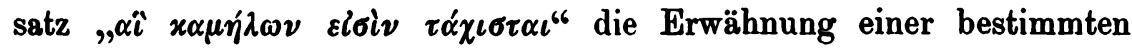
Kamelart fordert. Noch in dem letzten Absatz haben beide die ganz nebensächliche Bemerkung gemein, daB Aurelian nach dem Orient auf-

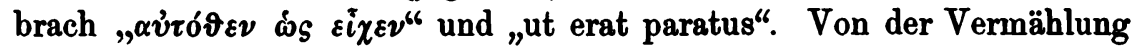
Zenobias mit einem Senator sagt Vop. nichts, steht also auch darin der gemeinsamen Vorlage wohl näher als Synk. und Eutrop. Unzweifelhaft ist das eine Ergebnis: Auch Vopiscus hat die Zosimosquelle benutzt.

Ich stelle die Autoren zusammen, die nach den bisherigen Aus- 
führungen aus dieser Quelle ${ }^{1}$ ) oder einem ihrer Ausflüsse geschöpft haben; es sind: Zosimos, Zonaras, Kedrenos, Synkellos, Eutrop, der Epitomator, Trebellius Pollio und Vopiscus.

\section{Bestand der Zosimosquelle von der Regierung des Philippus Arabs bis zum SchluB.}

Ich kann jetzt den Versuch machen, den Bestand der Zosimosquelle von der Zeit des Philippus Arabs an festzustellen; dies geschieht durch Beantwortung der Frage, welche Berichte des Zosimos in den verwandten Geschichtswerken belegt sind:

Zos. I 20-22.

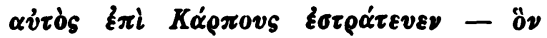

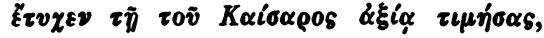

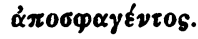

Zon. XII 19 I 624 D-625 A.

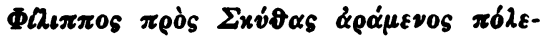

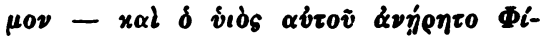
$\lambda\left(\pi \pi 0^{2}{ }^{2}\right)$

Die Parallelen, denen sich noch Synk. P. 362 D und Kedrenos-Leo (Kedr. P. $257 \mathrm{C}$ ) anschlieBen, gehören um so sicherer unserer vielbenutzten Vorlage an, als auch des Decius Gotenkampf und Tod dafür gesichert sind: Zos. I 23, Zon. XIl 20 I 627 C, Kedr. P. 258 D, Epit. 29, Eutr. IX 4. ${ }^{3}$ ) Zos. I 24. Zon. XII 21 I $628 \mathrm{~A}$.

Zos. I 25 ist bereits durch Epit. 30 (dazu Zon. XII 18 I 624 B und Kedr. P. 257 C) gesichert. $\left.{ }^{4}\right)$

Zos. I 26-27, Zon. XII 21 I 628 A B, Kedr. P. 258 A B zeigen keinerlei wörtliche Übereinstimmung, entsprechen sich aber dem Inhalte nach vollkommen, besonders wenn wir noch Zos. I 28 hinzunehmen, daB die Skythen auch in Asien bis Kappadokien, Pessinus und Ephesus gekommen seien. Der wesentlichste Unterschied ist, daB Zon. und Kedr. die europäischen Züge, die sich bei Zos. nur in den Namen der beteiligten Stämme unterscheiden, statt zweimal nur einmal erwähnen. Dabei spricht aber auch Zon. nicht nur von der Menge der Skythen, sondern scheint mit den Worten , $x \alpha \grave{\alpha} \ddot{\alpha} \lambda \lambda \alpha \delta \xi \pi$ ro $\pi \lambda \dot{\alpha}$

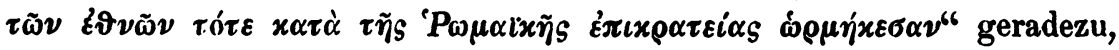
wenn nicht auf einen zweiten Einfall, so doch auf eine Völkerliste, wie sie Zos. gibt, hinzuweisen. Vielleicht erklärt sich die Erscheinung, daB die Nachricht von der großen Pest (Zos. I 26,2, Zon. XII 21 I 628 B, Kedr. P. 258 A) bei Zon. hinter, bei Kedr. vor den Skythenzügen steht, im letzten Grunde $^{5}$ ) eben aus dem Zurückgehen auf einen Bericht, wie

1) Die Einheit der Quelle ergibt sich deutlich aus Kap 3-5.

2) Darüber, daB hier nicht Zos. selbst Quelle des Zon. ist, vgl. Patzig Byz. Z. V, S. $44 . \quad$ 3) S. 90 f. u. $94 . \quad$ 4) S. 91.

5) Nach De Boor Byz. Z. II p. $11 \mathrm{ff}$. und Praechter ebenda V p. 630 wäre der nächste Grund eine Mehrheit der Quellen, die ja aber doch alle zuletzt aus 
ihn Zos. hat; bei ihm steht die Pest zwischen der ersten und zweiten Erwähnung der Skythenzüge. Für die Erzählung von den Eroberungen der Perser, die Zon. mit Zos. in diesem Zusammenhange bringt, hat er die Einzelheiten einer anderen Quelle entnommen.

Völlig festen Boden gewinnen wir wieder mit dem folgenden Kapitel: Zos. I 28, Zon. XII 21 I 628 C. $^{1}$ ) Leo steht hier Zon. und damit zum Teil auch Zos. näher als Kedr., der Ämilians Regierung nur kurz erwähnt und ihn ein Jahr statt vier Monate wie Zon. und Leo regieren läßt. Dagegen geben Zon., Leo und Kedr. für Gallus die gleiche Regierungsdauer, und daB diese Angabe bei Zon. in dem ganz zu Zos. stimmenden Text, bei Kedr. und Leo in dem Abschnitt über Pest und Skythenzüge steht, erhöht die Wahrscheinlichkeit, daB Zos. I 26-27 als Parallelen der betreffenden Stellen des Zon., Leo und Kedr. zu gelten haben. Für Ämilian ist noch Eutr. IX 5 und Epit. 31 heranzuziehen, von denen die Epit. ebenfalls vier Monate als Regierungszeit angibt, während Eutr. schweigt, also wieder nicht Quelle der Epit. sein kann.

Zos. I 29,2-3 ist durch Zon. XII 23 I 629 C, Synk. P. $381 \mathrm{C}$ und wahrscheinlich Treb. Pollio Gall. duo 5,6 als Eigentum der Gesamtquelle erwiesen. ${ }^{2}$ )

Wenden wir uns zu Zos. I $30-37$, so ist erstens zu bedenken, daB der einzige Autor, der unsere Gesamtquelle auch nur annähernd so ausführlich ausschrieb wie Zos., daB Vopiscus diese Zeit noch nicht behandelt, und daB wir also bei allen verwandten Quellen an dieser Stelle nur mangelhafte Bruchstücke des Zosimosberichtes zu erwarten haben. Zweitens ist wichtig, daB in der Vorlage des Zos. die gesamten Skytheneinfälle seit Grllus als fortlaufende Frscheinung, wenn auch nicht hintereinander erzählt, so doch als zusammengehörig deutlich gekennzeichnet waren: Kap. 26 erzählt er, daß die Skythen zuerst die Nachbargebiete geplündert, dann vorschreitend das ganze römische Gebiet bis ans Meer verwüstet hätten; Kap. 27 gibt er an, daß die Plünderungen in Europa während der Pest andauerten, und nennt die

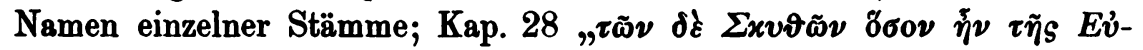

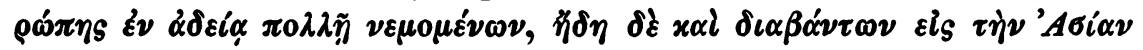

gemeinsamem Born fließen dürften. DaB übrigens Zos. hier nicht direkte Quelle der andern sein kann, ist klar, aber auch nicht indirekte; das verbietet ein Mehr bei Kedr.-Leo, vgl. unten S. 101. Auch Patzig läBt ja seine Leoquelle aus einer Vorlage des Zos. schöpfen.

1) Die größere Vollständigkeit des Zon. verbietet auch hier, Zos. selbst als Quelle anzusehen.

2) S. 88 u. 96. 


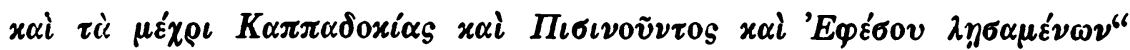
bezieht sich erstens deutlich auf Kap. 27 zurück, andrerseits weist es ebenso klar auf die im folgenden erzählten Einfälle in Kleinasien; Kap. 29,2 wird neuerdings darauf hingewiesen, daB die Skythenzüge in Europa bereits zur Gewohnheit geworden waren; Kap. 30,2 spricht ron den Scharen in Italien, Illyrien und Hellas als von etwas Bekanntem; Kap. 31,2 werden dieselben Stämme wie in Kap. 27 und dieselben Provinzen wie in Kap. 30,2 genannt, es wird die Bemerkung vou Kap. 27 wiederholt, daB sie nichts ungeplündert gelassen hätten. Dadurch wird sichtlich dokumentiert, daB es sich hier nach Aussagen seines Gewährsmannes um die gleichen Ereignisse handelte, die sich eben über eine längere Reihe von Jahren erstreckten. Zugleich wird

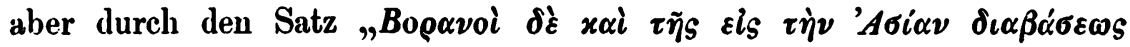
$\dot{\varepsilon} \pi \varepsilon\left\llcorner\tilde{\omega}_{\nu} \nu 0^{\text {" }}\right.$ die Kap. 28 abgebrochene Erzählung wieder aufgenommen. Wir werden uns demnach nicht wundern, wenn wir die bei Zos. getrennten Berichte in einer oder der anderen verwandten Quelle zusammengefabt finden. Erleichtert wird unsere Aufgabe dadurch, daB in zweien unserer Chroniken, bei Trebellius Pollio und Synkellos, ein von dem des Zosimos verschiedener Bericht über die Skythenzüge sich findet. ${ }^{1}$ ) Seine Hauptcharakteristika sind folgende: Er nennt von den skythischen Stämmen besonders die Heruler, hat Byzanz gegenüber statt Chalkedon Chrysopolis, läßt die Barbaren bis nach Kyzikos kommen (und es erobern), ja sogar Lemnos und Skyros plündern, nennt statt Hellas Achaia, als dessen Verteidiger Marcian bezeichnet wird, berichtet den Kampf der Athener gegen die Skythen, sowie die Einnahme von Korinth, Sparta, Argos. Dagegen weiB er nichts von der Verwüstung Italiens, der Provinzen Pontus, Kappadokien, Galation, Bithynien. Alles in allem erscheinen in ihm die Einfälle der Skythen wesentlich als Seezüge, während sie nach Zos. die Schiffe nur gerade immer zum Übersetzen verwenden und so bald als möglich ihre Fahrten zu Lande fortsetzen.

Nach diesen Vorbemerkungen können wir zunächst feststellen, daB Zon. XII 21 I 628 AB - Kedren. P. 258 AB und Leo, die hier eng

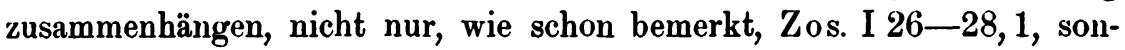
dern auch 30-35, 37 entsprechen, wie besonders aus Kedren (und Leo)

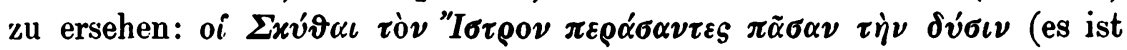
doch wohl der Westen der Balkanhalbinsel, also Illyrien, gemeint) $x a i$

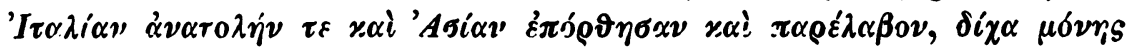

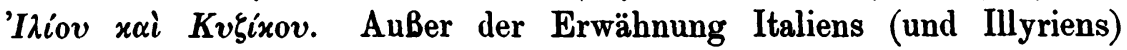

1) Unten S. 120. 
[Zos. I 30, 2 u. 37] ist besonders die nachdrückliche Ausnahme der Stadt Kyzikos von der Plünderung zu beachten.

Synkellos gibt außer dem erwähnten, von Zos. abweichenden Be-

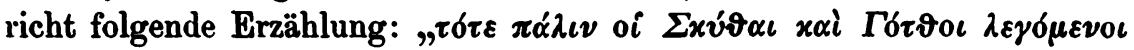

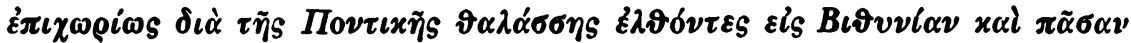

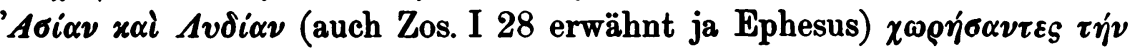

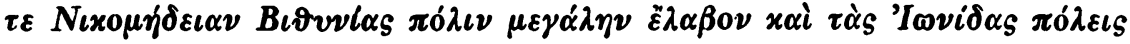

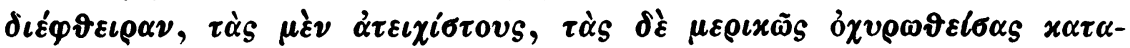

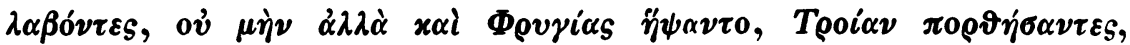
$K \alpha \pi \pi \alpha \delta 0 x i \alpha \nu \kappa \alpha i \Gamma \alpha \lambda \alpha \tau i \alpha \nu$." Abgesehen von der Anführung von Troia stimmt der Bericht vollständig mit Zos. überein: Kappadokien erwähnt Zos. selbst; Kios, Apameia, Prusa liegen in Bithynien, die ionische Stadt Ephesus in Lydien, Pessinus an der Grenze von Phrygien und Galatien. Kyzikos, überhaupt Mysien wird nicht erwähnt. Die Ein-

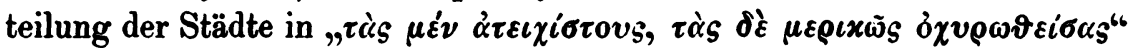

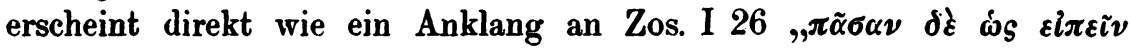

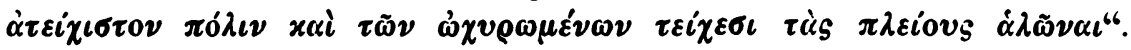
Endlich schlieBt sich bei Synk. unmittelbar der Perserkrieg des Odenathos aus der mit Zos. gemeinsamen Quelle an, und auch bei Zos. selbst wird zu Beginn des Odenathkapitels (Kap. 39) auf die Skythenzüge zurückgegriffen, nachdem in Kap. 38 von anderem die Rede gewesen war.

SchlieBlich stellen sich auch Trebellius Pollio und Eutrop. wieder zu Zos.: Treb., Gallieni duo c. 4,7-8: „Accesserat -, quod Scythae Bithyniam invaserant civitatesque deleverant. Denique + contum, quae Nicomedia postea dicta est, incensam graviter vastaverunt" und c. 11,1: „Dum haec apud Persas geruntur, Scythae in Cappadociam pervaserunt. Illis captis civitatibus bello etiam vario diu acto se ad Bithyniam contulerunt", wo die Phrase "bello vario diu acto" anzudeuten scheint, daB von dem ersten Einfall in Kappadokien bis zu dem bithynischen Zuge, der schon vorher erzählt ist und bei dem auch nach Zos. und Synk. Nikomedien verbrannt wurde, längere Zeit verstrich. Eutrop. läbt sich trotz seiner Kürze wegen seiner Abweichung von den Caesares heranziehen; während diese die Gothen „Macedonas Achaeosque et Asiae finitima" (also nur die asiatischen Küsten des Ägäischen Meeres) plündern lassen, nennt Eutrop „Graecia, Macedonia, Pontus, Asia“.

Wenn die mit Zos. verwandten Quellen trotz ihrer Dürftigkeit so viele Parallelen zu ihm und Abweichungen von der oben charakterisierten anderen Überlieferung zeigen, so ist der einzig mögliche SchluB: Auch die Kap. 30-35 und 37 hat Zos. derselben Vorlage entnommen, auf die Zon., Kedr., Synk. und die übrigen gemeinsam mit ihm zurückgehen. 
Zos. I 36 ist nach Zon. XII 23 I 629 D-630 A, Epit. 33 und Eutrop. IX 7 der Gesamtquelle zuzuweisen. ${ }^{1}$ )

Auch Zos. I 38 ist durch Treb. Pollio Gall. duo c. 19 und trig. tyr. 3, sowie Epit. 33 bereits gesichert ${ }^{2}$ ), genau parallel mit Zos. geht aber wieder Zon. XII 24 I 632 AB, nur daB er den Namen des Caesar verschweigt und aus dem Silvanus einen Albanus gemacht hat. Zon. beruht nicht auf Zos., da er das Lob des Saloninus , $\pi \alpha i \delta \alpha-$

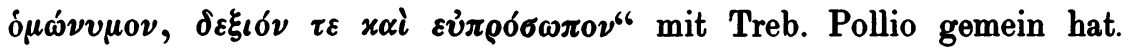
Kurz vor dieser Stelle scheint in der Zosimosquelle von einigen Truppenerhebungen und dabei vorgreifend auch von der des Hipparchen Aureolus

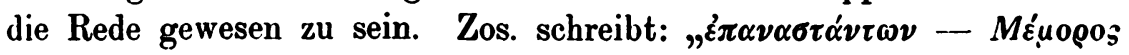

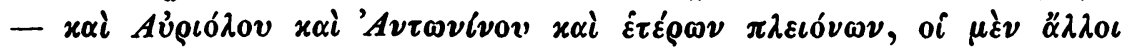

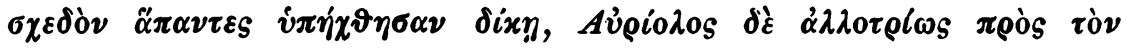

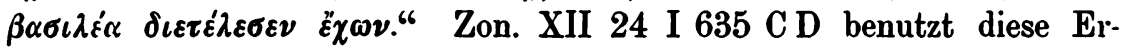
wähnuug, um aus anderer Quelle eine Erzählung von der Laufbahn des Aureolus und seinem Kampfe gegen Ingenuus anzuschließen ${ }^{3}$ ), und Treb. Pollio trig. tyr. 11 u. Gall. duo 4,6 hält gar die hier erwähnte Erhebung für eine andere als die später berichtete, so daB er Aureolus ror dem Kampf gegen Postumus mit Gallienus Frieden schlieBen läBt. Kedrenos-leo endlich behalten nur die Erinnerung an den kaiserlichen

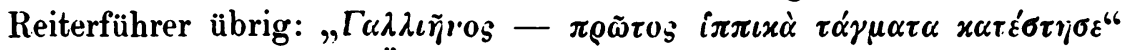
(Kedr. P. 258 D). ${ }^{4}$ ) Übrigens steht Zon. XII 24 I 623 BC mit dem Vorhergehenden in so enger Verbindung, daB ich auch diesen Bericht der Zosimosquelle zuschreiben möchte, trotzdem Zos. ihn übergeht; die Verwundung des Gallienus kehrt bei Treb. Pollio trig. tyr. 3 wieder.

Zos. I $39=$ Zon. XII 24 I 631 A und 633 B C, Synk. P. 382 B, Eutr. IX 10, Treb. Pollio trig. tyr. 15, 17, 30, Gall. duo 12,1.5)

Zos. I $40-41=$ Zon. XII 25 I 633 D und I $634 \mathrm{CD}$, Treb. Pollio Gall. duo 14. Ich kann nicht umhin, den Bericht, soweit alle drei Autoren parallel gehen, wörtlich herzusetzen, weil hier zum ersten Male ein längerer Text des Treb. Pollio die Vergleichung erleichtert, und weil es weiter für die Beurteilung des Zonaras ${ }^{6}$ ), der hier zwei Erzählungen des Ereignisses nebeneinanderstellt, wichtig ist zu entscheiden, welche der beiden Versionen aus der Zosimosquelle stammt:

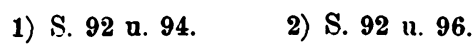

3) Vgl. unten S. 122.

4) Darüber Patzig Byz. Z. V, p. 45.

כ) S. 94.

b) Zonaras wird übrigens durch Treb. Pollio gegen Patzig a. a. 0. p. $46 \mathrm{f}$. gesichert. 
Zos. I 40, 1-3.

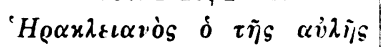

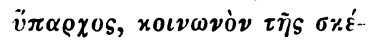

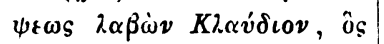

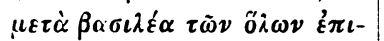

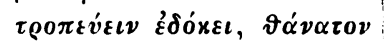
$\dot{\varepsilon} \pi \iota \beta 0 v \lambda \varepsilon \dot{v} \varepsilon \iota \Gamma \alpha \iota \dot{r}_{i} v \omega . \not \alpha \nu \delta \rho \alpha$

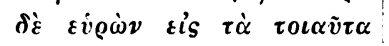

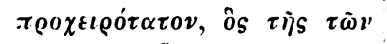

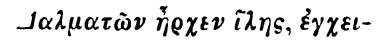

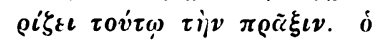
$\delta \dot{\varepsilon} \dot{\varepsilon} \pi \iota \sigma \tau \eta^{\prime} \sigma \alpha \varsigma \tau \tilde{\omega} \Gamma$. $\delta \varepsilon \iota \pi v 0-$

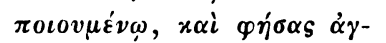

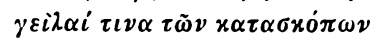

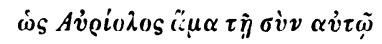

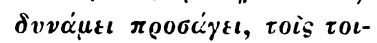

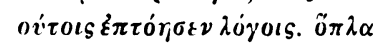

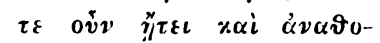

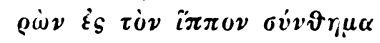

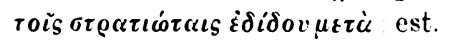

Gallieni duo 14, 1.

Verum cum Gallieni tantam improbitatem ferre non possent, consilium inierunt Marcianus et Heraclianus, ut alter eorum imperium caperet. - et Claudius quidem, -, electus est. -.. Fuit isdem socius in appetendo imperio quidam Ceronius sive Cecropius, dux Dalmatarum,- - Hoc scientes Marc. et Cecr. subito Gallieno miserant nuntiari Aureolum iam venire. Ille igitur militibus cogitatis quasi certum processit ad proelium atque ita missis percussoribus interemptus

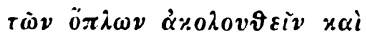

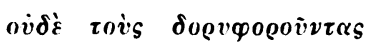
$\dot{\varepsilon} x \delta \varepsilon \xi \dot{\alpha} \mu \varepsilon v 0 s \quad \ddot{\eta} \lambda \alpha v \nu \varepsilon v . \quad \gamma v-$

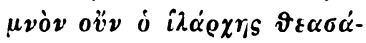

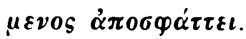

Zon. XII 25 I 634 CD.

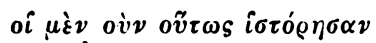

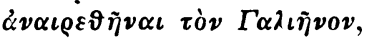
ố $\delta \grave{\varepsilon} \pi \alpha \rho \dot{\alpha} ~ ' H \rho \alpha x \lambda \varepsilon \varepsilon \alpha \nu 0 \tilde{v}$ $\tau 0 \tilde{v} \varepsilon \dot{\pi} \alpha \dot{\varrho} \chi 0 v \sigma \varphi \alpha \gamma \tilde{\eta} \nu \alpha \iota \tau o \tilde{v}-$ $\tau o ́ v ~ \varphi \alpha \sigma t .-v v x \tau o ̀ s \delta \grave{~} \pi \rho o ́ \sigma-$

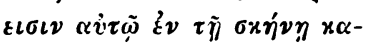

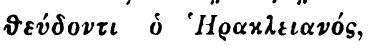

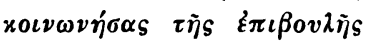

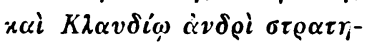

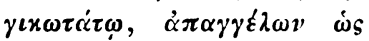

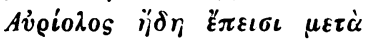
$\beta \alpha \rho \varepsilon i \alpha s \quad \delta v \nu \alpha \dot{\mu} \varepsilon \omega s . \quad \dot{\delta} \delta \dot{\varepsilon}$

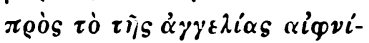

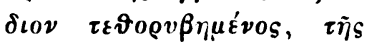
$x \lambda i v \eta s \dot{\alpha} \nu \alpha \vartheta$

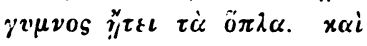

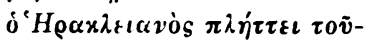

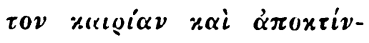
$v v \sigma \iota v$.

Augenscheinlich hat Treb. Pollio, um Claudius, den angeblichen Ahn des Constantius, vom Verdachte des Mordes zu befreien, den Marcian, den er in seiner Quelle erwähnt fand (vgl. Zos.), an dessen Stelle gesetzt. Tatsächlich ist sein eigener Text auf die Teilnahme des Claudius zugeschnitten; denn „consilium inierunt Claudius et Heraclianus, ut alter eorum imperium caperet. -... et Claudius quidem electus est" gibt einen guten Sinn, der jetzige 'T'ext enthält einen Widerspruch. Zonaras gibt das Richtige, nur läßt er den Heraklian selbst Hand an Gallien legen, während Zos. und Treb. ïbereinstimmend dem Anführer der Dalmater die Tat zuschreiben.

Von den Angaben über das Verhalten des Aureolus nach Galliens Tode Zos. I 41 und Zon. XII 26 I 635 B hat Treb. Pollio Claud. c. 5 wenigstens die Bemerkung, daB Aureolus den Versuch gemacht habe, von Claudius zu Gnaden aufgenommen zu werden. Nur Zonaras und Pollio wissen von einer neuen Erhebung. Ziemlich ähnlich klingen schlieBlich Treb. Pollio Gall. duo 15 ,sic militibus sedatis Claudius

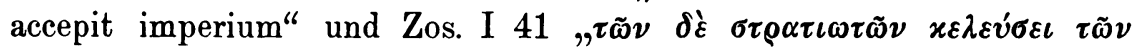

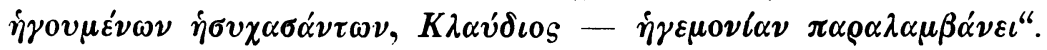

Zos. I 42-43 findet bei Zon. keine Parallele, da dieser einer anderen Quelle folgt, wohl aber in dem aphoristischen Bericht des 
Treb. Pollio Claud. 6 u. 9; ich verweise nur auf die gleiche Zahlenangabe 320000 und den Schiffbruch in der Propontis, sowie Pollios

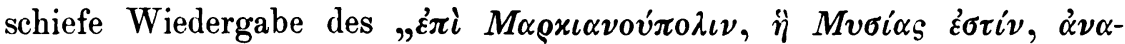
$\beta \alpha \dot{v} \tau \varepsilon g^{6}$. Den eigentlichen Kampf des Claudius mit den Goten tut Treb. Pollio mit panegyrischen Phrasen ab; aber bezeichnend für den Parallelismus beider Autoren ist wieder, daß bei beiden die Erzählung des Gotenkrieges an der gleichen Stelle durch einen z. T. wörtlich übereinstimmenden Bericht von der Eroberung Ägyptens durch Zenobia unterbrochen wird: Zos. I 44 und Treb. Pollio Claud. 11. Die gleichen Angaben treten in ganz knapper Fassung bei Zon. XII 27 I 636 D und Synk. P. $384 \mathrm{D}$ auf, bei beiden dem Bericht über Aurelians Feldzug gegen Zenobia eingefügt; daB Zon. mit Zos. von der Gefangennahme des Probus weib, schlieBt hier, wie auch sonst, trotz wörtlicher Übereinstimmung ein Zurückgehen auf Synk. aus.

Zos. I 45-46 führt genau parallel Treb. Pollio Claud. 11, 3, 6, 7; 12,$1 ; 9,4 ; 12,2$ den Gotenkrieg mit seinen Zwischenfällen bis auf den Tod des Claudius fort. Dazu kommen hier noch Zon. XII 26 I 636 A und Synk. P. 384 C, die beide Treb. Pollio näher stehen als dem Text des Zosimos.

Für Zos. I 47 tritt neben Zon. XII 26 I 636 A B, Kedr. P. 259 B, Synk. P. 384 C, Epit. 34, Eutr. IX 12 und Treb. Pollio Claud. 12,3- ${ }^{1}$ ) noch besonders Vopiscus Aurel. 37, כ.

Zos. I 48 ist nur bei Vop. Aurel. 18,2 belegt, wo der glänzende Sieg noch dazu dem Optimismus des Römers entsprungen ist; dagegen findet Zos. I 49 bei Vop. Aurel. 18,4; 21, 5; 21,9 sichere Parallelen. Fast scheint es, als wenn auch die Markomannenkämpfe Aurel. 18 u. 21 der Zosimosquelle angehörten, da die Schlachtorte z. T. in der Epit. 35 wiederkehren; den römischen Historikern muBte es leicht sein, den Fehler des orientalischen Autors, den Zos. abschrieb, zu vermeiden, Norditalien und die Donauprovinzen, die jener zusammenwarf, auseinanderzuhalten. - Zos. und die Epit. nennen als einzige Quellen den Septimius als Gegenkaiser.

Zos. I 50-56; 59,5-61,6 war durch Vop. Aurel. 22,3; 25--26; 28; 31, Zon. XII 27 I 636 D, Synk. P. 384-385, Eutr. IX 13 bereits gesichert.:) Die eingeschobenen Kapitel $57-59,4$ sind die ersten, zu denen sich in den verwandten Quellen kein Seitenstück findet.

$\mathrm{Zu}$ den übrigen Angehörigen der Zosimosfamilie tritt von Aurelian an - das muB nachdrücklich betont werden - die Schrift De Caesaribus des Aurelius Victor. Schon von den Plünderungen der Alamannen in Italien und Aurelians Kämpfen gegen sie, sowie von dem Mauerbau ist De Caes. 35 die Rede.

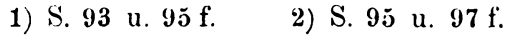


Zos. I 61 findet sich mehr oder weniger vollständig bei Vop. Aurel. 32,2-4; 35, Zon. XII 27 I 636 D - 637 A, Synk. P. 385 A, Eutr. IX 13. Die gemeinsame Vorlage von Eutrop und Aurel. Victor, die auch Vop. nehenbei heranzog, erwähnt den Bau des Sonnentempels und einen Aufstand der monetarii, der wohl mit der von Zos. angeführten FinanzmaBregel zusammenhängt.

Für Aurelians Tod bietet sich die Gesamtzahl der Zosimosverwandten der Vergleichung; da die Berichte zugleich für die Stellung der einzelnen Quellen zueinander sehr lehrreich sind, versage ich mir nicht, die ganze Reihe aufmarschieren zu lassen:

Zos. I 62.

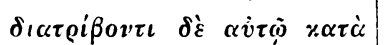

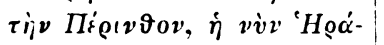

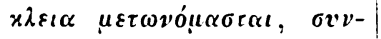

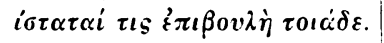
$\dot{r} \nu$ tıs $\dot{\varepsilon} \nu$ tois $\beta \alpha \sigma i \lambda \varepsilon i o ı s$

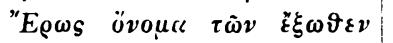

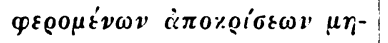

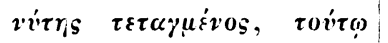

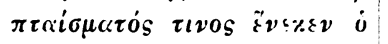
$\beta \alpha \sigma \iota \lambda \varepsilon \dot{v} s \dot{\alpha} \pi \varepsilon 1 \lambda \eta^{\prime} \alpha_{S} \xi_{S} \varphi \dot{\beta} \beta o v$

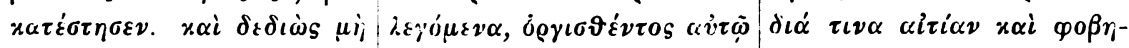

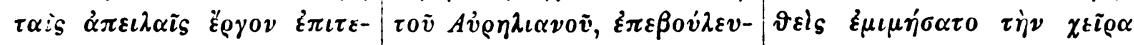

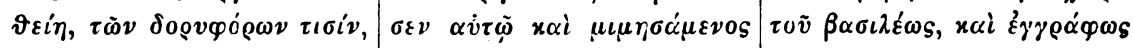

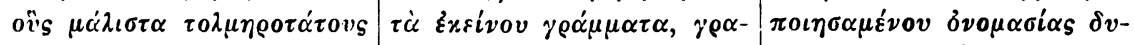

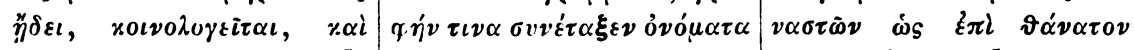

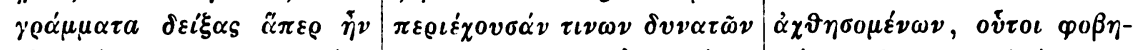

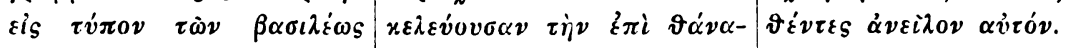

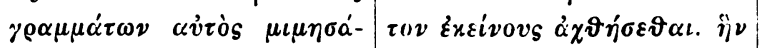

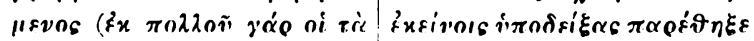

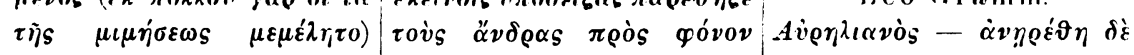

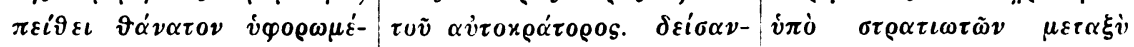

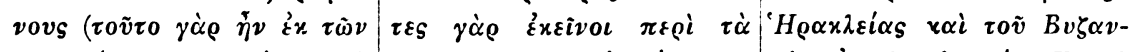

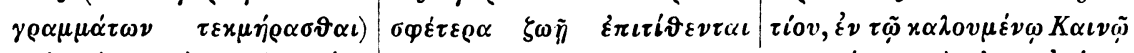

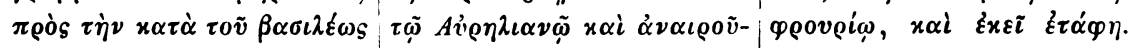
$\dot{\delta} \varrho \mu \tilde{\eta} \sigma \alpha \iota \sigma \varphi \alpha \gamma \dot{\eta} \nu . \quad \sigma \iota \nu \alpha \dot{v} \tau \dot{v} \nu .$.

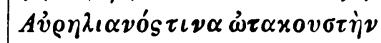
$\varepsilon \sigma \chi \varepsilon v \quad x \tau \lambda$.

Syncellus P. $385 \mathrm{~A}$ gibt nur mit Zon. (und Vop.):

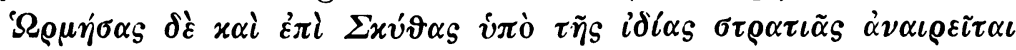

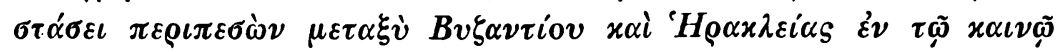

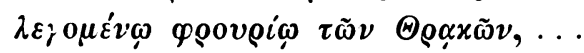

Synk., Kedr., Leo, Vop., Eutr. und Victor haben als Tatort Känophrurion zwischen Byzanz und Heraklea, und zwar sind die betreffenden Sätze überall außer bei Synk. und Victor dem Übrigen locker ange- 
fügt; bei Vop. und Leo handelt es sich deutlich um zwei verschiedene Erzählungen desselben Ereignisses. Das erklärt sich folgendermaßen: Die Erzählung ging aus der Gesamtquelle auf Zos., Zon., Kedr., Leo, Eutr., die Epit. und Vop., aber auch in die Eutr. und Victor gemeinsame Quelle über. Auf dieser, die den Ortsnamen hinzufügte, beruhen auch die Nebenberichte der übrigen Quellen; sie stehen bei Kedr., Leo und Vop. vor, bei Eutr. hinter dem Hauptberichte.

Zos. I 63 ist bei Zon. XII 28 I 637 B belegt, dessen Unabhängigkeit von Zos. durch Abweichungen in den Daten des Skytheneinfalles (Zos.: Mäotis, Pontos, Kilikia; Zon.: Mäotis, Phasis, Pontos, Kappa-

Eutrop. IX 15. Epit. XXXV. Vop. vit. Aur. 35, 5f. Caesares 35, 8. Occiditur servi Novissime fraude Sed cum iter faceret, apud Cae- - ministri scesui fraude, qui ad servi sui, qui ad nofrurium, mansionem, quae lere, cui secretoquosdam milita- quosdam milita- est inter Heracleam et Byzan- rum officium creres viros, amicos res viros, amicos tium, malitia notarii sui et diderat, circumipsius, nomina ipsius, nomina manu Mucaporis interemptus ventus apud Caepertulitadnotata, pertulitannotata, est. - nofrurium intefalso manum eius falso manum eius 36,4 . Incidit autem, ..., ut riit, cum ille imitatus, tam-imitatus, tam- Mnesteum quendam, quem pro praedae conquam Aurelianus quam Aurelianus notario habuerat, - infensio- scientia delictiipsos pararet oc- ipsos pararet oc- rem sibi minando redderet, que scripta calcidere. Itaque ut cidere; ab iisdem quod nescio quid de eo suspi- lide composita praevenirent, ab interfectus est in catus esset. Mnesteus, qui tribunis, quasi isdem interfectus itineris medio, sciret Aurelianum neque frustra per gratiam, proest in itineris quod inter Con- minari solere neque si mina- didisset, quibus medio, quod inter stantinopolim et retur ignoscere, brevem no- interfici iubebanConstantinopo- Heracleam est. lim et Heracleam est stratae veteris. Tocus Caenophrurium appellatur.

minum conscripsit mixtis is, tur, illique eo
de quibus nil asperum cogita- metu accensi fa-
bat, addito etiitm suo nomine, cinus patravere.
quo magis fidem faceret in-
gestae sollicitudinis, ac brevem
legit singulis, quorum nomina
continebat, addens disposuisse
Aurelianum eos omnes occi-
dere -. Hic cum exarsissent
timore-, in supra dicto loco
iter facientem principem subito
adorti interemerunt.

dokia, Galatia, Kilikia) gewährleistet wird. Ganz kurz, aber mit bestimmtem Anklang, erzählt Vop. Tac. 13, dessen Bemerkung ,gessit autem propter brevitatem temporum nihil magnum" sich noch bei Eutr. JX 16 findet, ehenso wie die 6 Monate der Regierungsdaner, wie sie auch Synk. P. 38こ̃ D aufweist. Kedr. und Leo weichen darin ab, stimmen aber $\%$ T. wörtlich zu Zonaras.

Zos. I 64 kehrt bei Zon. XII 29 I 637 CD, Vop. Tac. 14, 1; Prob. 
10, 1; Tac. 14, 2 und ins Schematische verdorben bei Kedr. P. 264 B (u. Leo) wieder. Tarsus als Todesort haben außer Zos. und Vop. noch Synk. P. 385 D und Aur. Victor 37. Die Epit. hat hier Unglück: statt Florian läBt sie Tacitus bei Tarsus sterben, und auf der andern Seite schreibt sie Florian die Todesart zu, die eigentlich Quintillus zukam. In der Regierungsdauer stimmen Synk. und Eutr. ungefähr mit Zon. ïberein (88 Tage, 80 Tage, 3 Mon.).

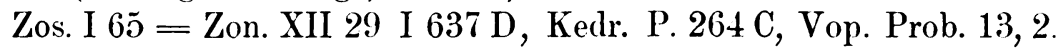

Zos. I 66, Zon. XII 29 I 638 A, Kedr. P. 264 BC, Synk. P. 386 A lassen wieder keinen Zweifel, daB Zon.-Kedr. nicht aus Zos. geflossen ist, da Kedr. am genauesten erzählt, und ebensowenig aus Synk., der nur die Ermordung des Saturninus kurz erwähnt. Daß dieser gegen den Willen des Probus getötet wurde, sagt mit Zos. auch Vop. Firm. Sat. Proc. et Bon. 11. Eutr., die Epit. und Vop. nennen als Gegenkaiser noch Proculus und Bonosus, die vielleicht trotz Victors Schweigen nur auf die „Kaisergeschichte“ zurïckgehen.

Zos. I 67, 1-2 = Zon. XII 29 I 638 B, Kedr. P. 264 B. Vop. Prob. $13, \tilde{o} \mathrm{ff}$. berichtet über den Feldzug in Gallien rein panegyrisch.

Zos. I 67, 3--68, ; entspricht Vop. 16; ebenda wird auch der Isaurerkrieg (Zos. I 69-70) berührt. Da aber die Einzelheiten völlig abweichen, dürfte die gemeinsame Quelle diesen Kampf nur kurz erwähnt, jedenfalls nicht den vollen Inhalt der beiden Zosimos-Kapitel enthalten haben.

Zos. I 71 genau parallel geht Vop. Prob. 17, 18. Beide erzählen auch die berühmte Fahrt der im Orient angesiedelten Germanen, die Vop. aber auffallenderweise nicht als Franken, sondern als Gepiden, Greuthungen und Vandalen bezeichnet, doch wohl zweifellos eine von ihm selbst herrührende Korrektur. Bei Zon. fehlt jede Parallele; doch

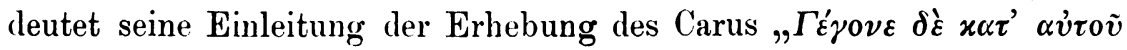

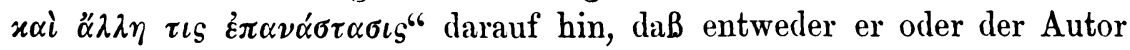
seiner Vorlage einen reicheren Text vor sich hatte, in dem vorher bereits von mindestens einer $\dot{\varepsilon} \pi \alpha \nu \alpha \dot{\sigma} \sigma \alpha \sigma \iota \varsigma$ die Rede war.

Zos. I 71, 4-5 kann wieder nicht die Quelle von Zon. XII 29 I $638 \mathrm{BC}$ sein, wo die Darstellung mehr ins einzelne geht, auch die Regierungsdauer abweichend gegeben ist. Vop. kannte diese Überlieferung von der Erhebung des Carus unzweifelhaft gleichfalls, da er sie Carus 6 zurückweist. ${ }^{1}$ ) Betreffs der Regierungsdauer steht Synk. zu Zos., und auch der verschriebenen Zahl bei Kedr. liegt wohl die gleiche Angabe zugrunde.

1) Gegen Patzig, B. Z. XIII S. 16. 
Schou von dem eben angeführten Text ist nur noch der Anfang bei Zos. erhalten, das andere aus den Fraginenten des Johannes Antiochenus ergänzt, der ihn ausschrieb. Außerdem dürften noch fr. 161-163 für Zos. in Anspruch zu nehmen sein; ohne Zweifel gehen sie auf unsere Gesamtquelle zurück, deren Bestand wir so anch ohne Zos. weiter festzustellen in der Lage sind.

$\mathrm{DaB}$ Carus von Geburt Gallier war, haben alle Quellen außer Kedr., Leo und Vop. (der sich aber doch auch mit der Abstammungsfrage beschäftigt) und ebenso die Ernennung der Söhne zu Caesares alle Quellen außer Synk. Der Sarmatenkrieg muß, dem übereinstimmenden Urteil aller Autoren außer Zon. nach, vor dem Perserkrieg erzählt gewesen sein. Dieser selbst ist allen gemein:

Zon. XII 30 I 638 D, Kedr. P. 264 D, Synk. P. 386 D, Vop. Carus 8, Eutr. IX 18, Victor 38. DaB Numerian den Vater begleitete, haben außer Zon. und Victor noch Vop. und Eutr.

Weiter läßt sich jetzt mit Bestimmtheit entscheiden, welche seiner beiden Versionen vom Tode des Carus Zon. der Zosimosquelle entnahm (die andere entstammt der Vorlage, die zu Malalas in Beziehung steht):

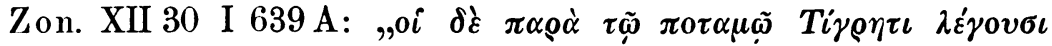

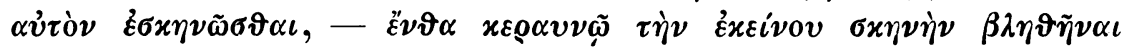

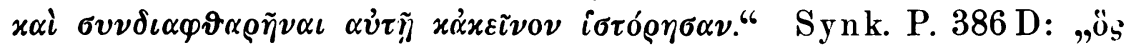

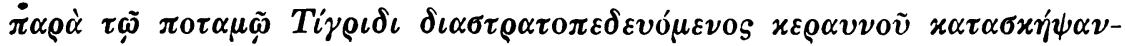

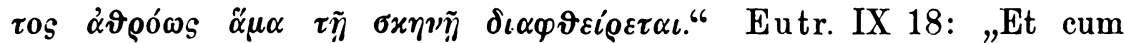
castra supra Tigridem haberet, vi divini fulminis periit." Victor 38: „fulminis tactu conflagravit.“ Epit. 38: „Hic apud Ctesiphonta ictu fulminis interiit." Carus 8 setzt die Angelegenheit am genausten auseinander: „Ut alii dicunt morbo, ut plures fulmine interemptus est. Negari non potest eo tempore, quo periit, tantum fuisse tonitruum, ut multi terrore ipso exanimati esse dicantur. Cum igitur aegrotaret atque in tentorio iaceret, ingenti exorta tempestate inmani coruscatione, inmaniore, ut diximus, tonitru exanimatus est." Das ist augenscheinlich der Bericht, der auch Zonaras vorlag; denn er sagt ebenfalls nichts davon, daB Carus selbst vom Blitz erschlagen worden sei. DaB tatsächlich auch in der Zosimosquelle von der Krankheit des Kaisers die Rede war, darauf deutet noch die Angabe des Kedr. P. 264 D (und Leo), der hier von den ihm sonst nächstrerwandten Quellen abweicht:

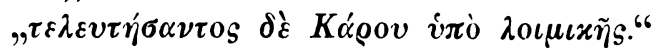

Über den Tod des Numerian sind wieder unsere sämtlichen Quellon einig; für Zosimos tritt Johamnes Antiochenus ein: 


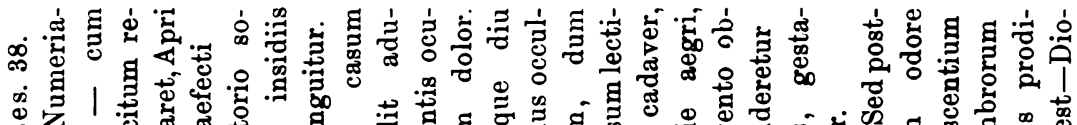

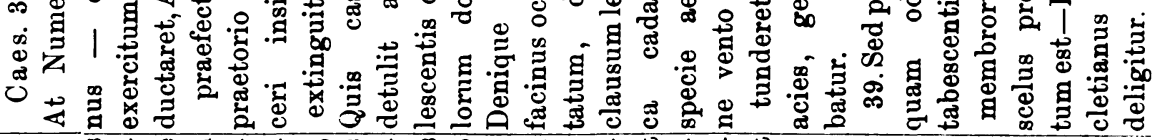

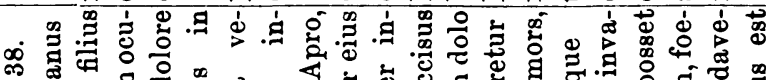

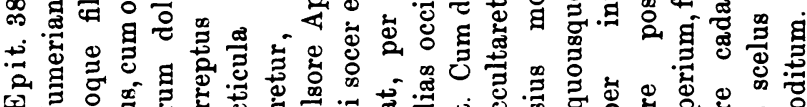

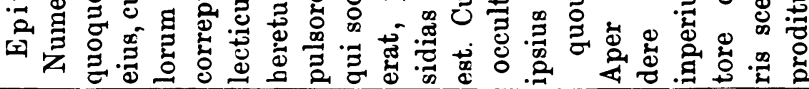

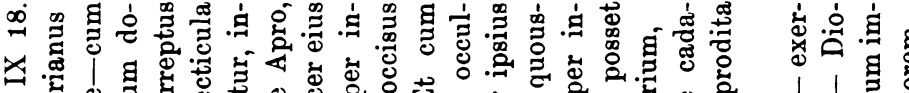

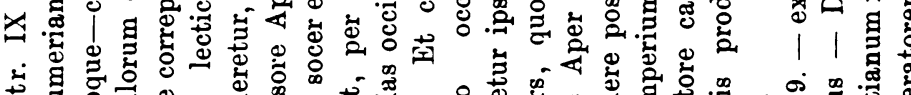

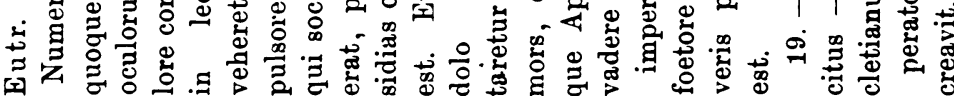

ค1

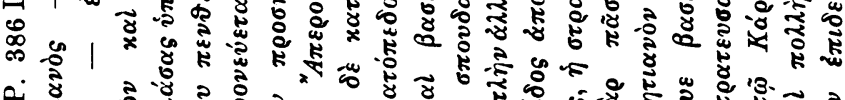

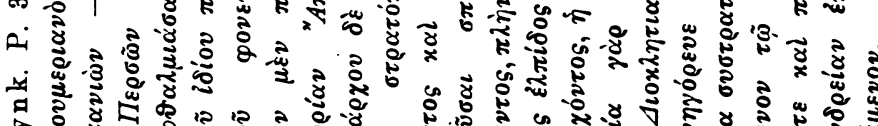

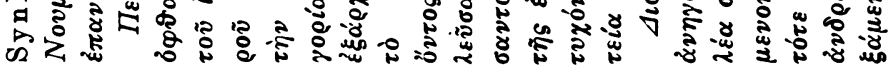

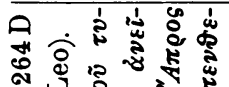

$x^{2}$

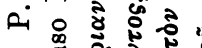

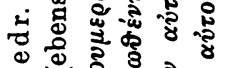

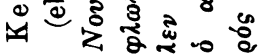

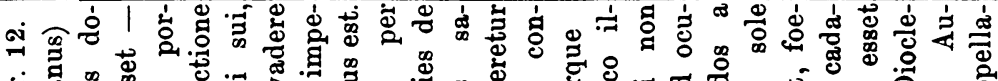

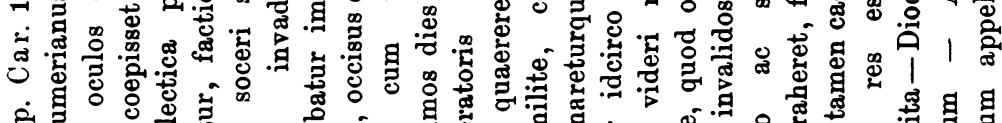

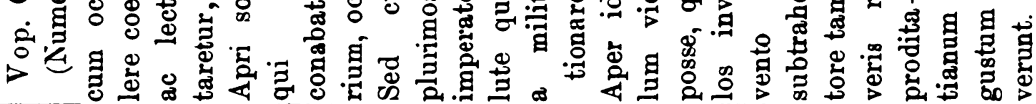

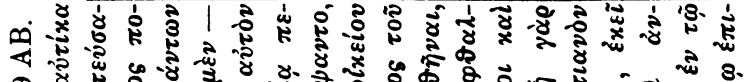

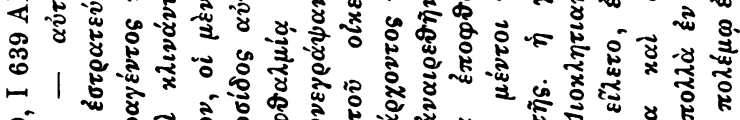

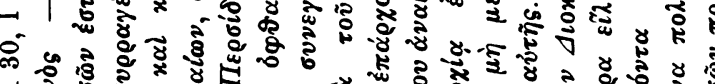

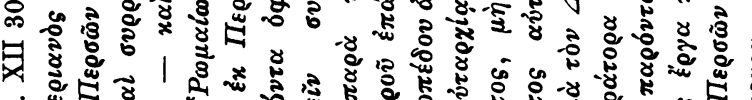
वं

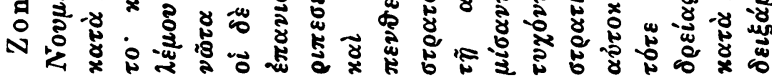

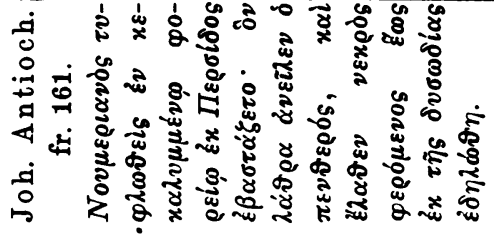


Für das Ende des Carinus gebe ich außer Joh. Ant. nur Eutr., die Epit. und Victor, besonders um die Stellung des Joh. Ant. zu beleuchten. Ersichtlich ist, daB dieser hier nicht aus Eutrop, den er neben Zos. benutzt hat, schöpfte. Die Epit. steht, wie sonst zu Zos., so jetzt völlig auf seiten des Joh. Ant. Victor gibt wieder einen verschiedenen Ausfluß derselben Überlieferung; er läBt Carinus während des Kampfes gegen Diocletian am Margus fallen, und darin tritt ihm Eutr. bei:

\begin{tabular}{l|l|l|r|} 
Joh. Ant. fr. 162-163. & Eutr. IX 19. & Epit. 38. & Caes. 39.
\end{tabular}

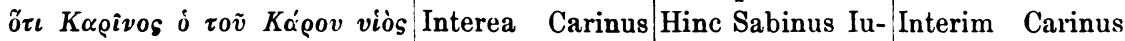

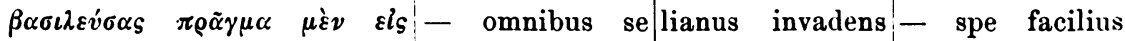

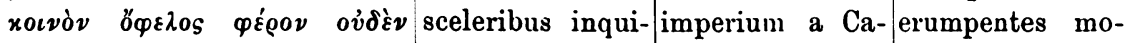
$\varepsilon i \varrho \gamma \dot{\alpha} \sigma \alpha \tau o, \tau \varrho v \varphi \tilde{\eta} \delta \dot{\varepsilon} x \alpha \dot{\varepsilon} \varepsilon$-navit. Plurimos rino in campis tus sedatum iri,

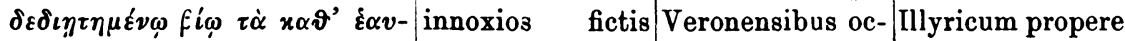

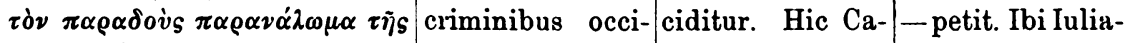

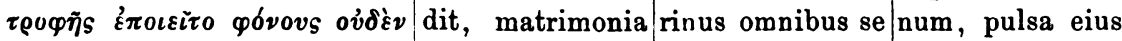

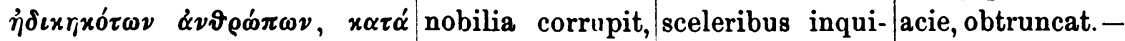

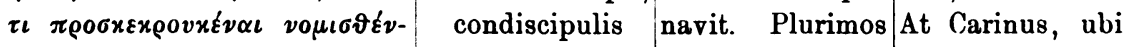

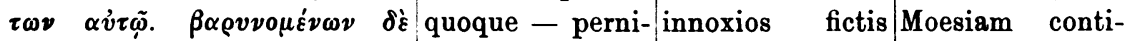
$\pi \dot{\alpha} \nu \tau \omega \nu \dot{\varepsilon} \pi i \tau \tilde{\eta} \pi \iota x \rho \tilde{\alpha} \tau v \rho \alpha \nu v i \delta \iota$ ciosus fuit. Ob criminibus occi- git, illicoMargum $\sigma v \nu \alpha \nu \alpha \mu \iota \chi \vartheta \varepsilon i ́ \sigma \eta \emptyset \varepsilon \delta ́ \tau \eta \tau \iota, ~ \varkappa \alpha i$ quae omnibus ho- dit, matrimonia iuxta Diocletia-

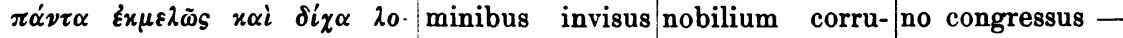

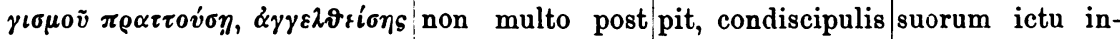

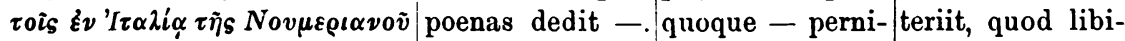

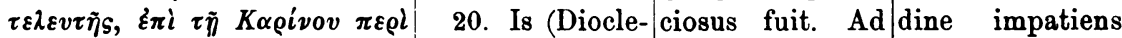

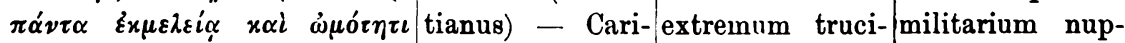
$\delta v \sigma_{\lambda} \varepsilon \rho \alpha \dot{\nu} \alpha \nu \tau \varepsilon S$ oi $\tau \tilde{\omega} \nu$ Ex $x \tilde{\tau} \tilde{\sigma} \sigma$ num omniumodio datur eius prae- tas adfectabat,

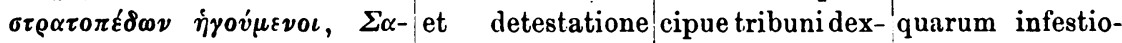

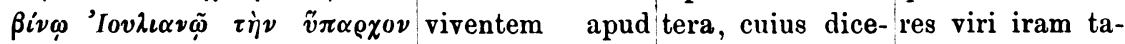
$\dot{\alpha} \varrho x \dot{\eta} \nu$ E้x $\chi \nu \tau \iota \beta \alpha \sigma \iota \lambda \iota x \dot{\eta} \nu \sigma \tau 0 \lambda \dot{\eta} \nu$ Margum ingenti batur coniugem men doloremque

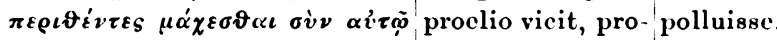

in eventum belli

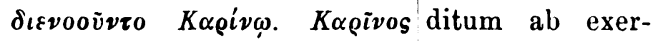

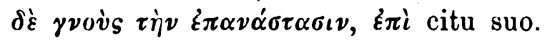

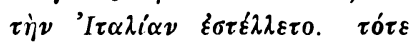

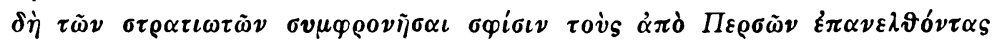

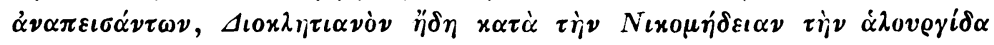

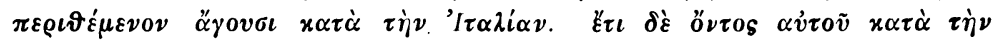

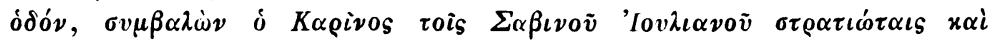

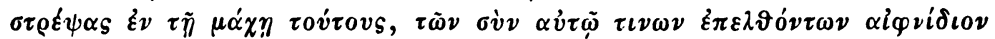

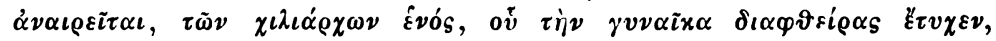

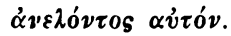

Mit der Erhebung Diokletians schlieBt die Zosimosquelle; in sämtlichen Quellen der Familie wird ein Einschnitt bemerkar: Da Zos. nach seiner großen Lücke noch unter Diokletian wieder eins tzt, läßt sich vermuten, daB er sein erstes Buch etwa mit dem Tode des Carinus abschlob. Zon. führt eine entschiedene Schwenkung zu Eutr.-Victor aus; 
daB Diocletian aus Dalmatien stammte und ein Freigelassener des Senators Anulinus war, hat er noch mit Eutr-Epit. gemein, aber bereits die Ermordung des Aper durch den Kaiser fehlt in der Epit., Vop. erzählt sie ausdrücklich als ihm vom GroBvater berichtet. ${ }^{1}$ ) Die Epit. gibt Diokletians Regierung unglaublich dürftig. Synk. hört ganz auf, da für ihn außer der Zosimosquelle auch die „Kaisergeschichte“ versagt; sie gab ihm gerade noch Maximians Erhebung zum Cäsar. Wird das Ende der Zosimosquelle durch all diese Tatsachen schon unzweideutig festgelegt, so findet diese Feststellung auch noch einwandfreie Bestätigung dadurch, daB Treb. Pollio und Vop., beide noch unter Diokletian, die Quelle benutzten, ja der letzte sogar bereits die „Kaisergeschichte" ausschrieb, die ja ihrerseits auf der Zosimosquelle fuBt.

\section{Die Zosimosquelle und Eunapios.}

Zosimos hat also nach den bisherigen Ermittlungen eine Quelle ziemlich vollständig ausgeschrieben, die mindestens die Zeit von der Regierung des Philippus Arabs bis zu Diokletian umfaBte. Bestimmt bezeugt ist aber, daB er Eunap benutzte, und dieser begann da, wo Dexippos aufhörte, also mit der Regierung des Claudius. Wie verträgt sich beides? Betrachten wir die Eunapiosfragmente 2-4, die einzigen, die für uns in Betracht kommen ${ }^{2}$ ): Fragm. 2 wird dem Eunap zugeschrieben, weil es augenscheinlich zu $\mathrm{Zos}$. I 57,6 in Beziehung steht. Kapitel 57-59 gehören aber zu den wenigen, deren Stoff Zos. nicht aus unserer gemeinsamen Quelle geschöpft hat; sie dokumentieren sich als eingeschoben außerdem durch ihre Einleitung und ihren Ab-

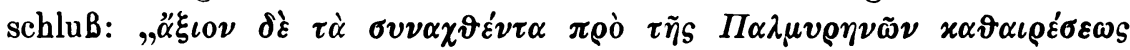

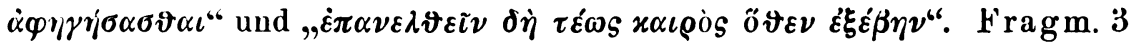
steht wahrscheinlich zu Zos. I 70,1; und wieder findet sich dasselbe Verhältnis: Der Isaurierkrieg war in der Zosimosquelle so flüchtig erwähnt, daß er sonst nur in die Lebensbeschreibung des Probus durch Vopiscus übergegangen ist, und dementsprechend erweisen sich Kap. 69

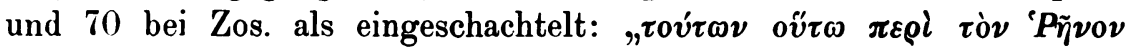

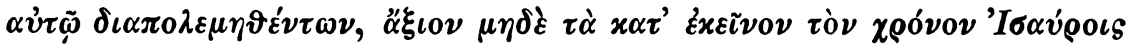

1) Vop. benutzte die „Kaisergeschichte“, nach der er unter anderem das Ende des Carinus erzählte. Apers Ermordung entnahm er aber wohl nicht aus ihr, erstens, weil er seine Quelle ausdrücklich nennt, zweitens, weil sie wahrscheinlich der später geschriebenen Fortsetzung jener Quelle angehört. Sehr möglich ist das Gegenteil, daß nämlich Vop. Quelle geworden wäre für den Bericht im zweiten Teile der "Kaisergeschichte“.

2) Sie finden sich, wie die des Joh. Antioch., des Petr. Patr. und des Anon. post Dionem in C. Müllers Fragm. hist. Graec. IV. 


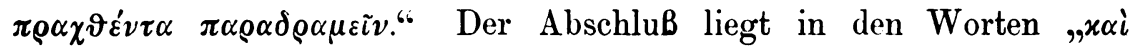

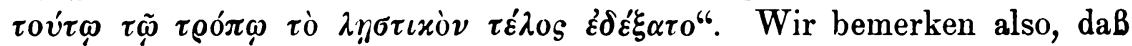
die einzigen beiden Stücke, die aus dem durchforschten Teil des Zos. in den verwandten Quellen keine Parallele fanden, wahrscheinlich auf Eunap zurückgehen. Dann stammen aber auch nur diese eingeschobenen Kapitel aus Eunap, das heiBt: Zosimos hat für sein erstes Buch den Eunap nur als Aushilfe benutzt.

Etwas anderes ergibt sich bei Fragm. 4; es stellt sich als ein Sündenregister des Carinus dar, wie wir es in den Zos. verwandten Quellen ebenfalls fanden, zeigt aber keine irgendwie wörtliche Übereinstimmung wie etwa Joh. Ant. mit Eutrop. und der Epitome. Eben aus Joh. Ant. ergibt sich, daB Zos. hier direkt, jedenfalls nicht über Eunap auf die Gesamtquelle zurückging. Die trotzdem vorhandene Analogie führt uns auf die Vermutung, daB Eunap in irgendeiner Beziehung zur Zosimosquelle stand, obwohl er selbst wenigstens für das erste Buch nicht mit ihr identisch ist. Die Frage findet ihre Beantwortung zugleich mit einer zweiten, der wir ebenfalls nicht aus dem Wege gehen dürfen: Die Verwandtschaft der meisten von uns herangezogenen Quellen dauert nämlich über den Regierungsantritt Diokletians hinaus fort; wie kommt das? Hat vielleicht unsere Zosimosquelle eine Fortsetzung gefunden und ist so im ganzen von den weiter reichenden Quellen verwertet worden? Dann wäre anzunehmen, daB das Verhältnis der Autoren zueinander wesentlich dasselbe bliebe, wie bisher. Für Zon. bemerkten wir schon, daB dies nicht der Fall ist. Ich gehe wieder von einem sicheren Punkte aus.

Enmann hat gezeigt, da B seine „Ka isergeschichte“, die ursprünglich ebenfalls bis zum Beginn Diokletians reichte, bis zum Jahre 357 fortgesetzt wurde, und da $B$ diese Fortsetzung ebenfalls von Eutrop und Aurelius Victor benutzt wurde. ${ }^{1}$ ) Er hätte hinzufügen können, daß Eutrop, im Gegensatz zu der Zeit vor Diokletian, für die späteren Abschnitte sich in wesentlicheu auf die Fortsetzung der Kaisergeschichte beschränkte. Die wenigen Daten, die er mehr gibt als Aurelius Victor, lassen sich nämlich zum großen Teil als Eigentum der „Kaisergeschichte“ nachweisen durch Hinzuziehung eines anderen Quellenpaares, des Zonaras und Kedrenos. Da der letzte doch zweifellos auf derselben Grundlage wie Zonaras beruht, können wir ihn in seiner Dürftigkeit hier beiseite lassen, die Vergleichung des Zon. genügt dem vorliegenden Zwecke vollständig: Zon. XII 31 I 640 A die Ermordung Apers und die Erhebung Maximians, CD die Erhebung und Niederwerfung Ale- 
xandrias und des Achilles in Ägypten, die Cäsarenkreation, die Verstoßung der Gattinnen und die neuen Heiraten, I $641 \mathrm{~A}$ die Empörungen des Amandus und Crassus (Carausius), die erste durch Maximian, die letzte durch Asklepiodotos niedergeschlagen, die Quinquegentianer in Afrika, der Alamannenkrieg des Constantius, C der Perserkrieg des Galerius mit der aufänglichen Niederlage, dem darauffolgenden Siege, I 642 A die Erwähnung vieler anderer Kriege (bei Eutrop gegen Carpen, Bastarnen, Sarmaten), endlich $\mathrm{C}$ die Abdankung mit dem Triumph, alles wird vollständig parallel zu Eutrop und Aurel. Victor erzählt. Es folgt I 643 A der Regierungsantritt des Constantius und Galerius mit der Gebietsteilung, BC, allerdings wie in A schon das Auftreten des Maxentius vorweggenommen, die Intriguen des Maximian - mit dem Versuch, Diokletian zur Teilnahme zu bewegen - und sein Ende durch den Verrat der Tochter, dann D der Tod des Constantius, 34 I 645 BC die Flucht Konstantins und seine Erhebung, sowie die des Licinius, des Galerius verunglückter Zug gegen Maxentius und D sein Tod. XUI 1 II $1-2$ der Kampf Konstantins mit Maxentius, die Schlacht an der Mulvischen Brücke, des Maxentius Tod, die Freundschaft zwischen Konstantin und Licinius; II 3 Kampf und Friede, Erneuerung des Kampfes, Ergebung des Licinius in Nikomedia, seine Internierung in Thessalonike und Ermordung; II 5 D-6 A die Ermordung des Crispus und der Fausta, der Sarmaten- und Gotenkrieg; 3 II 6 B ff. die Gründung Konstantinopels; 4 II $10 \mathrm{C}$ sein Tod in Nikomedia während eines Perserkrieges. Weiter findet sich 5 II $11 \mathrm{CD}$ der Bruderkrieg zwischen Constans und Konstantin, in dem Konstantin umkommt; 6 II 13 A B Erhebung des Magnentius, während Constanstius mit den Persern kämpft; II $14 \mathrm{~B}$ die Ermordung des Constans ह̇v

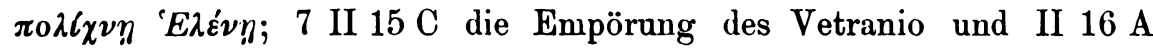
dessen Abdankung; 8 II 16 B die Ernennung des Decentius zum Cäsar durch Magnentius und von Gallus durch Constantius; weiterhin sehr ausführlich der Sturz des Magnentius, 9 II 19 BC die Ermordung des Gallus und der Aufstand des Silvanus; 10 II 20 A die Ernennung Julians zum Cäsar und seine Vermählung, B seine Entsendung nach Gallien, $\mathrm{C}$ die Besiegung der Alamannen.

Das ist für diese Zeit der wesentliche Inhalt des Zon., soweit er nicht Eusebios ausschöpfte, und, wie ein Vergleich zeigt, ist es zugleich fast genau eine Aufzählung dessen, was Eutrop und Victor gemein haben. ${ }^{1}$ ) In Reihenfolge und Reichhaltigkeit bestehen zwischen Zon.

1) Hier, wo die Einheit der Quelle so klar liegt, scheint mir das Verhalten der Autoren der Leosippe, die nicht nur kürzen, sondern vor allem ganze Abschnitte streichen, doch eine starke Stütze für die Ansicht, daB auch für die 
und Eutrop nicht entfernt so große Lnterschiede, wie zwischen Eutrop und Aurelius Victor; doch zeigen einige Übereinstimmungen mit den Caesares, wie Konstantins Flucht und des Galerius Zug gegen Maxentius, daB nicht Eutrop selbst die Vorlage gewesen ist. Gesichert erscheint also, daß auch Zon. (und Kedr.) auf die Fortsetzung der „Kaisergeschichte" zurückgehen. Dabei ist es nicht unsere Sache, zu entscheiden, ob die Reichhaltigkeit, die Zon. zuletzt aufweist, vollständig der mit Eutrop und Victor gemeinsamen Quelle angehört, oder ob diese, was wahrscheinlicher ist, mit einer anderen Vorlage verschmolzen wurde. ${ }^{1}$ )

Kommen wir zu Zosimos: Für die Regierung Diokletians ist er leider verloren, und auch Johannes Antiochenus ist nicht zu verwerten, weil er, soweit wir ihn kennen, hier rein den Eutrop ausschreibt. Von der Abdankung Diokletians und Maximians an aber, wo Zos. wieder einsetzt, können wir auch bei ihm eine durchgängige Verwandtschaft mit Eutrop und Victor feststellen. Infolgedessen könnte auch hier auf Benutzung jener Fortsetzung der "Kaisergeschichte“ geschlossen werden. Der Fall liegt aber anders: Im wesentlichen bildet das Skelett des Zosimostextes der Bericht des Aurelius Victor: Auf die Thronbesteigung des Constantius und Galerius folgt die Ernennung der Cäsaren; Konstantins Flucht wird mit den Einzelheiten erzählt, die sonst nur Aurel. Victor gibt. In dem Zuge des Severus gegen Maxentius, über den Zos. sonst stark auch von Aurel. Victor abweicht, steht

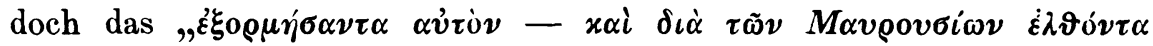
$\tau \alpha \gamma \mu \alpha \tau^{\prime} \omega \nu^{\prime \prime}$ (II 10,1) mit dem „Is circum muros cum ageret" ganz sicher in einem bestimmten Zusammenhang. Erst jetzt, vor dem Entscheidungskampf gegen Maxentius, berichtet er, wie Victor, die Umtriebe des Maximianus Herculius. Dessen Untergang war nach Eutr. und Zon. in ihrer Vorlage so klar dargestellt, daB gar keine Verwirrung möglich war, außerdem so früh berichtet, daß ein Zusammenwerfen mit dem Ende des Maximinus Daza, wie es Zos. II 11 fertig bringt, schlechterdings ausgeschlossen war. Auch hier ist der Zosimostext nur verständlich aus den allgemeinen Redensarten des Aur. Victor, sowie daraus, daB bei diesem in der Tat nur wenig später der Tod des Maximinus berichtet wird. Gleich darauf folgt bei Zos. II 12 der

früheren Teile das Plus oder Minus der einzelnen Chroniken nicht immer und vielleicht nicht einmal überwiegend der Quellenmischung zuzuschreiben sei, sondern häufig dem ungleichmäBigen Exzerpieren, wie wir es ja selbst in der besseren Zeit der Historiographie z. B. bei Trebellius Pollio, dann unter anderen bei Jordanes und schlieBlich bei Malalas finden.

1) Vgl. dazu Patzig Byz. Z. XIII S. $13 \mathrm{ff}$. 
Aufstand der Karthager und seine Unterdrückung; er steht in den Caesares, fehlt aber bei Eutr. und Zon., ebenso wie die Aufhebung des Prätorianerkorps (Zos. II 17,2). In dem Frieden Konstantins mit Licinius gibt Zos. II 20 die Cäsaren wie Aurel. Victor, nennt dann als von Konstantin besiegt ebenfalls mit Victor die Sarmaten; auch die Einfügung dieses Sieges ist Aurel. Victor näher als Eutr. In dem zweiten Kriege gegen Licinius endlich weist die Erwähnung des Martinian und die von Chalkedon auf Victor.

Dies sind die Hauptdaten, aus denen hervorgeht, daB Zos. nicht auf die „Kaisergeschichte“, der Aurel. Victor folgte, sondern auf diesen selbst zurückgeht. Ist dies aber der Fall, dann sind die ebenfalls unverkennbaren Anklänge an Eutr. ebenso nur durch direkte Benutzung dieses Autors zu erklären. Nicht dahin gehört wohl die Nennung Lukaniens als Aufenthaltsort Maximians, da dessen Stellungnahme bei Zos. I 10,2 in keiner Weise zu Eutr. stimmt. Erst Zos. II 10,4-7 konnte aus Eutr. stammen, was auch durch die räumliche Trennung von II 11,1 bestätigt zu werden scheint. Zwischen beiden steht die Ernennung des Licinius zum Cäsar, und in der Tat haben die Umtriebe des Maximian und sein Tod ihren Platz bei Eutr. vor, bei Victor hinter jenen Ereignissen, so daB die Erzählung bei Zos. als ein Versuch erscheint, beide Versionen zu vereinigen. Zos. II 17,2-3 ist, nachdem vorher schon aus Aurel. Victor das Ende Maximians und Maximins zusammengeworfen wurde, eine deutliche Wiederholung eines Teils dieser Vorgänge aus Eutr., wie denn diesmal richtig Maximin in Tarsus stirbt. Den Namen von Konstantins Schwester hat Victor ebensowenig wie den Ort Kibalis der ersten Schlacht zwischen Konstantin und Licinius. Zos. II 4.3 giht mit Futr. den Namen Nepotian statt Potentian wie Aurel. Victor, der auch den Schlachtort Mursia nicht erwähnt. Das gleiche gilt von der Alamannenschlacht bei Argentoratum. Ist nach alldem schon sicher, daB Zos. wie auf Aur. Victor, so auch auf Eutr. direkt zurückgeht, so kommt noch dazu, daB die Übereinstimmung mit Eutr. über das Ende der Schrift De Caesaribus hinaus fortdauert, also da, wo Eutr. Eigenes gibt. Der Perserkrieg des Julian allerdings ist nach Mendelssohns ${ }^{1}$ ) begründeter Ansicht aus Magnus Carrhenius entnommen; aber für die kurze Regierung des Jovianus macht sich Eutr. wieder bemerkbar. An einer Stelle ist das ganz auffallend: Eutr. X 17,2 stellt eine völlige Anomalie dar; der Autor, der sich sonst von Aurel. Victor so wesentlich durch das Fehlen jeder allgemeinen Betrachtung auszeichnet, verbreitet sich hier darüber, daB die Römer zwar oft

1) XXXIX ff. 
schwere Niederlagen erlitten, aber nie vor Jovian sich zu Landabtretungen verstanden hätten. Schlagen wir die analoge Stelle bei Zos. III 32 auf, so finden wir eine Betrachtung genau des gleichen Inhalts, auch bei Zos. eine entschiedene Seltenheit. So wird gewiB, daB Eutr. ebenso wie Aurel. Victor selbst, nicht nur ihre gemeinsame Quelle, zu den Vorlagen des Zosimostextes gehört.

Wie ich bemerkte, bildet der Bericht des Aurel. Victor besonders in den späteren Teilen nur das nackte Gerippe des Zosimostextes; auch was Eutr. dazu gibt, ist doch nur dürftig gegenüber der Ausführlichkeit des Zos. Daraus geht hervor, daß diesem außer den beiden schon genannten noch eine dritte Vorlage zu Grunde liegen muB. Und zwar hat er diese Vorlage ${ }^{1}$ ) mit Zon. gemein, wofür eine unzweifelhafte

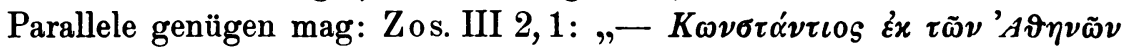

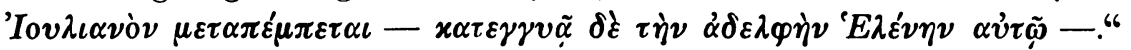

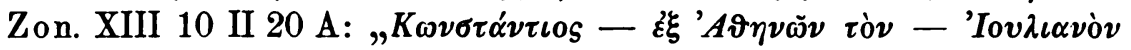

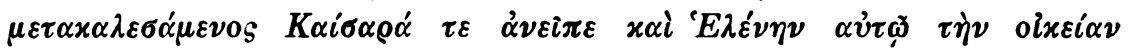

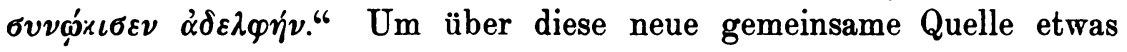
auszusagen, bedürfte es wieder einer ausführlichen Analyse, die uns hier viel zu weit führen würde, auch gar nicht zu unserer Aufgabe gehört.

C. Müller druckt für diese Zeit so viel Eunapiosfragmente ab, deren Inhalt bei Zos. wiederkehrt, da $B$ jeder $Z$ weifel darüber schwinden muB: Zos. hat für sein zweites Buch und mindestens für den Anfang des dritten Eunapios ausgeschrieben. Kein einziges dieser Fragmente enthält Daten, die zu Eutr. oder Victor stimmen. Trotzdem glaube ich nicht, daB man schließen darf, Zos. selbst habe neben Eunap noch jene beiden benutzt. Denn zunächst müBte auffallen, daß er den dürttigen Victor als Leitfaden genommen, den reichhaltigen Eunap als Dekoration verwandt hätte. Schwerer wiegt die zweite Erwägung: Wir sahen im ersten Buch, daB die aus Eunap eingefügten Stellen beide eine Art Einleitung hatten, die sie als Einschiebsel dokumentierte. Ähnliche Anflickungen finden sich auch in der Folge: Zos. II 36, , $\alpha i$

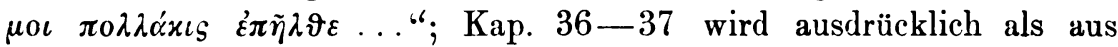
eigener Forschung hervorgegangen bezeichnet. Zos. II 52 , „' $\xi \iota \nu \nu \delta \dot{\varepsilon}$

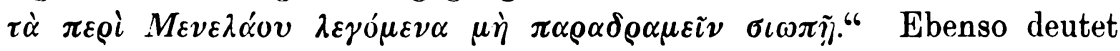

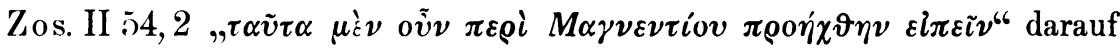
hin, daB hier wenigstens ein Teil der Nachrichten einer besonderen Quelle entstammte. Am deutlichsten ist aber die Einleitung des Abschnittes, in dem Zos., wie Mendelssohn wobl mit Recht vermutet,

1) Oder eine dieser Vorlagen. 


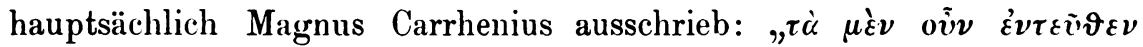

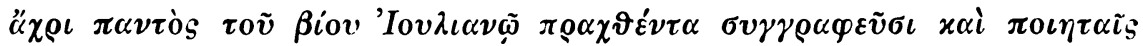

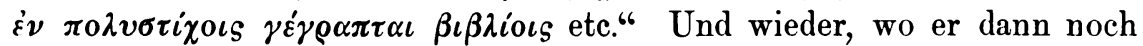

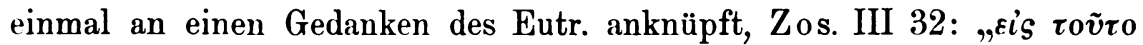

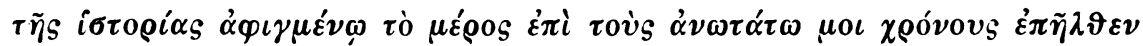
$\dot{\alpha} \nu \alpha \delta \rho \alpha \mu \varepsilon i \nu . "$ Nichts derart findet sich zwischen Angaben, die aus Eutr. oder Victor stammen, und solchen, die in Fragmenten des Eunap wiederkehren. Daraus ergibt sich mit einiger Wahrscheinlichkeit: Nicht Zos. selbst, sondern schon Eunap hat nicht nur die mit Zon. gemeinsame Quelle, sondern auch Aurel. Victor und Eutr. ausgeschrieben. l)em entspricht Eunap fr. 4, das eine reine Paraphrase des Eutroptextes ist, im besten Fall mit einigen anderswo gepflückten Lesefriichten verbrämt.

Das Verhältnis zwischen Zos. und Eunap stellt sich also folgendermaßen dar: Zos. hat für sein erstes Buch Eunap nur an zwei Stellen für Exkurse, für das zweite Buch aber als Hauptquelle benutzt. Eunap selber dagegen geht auf Aurel. Victor und Eutrop zurïck, die ihrerseits wieder teils indirekt, teils direkt für die Zeit bis Diokletian aus derselben Quelle wie Zos. schöpften.

\section{Dexippos}

von der Regierung des Philippus Arabs bis zum SchluB.

Wenn ich die gesamte Untersuchung vorläufig auf die Zeit nach Philippus Arabs beschränkt habe, so geschah das, weil für die vorhergehende Periode ein Zusammenhang irgendwelcher Art gesichert erscheint; es geschah, um den beliebten Suggestionsschlub zu rermeiden, da für einen Teil eine Verwandtschaft unleugbar sei, werde sie wohl auch für die übrigen Teile bestehen. Auf dem so begrenzten Gebiete hat sich nun bereits ergeben, daB die Überlieferung, Zos. habe nach Dex. den Eunap ausgeschrieben, für sein erstes Buch im wesentlichen unzutreffend ist. Und da er dieselbe Quelle, die er dort ausschrieb, auch für die von Dex. behandelte Zeit ausschrieb, so kann er auch hier nicht auf Dex. selbst fußen; es bleibt nur die Möglichkeit, daß eben die Zosimosquelle auf Dex. beruhe. Von vornherein ungünstig ist dieser Vermutung die Tatsache, daß die „Kaisergeschichte“ gerade erst von dem Punkte an Zos. näher steht, wo Dex. aufhört; denn läBt sich dieser Schritt nur dadurch erklären, daB sie vorher Dex. benutzte, so müBte doch wohl bei Abhängigkeit auch der Zosimosquelle von Dex. schon vorher eine weitgehende Übereinstimmung des Zos. und der „Kaisergeschichte" bemerkbar sein. Sehen wir aber, was sich in unserer 
Literatur als sicher von Dex. stammend erweist ${ }^{1}$ ), und wie sich diese Berichte zu den Angaben der Zosimosquelle verhalten.

Außer den authentischen Dexipposfragmenten ${ }^{2}$ ), die alle den Skythika entstammen, sind mehrere Stellen des Synk. durch ausdrückliches Zitat für Dex. gesichert, und gleich die erste erweist den vermuteten Zusammenhang mit Aurel. Victor; außerdem tritt Jordanes hinzu, der Dex. an anderer Stelle auch zitiert:

Synk. P. 376 A. : Caes. 29.

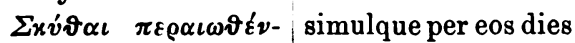

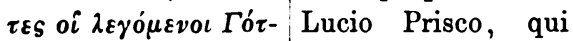

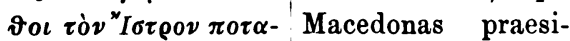

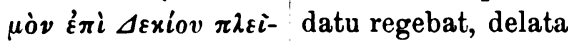

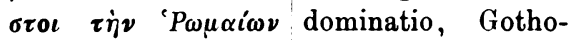

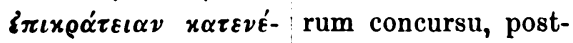

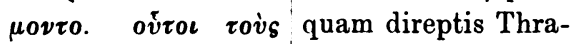

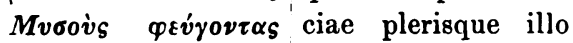

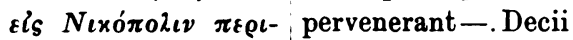

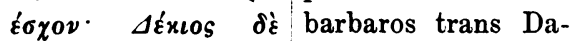

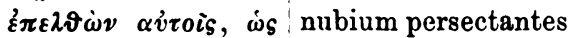

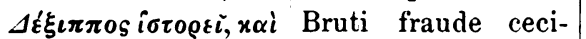
$\tau \rho i \sigma \mu v \rho i o v s \quad x \tau \varepsilon i v \alpha s$ dere, exacto regni $\varepsilon \lambda \alpha \tau \tau 0 \hat{v} \tau \alpha \iota \quad x \alpha \tau \dot{\alpha} \tau \dot{\eta} \nu$ biennio. Sed Deci$\mu \alpha \dot{x} \eta \nu, \dot{\omega} s x \alpha i$ iो̀ orum mortem pleri-

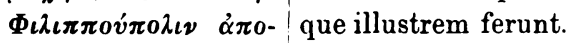
$\lambda \dot{\varepsilon} \sigma \alpha \iota \lambda \eta \varphi \vartheta \varepsilon i \sigma \alpha \nu \dot{v} \boldsymbol{\pi}$ Namque filium au-

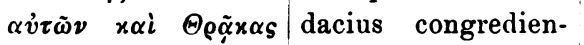

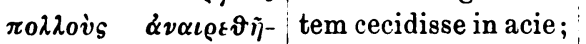

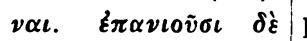

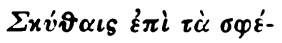

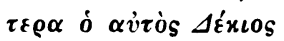
$\dot{\varepsilon} \pi \iota \vartheta \dot{\varepsilon} \mu \varepsilon \nu 0 \mathrm{~S} \dot{\alpha} \nu \alpha \iota \varrho \varepsilon i-$

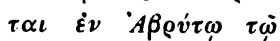

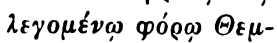
$\beta \rho \omega \nu i \omega$ бiv $\tau \tau \tilde{\omega} \pi \alpha \iota \delta i$

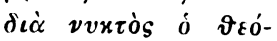
$\mu \alpha \chi o s$. patrem autem, cum perculsi milites ad solandum imperatorem multa praefarentur, strenue dixisse: Detrimentum unius militis parum videri sibi. Ita refecto bello cum impigre decertaret, interiisse pari modo.
Jord. Getica 18.

Cniva - nonnullos ad vastandum Moesiam dirigit -; ipse vero cum LXX milibus ad Eusciam id est Novas conscendit. Unde a Gallo duce remotus Nicopolim accedit - . Ubi Decio superveniente imperatore tandem Cniva in Hemi partibus - recessit, unde apparato disposito Philippopolim ire festinans. Cuius secessu Decius imperator cognoscens et ipsius urbis ferre subsidium gestiens iugo Hemi montis transacto ad Beroam venit. Ibique - illico Cniva cum Gothis in modum fulminis ruit, vastatoque exercitu imperatorem - ad Eusciam rursus trans Alpes in Mysia proturbavit, ubi tunc Gallus dux limitis cum plurima manu bellantium morabatur; collectoque tam exinde quam de Usco exercitu, futuri belli se parat in acie. Cniva vero diu obsessam invadit Philippopolim praedaque potitus Prisco duce qui inerat sibi foederavit quasi cum Decio pugnaturum. Venientesque ad conflictum illico Decii filium sagitta saucium crudeli funere confodiunt. Quod pater animadvertens licet ad confortandos animos militum fertur dixisse: „nemo tristetur: perditio unius militis non est rei publicae deminutio", tamen paterno affectu non ferens hostes invadit - veniensque ad Abritto Moesiae civitatem circumseptus a Gothis et ipse extinguitur imperii finem vitaeque terminum faciens.

Die Belagerung von Philippopolis, wo Priscus Befehlshaber war, wird auBerdem durch Dex. fr. 19 u. 20 als Eigentum dieses Autors gesichert.

1) Eine Trennung von Chronilsa und Skythika scheint mir vorläufig nicht. tunlich und sicher nicht erforderlich, da sich ja Dex. wohl kaum in wesentlichen Punkten selbst widersprochen haben wird.

2) Im 3. Bande der Fragm. hist. Graec. 
In Kap. 16 der Getica ist die Belagerung von Marcianopolis mitsamt der Gründungsgeschichte durch Dex. fr. 18 festgelegt. Das ganze Kapitel außer wenigen Punkten, die zu Hieronymus und Orosius stimmen, dürfte Dex. angehören; es geht nicht nur z. T. parallel zu Dex. fr. 14 (Capitol. Mar. et Balb. 16), sóndern steht auch in enger Beziehung zu Petrus Patricius fr. 8, das uns einen Blick in die Vorgeschichte des Skythenkrieges tun läßt; Jord. wie Capit. setzen Petr. Patr. fast genau fort. DaB Petr. Petr. tatsächlich aus Dex. geschöpft hat, ergibt ein Vergleich von Dex. fr. 22 und Petr. Patr. fr. 12:

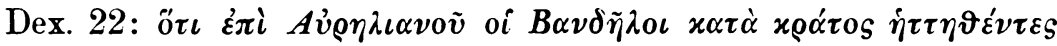

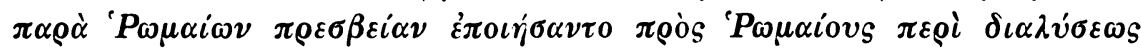

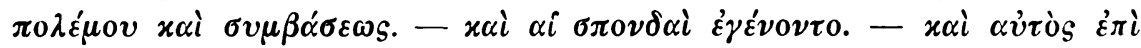

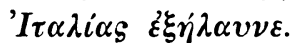

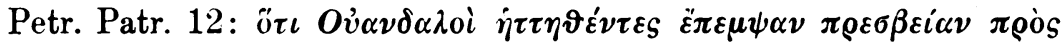

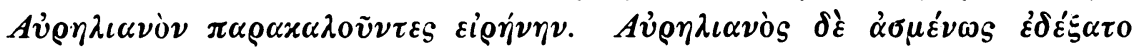

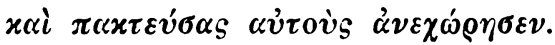

Einen Teil desselben Komplexes von Ereignissen, wie Dex. fr. 21, behandelt die Anekdote von der beabsichtigten Bücherverbrennung, die beim Anonymus post Dionem fr. 9 und bei Zon. XII 26 I $635 \mathrm{D}$ an die Einnahme Athens geknüpft ist; auch sie gehört ohne $\mathrm{Zweifel} \mathrm{Dex.}$ an. Ebensowenig werden wir bei Vergleich mit Dex. fr. 18 u. 20 im unklaren darüber bleiben, daB die Belagerung von Thessalonike mit der Notiz über die Namensänderung der Stadt, die bei Zon. dem eben angeführten Exzerpt unmittelbar vorangeht, aus Dex. stammt, und nicht anders liegt die Sache mit der darauf folgenden, eng damit verknüpften Nachricht; denn sie kehrt nicht nur bei Synk. wieder, sondern auch Treb. Pollio gewährt eine Parallele, und diese erwähnt den athenischen Historiker in derselben Rolle, die er nach seiner eigenen Darstellung (fr. 21) gespielt hat:

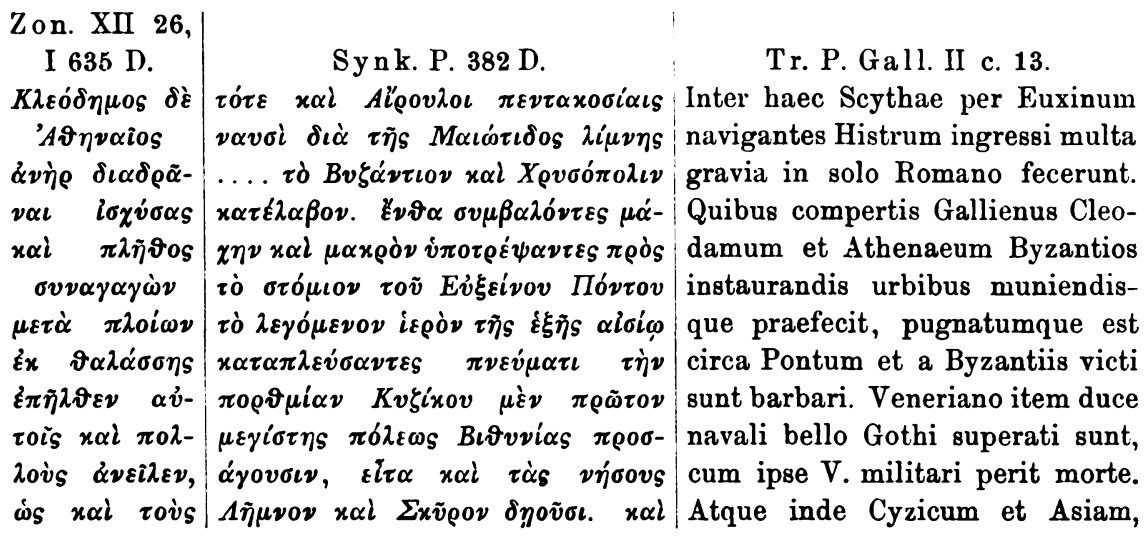




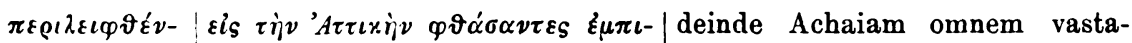

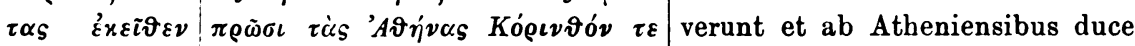

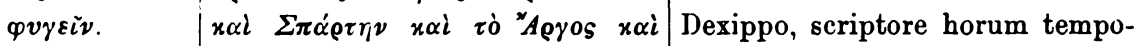

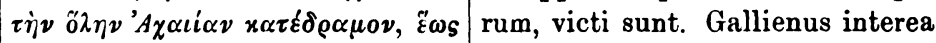

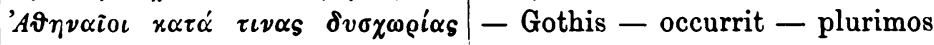

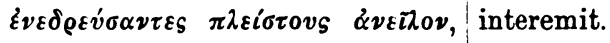

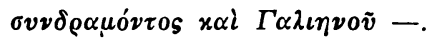

Wie schon oben S. 102 erwähnt, stellt sich auch Aurel. Victor hierzu; c. 33: „uti Thraciam Gothi libere progressi, Macedonas Achaeosque et Asiae finitima occuparent". Dex. fr. 8 belehrt uns zudem, daB der Autor die Heruler in seiner Chronik behandelt hat.

Vergleichen wir die so gewonnenen, einigermaßen sicheren Dexipposexzerpte mit Zos., so bemerken wir nicht nur eine große Anzahl bei Zos. fehlender Angaben, sondern, was am wichtigsten ist, wir erkennen, daB die auch bei Zos. erzählten Vorgänge von Grund aus verschieden dargestellt sind, wie z. B. das Ende des Decius und die Skythenzüge unter Gallienus. Bei den letzten ist der Unterschied so groB, daB Synk. und Zon. beide Berichte nebeneinander ausschrieben, in dem Glauben, es handle sich um ganz verschiedene Dinge, daB der Gewährsmann des Zon. die gesamten Vorgänge in die Regierungszeit des Claudius versetzte, augenscheinlich, weil er die Darstellung der Belagerung von Thessalonike nicht mit der aus der Zosimosquelle unter Valerian gegebenen zusammenreimen konnte. Bemerkenswert ist, daB dieser Zonarastext ebenso wie die Exzerpte des Jordanes sicher aus den Skythika stammen, also auch die Darstellung der Skythenzüge bei Zos. nicht für Dex. zu retten ist.

Von besonderer Bedeutung ist die Erkenntnis, daB Zon. z. T. auf Dex. beruht, daB aber alle die Teile, die sicher auf den attischen Autor zurückgehen, auBerhalb des Bestandes der Zosimosquelle stehen. Dieser Gesichtspunkt läßt sich weiter verfolgen: Zon. gibt über Valerians Ausgang zwei Versionen, von denen ich die eine mit Zos. und der Epit. verglich; die andere Zon. XII 23 I $630 \mathrm{~A}$ kehrt bei Synk. P. $381 \mathrm{D}$ wieder. Die Übereinstimmung dauert in dem Bericht ïber die Perserkämpfe Zon. XII 23 I 630 B -D und Synk. P. 381 D - 382 A fort. Der Held dieser Kämpfe auf römischer Seite ist Kallistos, doch wohl kein anderer als der Ballista des Treb. Pollio, den Zos. überhaupt nicht kennt. Die weitere Geschichte des Ballista in Verbindung mit der des Macrinus wird denn auch von Treb. Pollio völlig parallel zu Zon. dargestellt, Zon. XII 24 I $632 \mathrm{C}-633 \mathrm{~B}$ und Treb. Pollio Gall. duo 1-3 Pollio schreibt Quietus statt Quintus, läBt Aureolus wie überall als Kaiser auftreten und dessen Feldherrn Domitian gegen Macrinus ziehen;

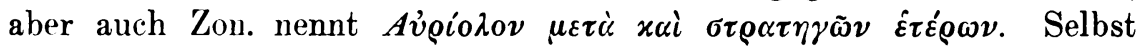


aus dem dürftigen Wortlaut des Pollio ist zu ersehen, daB auch in seiner Vorlage die beiden Macrinus erst nach der allgemeinen Übergabe getötet wurden, und ebenso zeigt Trig. tyr. 12 die Zonarasversion, daB nicht Macrinus selbst, sondern nur seine Söhne das Imperium übernahmen. Endlich gibt Gall. duo 3 (entgegen Trig. tyr. 14) mit Zon. auch die Einzelheit, daB Quintus durch die Einwohner von Emesa ermordet wurde.

Schon vorher geht eine Stelle des Zon. zu Aurel. Victor (und Eutr.) parallel:

Zon. XII 24 I $631 \mathrm{C}$.

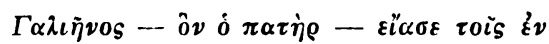

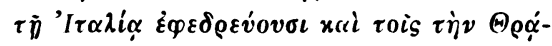

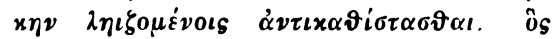

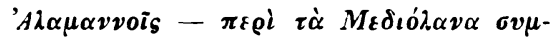

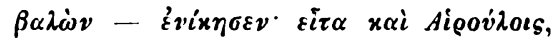

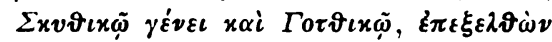

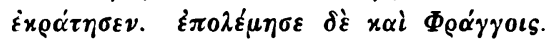

De Caes. 33 (Eutrop IX 8).

uti Thraciam Gothi - Mesopotamiam Parthi; Orienti latrones seu mulier dominaretur; Alamannorum vis tunc aeque Italiam, Francorum gentes, direpta Gallia, Hispaniam possiderent -. et amissa trans Istrum quae Traianus quaesierat.

Hier allein wird von den Frankenkämpfen geredet, und um so bemerkenswerter ist, daB auch Treb. Pollio Gall. duo 8, 7 in Galliens Triumphzug Franken aufzählt.

Zon. XII 24 I $634 \mathrm{~A}-\mathrm{C}$ und CD enthält zwei Überlieferungen der Ermordung des Gallienus, die sich im ganzen recht ähnlich sehen und von denen die zweite der Zosimosquelle entstammt. Uneinig sind sie hauptsächlich über den Anstifter des Mordes, und wieder ist Aurel. Victor 33,21 außer der ersten Zonarasversion der einzige Autor, der dem Aurelian die Urheberschaft der Tat zuschreibt.

Die der Zosimosquelle fremden Teile von Zon. XII 25 I 633 B$25 \mathrm{I} 634 \mathrm{~A}$, sowie $26 \mathrm{I} 635 \mathrm{BC}$ und 636 sind anderweit nicht belegt, doch lassen auch sie sich vielleicht Dex. näher bringen, wenn wir annehmen dürfen, daß der Anonymus, dem Zon. sicher einen großen Prozentsatz dieser Angaben verdankt, in hohem Grade von Dex. abhängig ist: fr. 9,1 wurde schon angeführt, fr. 8,1 handelt von dem oben genannten Quintus, dem Sohne des Macrinus. fr. 1 deutet durch Übereinstimmung mit Ammian auf Dex., sowie dadurch, daB hier Antiochia zur Zeit des Valerian von den Persern genommen wird, also wie bei Zon. und Synk., während Zos. und Treb. Pollio das Ereignis unter Gallus setzen. fr. 2 stimmt zu Zon. XII 22 I $628 \mathrm{D}$ und wird durch Victor 31 „Aemilianus quoque tres menses usus modesto imperio" gestützt. fr. 3 ist am besten verständlich, wenn Valerian sich freiwillig in Sapors Gefangenschaft gab. fr. 5 handelt von Galliens Kampf gegen Ingenuus, der sonst nur bei Zon. XII 24 I 631 D, Victor 33,2, Eutr. 
IX 8 und Treb. Pollio trig. tyr. 9, also gerade in den sicher von Dex. abhängigen Quellen erzählt wird; dazu kommt, daB Pollio die Konsulnamen voranstellt, wie das ja gerade von den Chronika des Dex. überliefert ist. Aus den Namen in fr. 4,6 und 7 dürfen wir nicht schlieBen, daß der Anonymus auch die Zosimosquelle ausgeschrieben habe. ${ }^{1}$ ) Odenath war ja, wie die Nachrichten über das Ende des Quintus und Ballista zeigen, bei Dex. genannt; Treb. Pollio berichtet von Odenath zweimal (Gall. duo 10,1 und 12,1) mit Voranstellung der Konsulnamen, und beide Male gibt er nicht den reinen Bericht der Zosimosquelle - ich weise nur auf die Erwähnung von Carrhae hin -, während Trig. tyr. 15 die Fasten fehlen. So wird wahrscheinlich, daB des Anonymus Erzählungen - und was Zon. aus ihı entnahm - wesentlich auf Dex. beruhen, soweit sie nicht, wie wohl die meisten aus der Zeit nach Claudius, einem ganz fremden Born entflossen, den außer dem Anon. nur noch Vopiscus gekannt zu haben scheint.

Ich erwähnte bereits, daB in der „Kaisergeschichte" ein deutlicher Quellenwechsel mit der Regierung des Claudius darauf hinweist, da $B$ vorher hauptsächlich Dex. benutzt war. Einmal findet sich dafür ein positiver Beweis: Nach Synk. P. 376 B hat Dex. die Regierung des Gallus auf 18 Monate angegeben. Aurel. Victor begreift Kap. 31 die gesamte Regierungszeit des Gallus und Ämilian zusammen innerhalb zweier Jahre. Davon kommen bei ihm auf Ämilian drei Monate, was sich ebenfalls bei Synk. P. $380 \mathrm{C}$ wiederfindet, da seine drei Jahre sicher auf ebensoviele Monate zu reduzieren sind. So kommt Victor wirklich mit Dex. überein, während Zonaras, bei dem dieser Abschnitt der Zosimosquelle entnommen ist, für Gallus allein 32 Monate, für Ämilian beinahe vier, also im ganzen drei Jahre für die zwei bei Victor gibt. ${ }^{2}$ )

Mit großer Wahrscheinlichkeit würden die Übereinstimmungen in der Geschichte der Gegenkaiser bei Eutr., Victor und den Triginta tyranni des Trebellius Pollio, die Enmann eingehend abgehandelt hat, auf Dex. zurückzuführen sein, wenn sie nicht, wie eben E. annimmt, auf die „Kaisergeschichte“ zurückgehen. ${ }^{3}$ ) Hauptbeweisstück ist der Bericht über Tetricus; aber gerade er ist im höchsten Maße verdächtig. Er zieht zusammen, was in der „Kaisergeschichte“ an zwei ganz aus-

1) Das müBte aber der Fall sein, wenn, wie Sotiriadis Jahrb. f. klass. Philol. XVI. Supplementbd. p. $36 \mathrm{f}$. will, der Anonymus mit der gemeinsamen Quelle des Zon. und Leo identisch wäre; die vorhandenen Fragmente gestatten nur, ibn als eine der Vorlagen jener Quelle anzusehen.

2) Uber eine Parallele zum Anon. und Zon. vgl. S. 122.

3) Philologus IV. Supplementbd. p. 375. 
einanderliegenden Orten steht, und vor allem ist er eben der einzige bei Trebellius, der die Vorlage des Eutr. und Victor Wort für Wort ausschreibt. Nun ist sicher, daB Capitolin, der SchluBredakteur der Kaiserviten, mindestens eine Lebensbeschreibung in die Trig. tyr. eingeschoben hat, die des Titus; von ihm wissen wir auch, dab er die „Kaisergeschichte" kannte und benutzte. Ich glaube deshalb nicht fehl zu gehen, wenn ich $\mathrm{ihm}$ auch die Vita des Tetricus wenigstens so weit zuschreibe, wie die „Kaisergeschichte" verbotenus ausgezogen ist. Zieht man infolgedessen diese Parallele ab, so bleibt zwischen Eutr. Victor und Trebellius gerade so viel Übereinstimmung, um eine gemeinsame Vorlage gesichert erscheinen zu lassen, aber nicht so viel, um auf einen gewissen beschränkten Umfang oder gar lateinische Abfassung dieser Vorlage zu schließen. Ich gebe nur eine der engeren Parallelen:

\section{Aurel. Victor 33, 9 f.}

Eo (Aeliano) occiso Marius, ferri quondam opifex, neque etiam tum militiae satis clarus, regnum capit. - Hoc iugulato per biduum Victorinus deligitur, belli scientia Postumo par, verum libidine praecipua; qua cohibita in exordio, post biennii imperium constupratis vi plerisque, ubi Attitiani coniugem concupivit, facinus ab ea viro patefactum est, accensis furtim militibus per seditionem Agrippinae occiditur. Tintum actuariorum, quorum loco Attitianus habebatur, in exercitu factiones vigent, -

\section{Treb. Pollio trig. tyr. 8.}

Victorino Lolliano et Postumo interemptis Marius ex fabro, ut dicitur, ferrario triduo tantum imperavit. - Et vita quidem strenuus ac militaribus usque ad imperium gradibus evectus, - . 6.

Victorinum, militaris industriae virum -. - interfecto etiam Lolliano solus Victorinus in imperio remansit, qui et ipse, quod matrimoniis militum et militarium corrumpendis operam daret, a quodam actuario, cuius uxorem stupraverat, composita factione Agrippinae percussus Victorino filio Caesare a matre Vitruvia sive Victoria - appellato, qui et ipse puerulus statim est interemptus --.

In dem Abschnitt über Marius stimmen nur die Namen und das Handwerk überein; nach Pollio hatte M. schon höhere militärische Grade erreicht, nach Victor nicht. Nicht anders ist auch der Bericht über Victorinus im wesentlichen parallel, aber Wortgleichheit ist nur da vorhanden, wo sie auch bei unabhängiger Übersetzung aus dem Griechischen kaum zu vermeiden war. Auch hier zeigt sich in der Bemerkung über die Schändung der Frau des Attitianus eine kleine Abweichung. Einen gleichnamigen Sohn des Victorinus kennt Victor nicht; bei ihm ist der ältere Victorinus selbst der Sohn der Victoria. In der Vita des Tetricus, die nach meiner Ansicht von Capitolin nach der „Kaisergeschichte“ überarbeitet ist, wird das Verwandtschaftsverhältnis, trotzdem der Sohn genannt ist, doch anscheinend wie bei Victor aufgefaBt. Der SchluB ist: Benutzung einer gemeinsamen Quelle durch 
Eutr.-Victor und Yollio liegt vor, es ist aber vorläufig nichts über die Art der Quelle auszusagen. Die Nachrichten der Zosimosquelle hat Treb. Pollio nicht aus der „Kaisergeschichte“, da die meisten davon dort fehlen. Auch Dex. hat er unabhängig von der Vorlage des Eutr. und Victor ausgeschrieben: Deren Bericht über die Skythenzüge unter Gallien zeigt deutlich, daß das gemeinsame Vorbild nicht wesentlich reichhaltiger gewesen sein kann; der des Treb. ist ganz fragmentarisch, aber dabei in den Einzelheiten ganz unverhältnismäBig ausführlicher. Besonders Victor legt deutlich großen Wert auf die Vollständigkeit in der Liste der Gegenkaiser, um aus ihrer großen Zahl dem Gallienus einen Vorwurf zu machen. Hätte er also wohl Odenath und besonders Macrinus übergangen, wenn er etwa des letzten Geschichte auch nur annähernd so ausführlich in der „Kaisergeschichte“ vorgefunden hätte, wie sie bei Pollio steht? Und daB dieser nur gerade die Geschichten der kleineren gallischen Gegenkaiser der „Kaisergeschichte“ entnommen hätte, zu dieser Ausflucht würde man sich nur dann verstehen, wenn eine Übereinstimmung bestände, so eng etwa, wie in der Vita des Tetricus. Da dies nicht der Fall ist, bleibt die einzige ungezwungene Erklärung der vorhandenen Übereinstimmung, daB sowohl die „Kaisergeschichte" wie Treb. Pollio den Dex. benutzten. DaB die erste wahrscheinlich in Gallien entstand, erklärt zugleich das besondere Interesse, das sie den gallischen Gegenkaisern zuwandte.

Zum SchluB erhebt sich noch die Frage, welche der Quellen aus den Chronika, welche aus den Skythika geschöpft haben. Bestimmt den Skythika zuweisen läßt sich Petrus Patricius und Jordanis Getica. Die Bücherverbrennungsanekdote und die Gründungsgeschichte von Thessalonike bei Zon. weisen ebenfalls auf die Skythika, während die zahlreichen von mir vorhin dem Dex. zugewiesenen Nachrichten des Zon. und Anon., die mit den Skytheneinfällen in gar keinem Zusammenhange stehen, zeigen, dab der Anonymus auch die Chronika ausgeschrieben hat. Alle übrigen Autoren, also Synkellos, der Verfasser der „Kaisergeschichte" und Treb. Pollio, haben sicher die Chronika benutzt, und ihre Exzerpte geben uns in ihrer Knappheit kein Recht, auBerdem noch die Skythika in Anspruch zu nehmen.

\section{Zosimos und Julius Capitolinus.}

Im vorigen Kapitel hat sich nicht nur gezeigt, da $B$ die sicheren Dexipposreste zu Zosimos in keiner deutlichon Bezichung stehen, sondern auch, daB im Gegenteil gerade die nicht der Zosimosquelle angehörigen Berichte der Autoren inmer wieder Spuren dexippeischen Ursprungs enthalten. Alle diese Ausführungen gelten aber vorläufig 
nur für die Zeit nach Philippus Arabs; lange war ich selbst der Meinung, daB Zosimos wenigstens die erste Ausgabe der Chronika, die Dex. nicht unwahrscheinlich nur bis zur römischen Millenniumsfeier geführt hat, benutzt habe. Nach nochmaliger Prüfung muB ich diese Anschauung als Phantasiegebilde bezeichnen.

Die Hauptbeweismomente, die Übereinstimmungen zwischen Zos. und Julius Capitolinus, gehen in letzter Linie auf Herodian zurück; ich führe zunächst den Beginn der Lebensbeschreibung Maximins an und füge die Parallelen der übrigen Quellen zum Vergleiche bei:

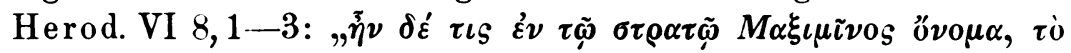

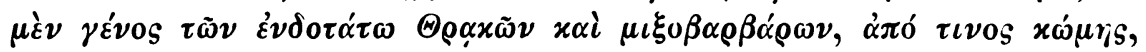

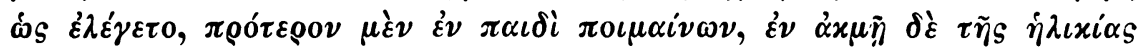

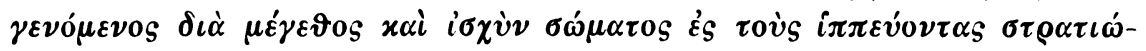

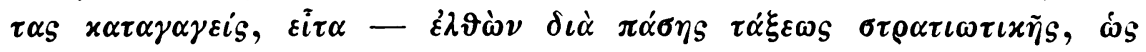

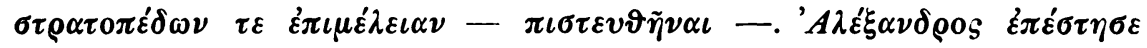

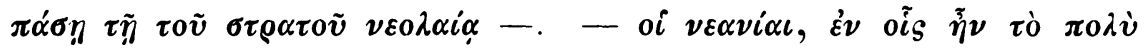

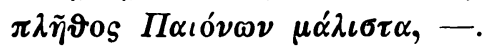

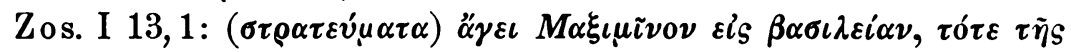

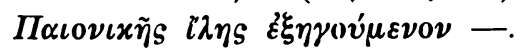

Cap. vit. Max. 1: - de vico Threiciae vicino barbaris - - - patri quidem nomen Micca, matri Hababa fuisse dicitur. 2: Et in prima quidem pueritia fuit pastor, .... es folgt die Schilderung seiner Kraft und die Erzählung, wie er Soldat wurde. Dann 5,5: (Alex.) statim denique illum tribunum legioni quartae, ex tironibus quam ipse composuerat, dedit ....

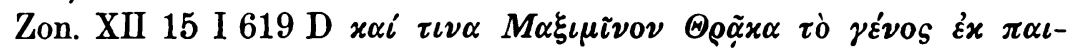

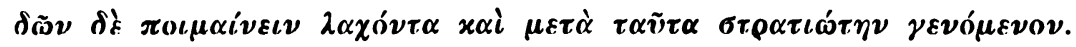

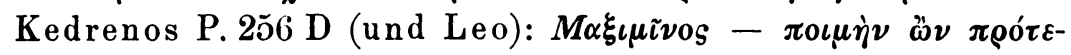

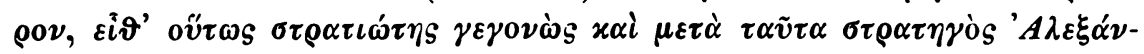

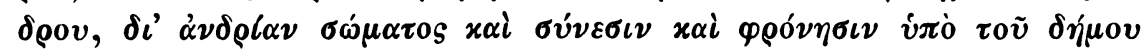

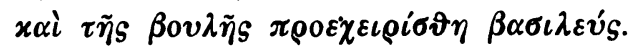

Eutrop IX 1: Post hunc Maximinus ex corpore militari primus ad imperium accessit sola militum voluntate, cum nulla senatus intercessit auctoritas neque ipse senator esset.

Epitome 25: Iulius Maximinus Thrax, ex militaribus, imperavit annos tres.

Victor 25: Namque Caius Julius Maximinus, praesidens rei bellicae, primus e militaribus, litterarum fere rudis, potentiam cepit suffragiis legionum. Quod tamen etiam patres - approbaverunt -.

Wie man sieht, gibt Capit. den Herodian so genau wieder, daB er sogar aus den $\mu \iota \xi o \beta \alpha ́ \rho \beta \alpha \rho o \iota$, mit denen er nicht recht etwas anzu- 
fangen wuBte, die Namen der Eltern herauslesen zu können meinte. Aber auch bei den übrigen ist die Abhängigkeit deutlich. Dabei treten sichtlich gleich wieder einige Gruppen zusammen: Eutr., Victor und die Epit. sind durch die gemeinsame Benutzung der „Kaisergeschichte“ verwandt, Zon. und Kedr. stehen wieder zusammen. Auch Zos. geht auf Herod. zurück, aber dasjenige nähere Datum, das er gibt, fehlt gerade den übrigen, während Zon. und Kedr. sich zu Capit. stellen.

Um im AnschluB auch ein Beispiel aus den letzten Kapiteln Herodians zu geben, zugleich aber zu zeigen, daB sich die Übereinstimmung Capitolins mit Herodian nicht auf kurze Sätze oder Notizen beschränkt, füge ich den Bericht über den Sturz der beiden Senatskaiser hier ein:

Herod. VIII 8.

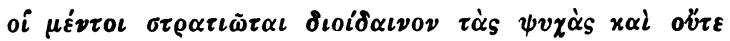

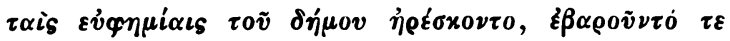

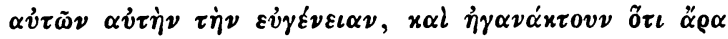

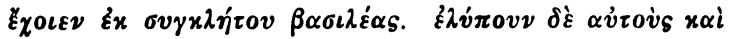

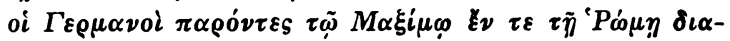

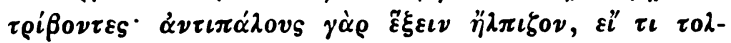

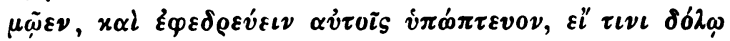

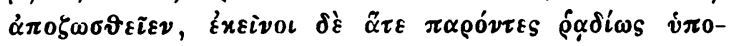

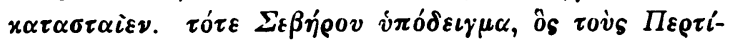

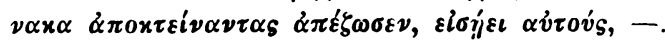

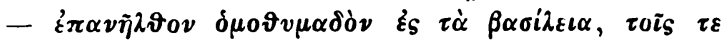

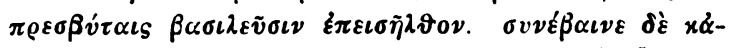

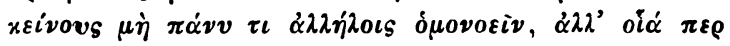

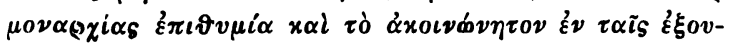

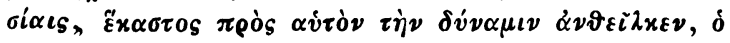

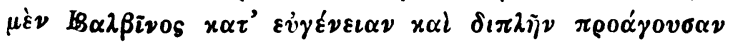

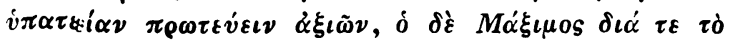

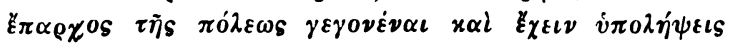

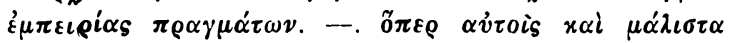

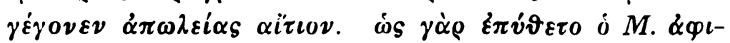

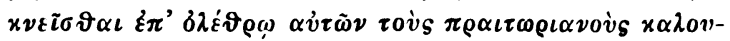

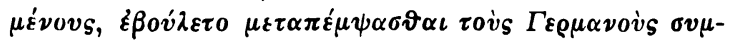

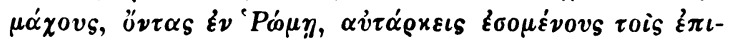

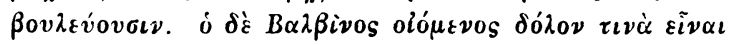

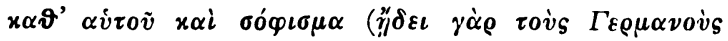

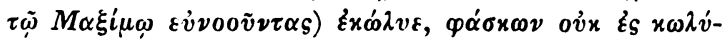

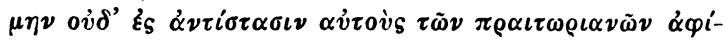

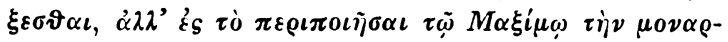

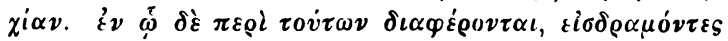

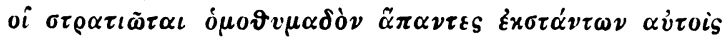

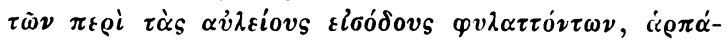

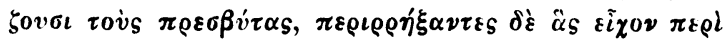

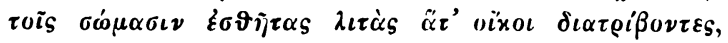

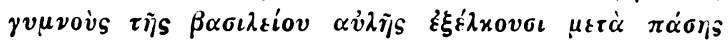

Cap. Max. et Balb. 13, 5 . - milites occasionem quaerentes occidendorum principum, cum primo invenire vix possent, quia Germani stipabant Maximum atque Balbinum, cotidie ingravescebant.

14. Et erant quidem discordiae inter B. et M., - cum Balbinus Maximum quasi ignobilem contemneret, Maximus Balbinum quasi debilem calcaret. Qua re occasio militibus data est intellegentibus facile discordes imperatores posse interfici - , impetum in eos fecerunt. Turbantibus igitur militibus, cum primun nuntiatum esset Maximo turbam illam tempestatemque vix evadi posse, nisi ad Germanos mitteretur, -, mittit ad Balbinum Maximus petens, ut ei praesidium mitteret. Sed ille suspicatus, quod contra se eos peteret, quem postulare putabat monarchiam, primo frustratus est, deinde usque ad litem perrentum 


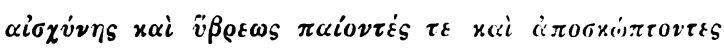

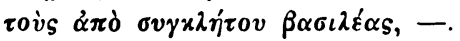

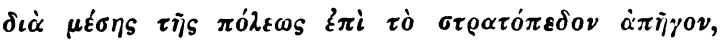

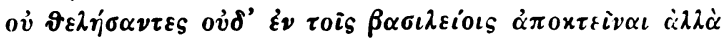

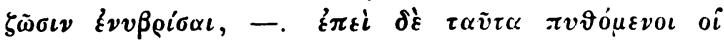

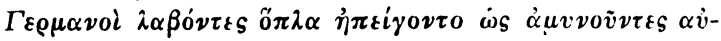

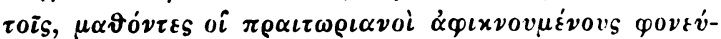

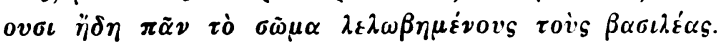

est. In hac tamen seditione illis contendentibus milites supervenerunt atque ambos eos nudatos vestibus regalibus de palatio cum iniuriis produxerunt

et per mediam civitatem ad castra raptare voluerunt magna ex parte laniatos. Sed ubi conpererunt Germanos ad defensionem illorum supervenire, ambos occiderunt -

So weit möge es genügen; es folgt die Erhebung Gordians mit fast gleichen Worten und der Rückzug der Germanen. Zur Vergleichung füge ich Zos. I 16,2 und Zon. XII 17 P. $622 \mathrm{~B}$ hinzu, bei denen das Ganze viel kürzer erzählt wird:

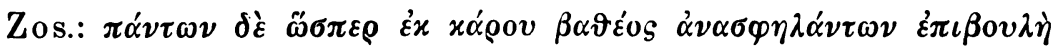

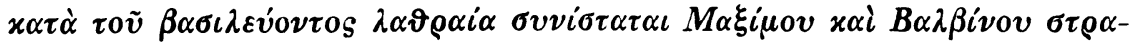

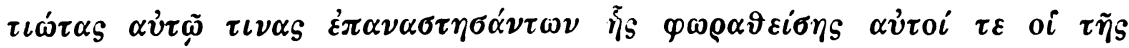

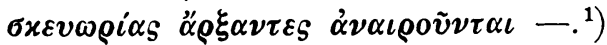

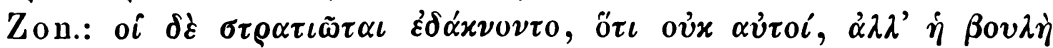

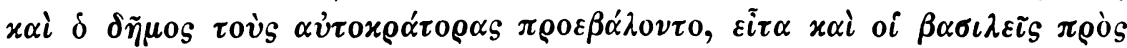

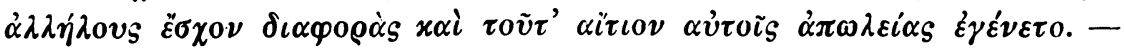

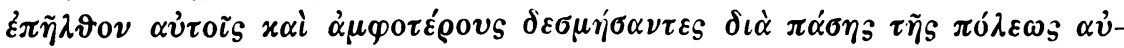

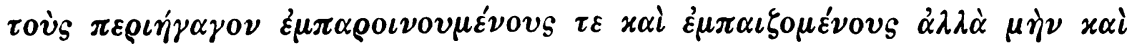

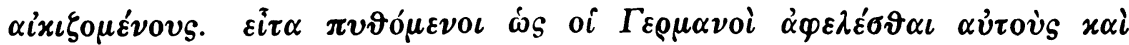

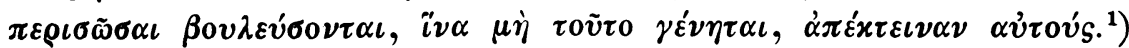

Buehme hat bereits gezeigt, daB Capitolinus nicht dirokt auf Horodian zurückgeht, sondern ihn nur aus Dexippos kennt. ${ }^{2}$ ) Sein Urteil "Herodianus - ei (Maximino) - in odium Alexandri plurimum favit" läbt eine vollständige Unbekanntschaft mit Herodian erkennen. Und in der Tat sind in seinen Zituten die Namen Herodian und Dexipp so eng verknüpft, daB er kaum einmal den einen ohne den andern nennt. Dies ist der Sachverhalt, wenn wir, wie wir meines Erachtens müssen, nicht nur mit Brocks den sonst unbekannten Arabianus, sondern auch mit Peter den fast ebenso mythischen Arrianus für Verstümmelungen von Herodian halten. Da zeigt sich die ganze Unselbständigkeit des Capitolin, der sogar ein Zitat in der Regel nur da anbrachte, wo er

1) Alle übrigen Quellen bringen nur ganz kurze Notizen. DaB Zos. beträchtlich abweicht, sah auch Boehme „Dexippi fragm. etc." p. 53.

2) Dexippi fragm. etc. Diss. Jena, S. 10-12. 
bei Dexipp eins fand, dann aber die Gelegenheit benutzte und den Namen seines Gewährsmannes gleich dazu setzte. Also - alle Übereinstimmungen Capitolins mit Herodian gehen auf Dexippos zurück.

So ist es denn nur eine Bestätigung dessen, was wir schon aus dem vorigen Kapitel wissen, wenn Zon. an vielen Stellen, wie z. B. den beiden angeführten, deutlich zu Capitolin parallel geht, und zwar auch er dort, wo er am klarsten auf Herodian zurückgeht. ${ }^{1}$ ) Capitolinus und Zonaras, soweit sie sich eng an Herod. anschlieBen, ermöglichen uns somit die Feststellung eines sicheren Dexipposbestandes, zumal wo sie sich gegenseitig stützen:

Schon den Perserkrieg des Alexander Severus erzählt Zon. XII 15 I $618 \mathrm{D}-619 \mathrm{C}$ ausführlich nach Herod. VI 2-6; er findet sich außerdem bei Kedr. P. 256 C, Synk. P. 357 D, Eutr. VW 23 und Victor 24, also lauter Dexipposexcerptoren. Zon. XII 15 I 618 D gleicht Herod. VI 1,9-10. Die Begründung von Alexanders Sturz Zon. XII 15 I619 D zeigt wörtliche Anklänge an Herod. VI 7,9. Über die erste Einführung Maximins vgl. S. 126, wo auch Capit. schon einsetzt; das Verhältnis bleibt bei Alexanders Sturz:

Herod. VI 9,6, Zon. XII 15 I 620 A, Capit. Max. 7,4-5.

Für die Folge ist Capit. unser Hauptführer. Bis in die Einzelheiten entspricht

$$
\begin{aligned}
& \text { Max. } 8-9 \\
& \text { Max. } 10 \\
& \text { Max. } 11
\end{aligned}
$$$$
\text { Herod. VII 1, 1-4, }
$$$$
\text { Herod. VII 2, }
$$$$
\text { Herod. VII 1,9-11. }
$$

Die Empörung der Osroëner fügte Capit. als SchluBredakteur der Script. hist. Aug. auch in die Viten der Trig. tyr. als Kap. 32 ein. $^{2}$ ) Und

1) Auch De Boor Byz. Zeitschr. I S. 25 f. schlieBt, daB der Anonymus, die eine Quelle des Zonaras, z. T. auf Herodian beruht, schweigt aber über die Vermittlung des Dexippos. Wie schon S. 89 Anm. 1 erwähnt, spricht das hier festgestellte Verhältnis des Zonaras zu Capitolin und damit zu Dex. stark gegen Patzig Byz. Zeitschr. V $24 \mathrm{ff}$. Denn nach Ausscheidung der Zosimosquelle und des Dex. bleiben bei Zon. nur 'gauz geringe zum Teil bei Kedr. wiederkehrende Reste, die in wesentlichen Punkten mit Malalas übereinstimmen. Wie ich über die Primärquelle dieser Daten denke, ist weiter unten auseinandergesetzt; betreffs der näheren Verwandtschaft scheint mir nur so viel halbwegs sicher, daB nicht Malalas selbst die Quelle war.

2) Boehme „Dex. fragm. etc." S. 12 schloB schon, daB auch Treb. Pollio, dem er die Vita noch zuschrieb, Herodian nur durch Dex. kenne. Die Titusvita ist aber ihrer ganzen Fassung nach, nicht zum wenigsten nach ihrer Art zu zitieren, eins der besten Beweisstücke für Peters Ansicht („Die Script. hist. Aug.“ 6 literargesch. Unters. 1892, S. 103-153), daB Capit. die ganze Sammlung zusammengefaBt und redigiert habe. 
wieder verrät er, daB er Herod. nur aus Dex. kennt, indem er behauptet, Herod. habe das Opfer der Empörung Titus genannt, während jener ihm in Wahrheit den Namen Quartinus gibt. Um den Fall recht klar zu machen, findet sich übrigens hier auch wieder das ominöse Doppelzitat.

Mit dem Germanenkrieg tritt Zon. wieder auf den Plan:

Herod. VII 2, Zon. XII 16 I 621 A, Capit. Max. 12.

Die Übereinstimmung ist auffallend, ihre Bedeutung für die vorliegende Frage wird weiter dadurch beleuchtet, daB Eutr. IX 1 und Victor 26 ebenfalls den Germanensieg des Kaisers kennen.

Herod. VII 3 bringt eine zweite Charakteristik der Regierung Maximins; ebenso Capit. Max. duo 13,5 f. und Zon. XII 16 I $621 \mathrm{~B}$. Daran schlieBt sich der Aufstand der Provinz Afrika; Zon. a. a. O. gibt

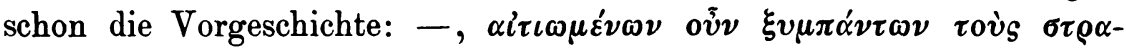

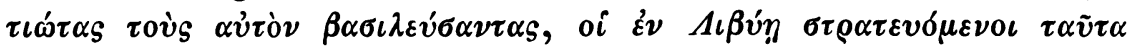

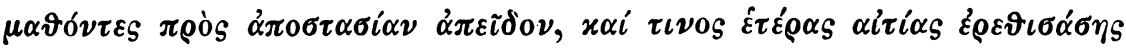

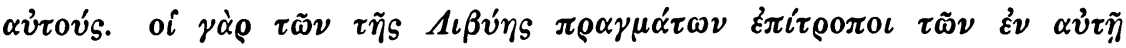

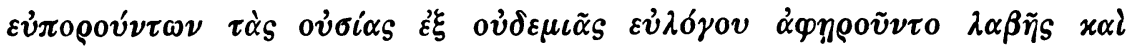

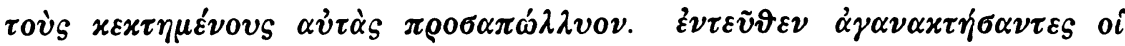

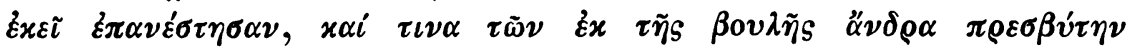

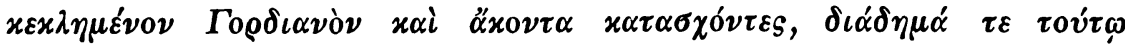

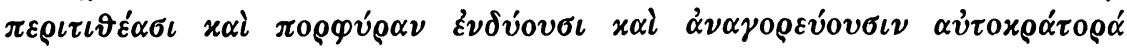

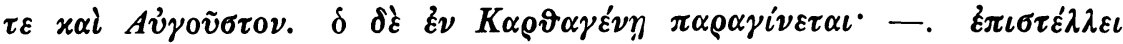

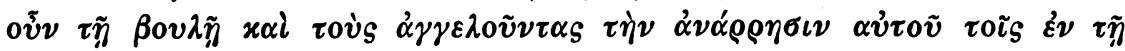

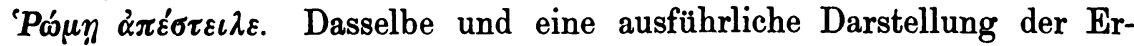
hebung selbst bringt Capit. Max. duo 14: Erat fisci procurator in Libya qui omnes Maximini studio spoliuverat; hic per rusticanam plebem, deinde et quosdam milites interemptus est - . sed cum viderent auctores caedis eius acrioribus remediis sibi subveniendum esse, Gordianum proconsulem - reclamantem et se terrae adfligentem, opertum purpura imperare coegerunt, instantes cum gladiis et cum omni genere telorum et primo quidem invitus - postea vero volens suscepit imperium et appellatus est omnibus Afris Augustus cum filio apud oppidum Tysdrum. inde propere Carthaginem venit cum pompa regali -, unde Romam litteras misit - . Ich füge aus Herod. kurze Worte bei,

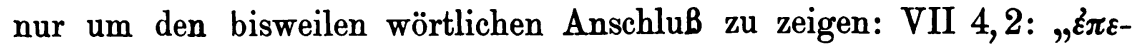

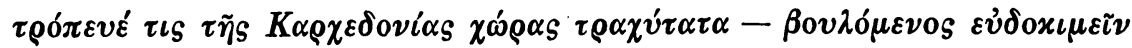

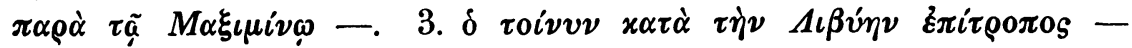

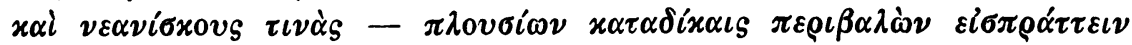

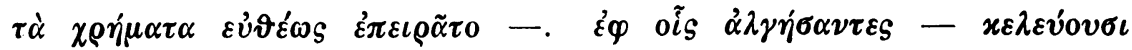

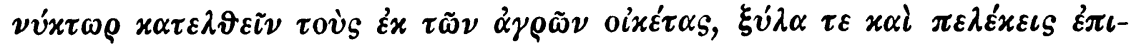




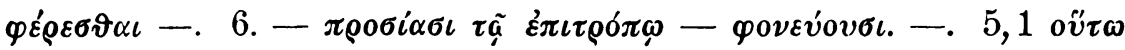

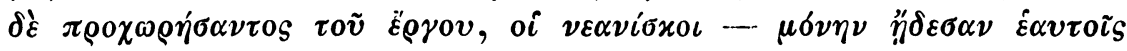

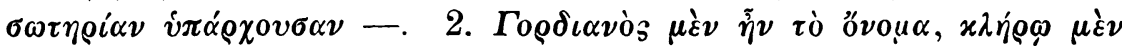

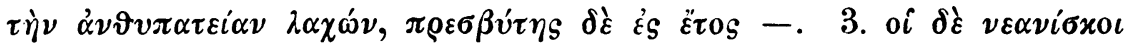

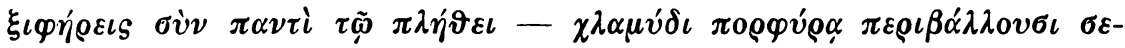

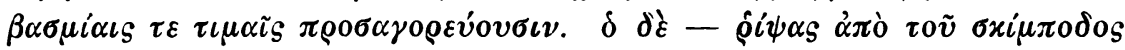

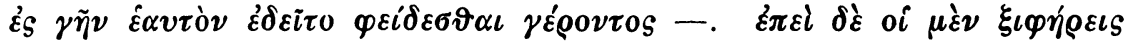

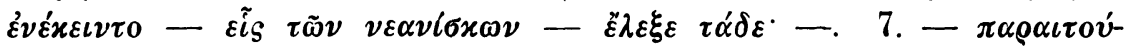

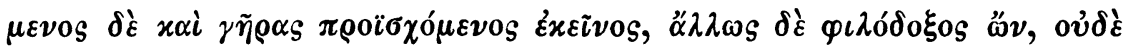

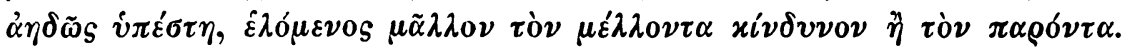

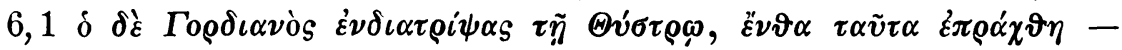

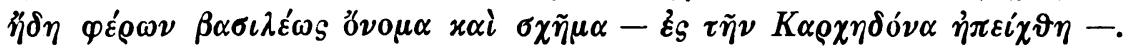
Nach 6, $3 \mathrm{ff}$. schickt G. Briefe an die Senatoren, den Senat und das Volk, mit Versprechungen besonders auch für die Soldaten.

Wie ersichtlich, bei Zon. und besonders Capit. derselbe enge Anschlub an Herod. wie in den übrigen Dexipposexzerpten. Und wieder tritt bestätigend Victor 26 hinzu: - repente Antoninus Gordianus Africae proconsul ab exercitu Princeps apud Thydri oppidum absens fit. Quo ut accitus pervenit - seditione excipitur; qua lenita facile Carthaginem petit. - prodigia. - G. postquam delatum sibi imperium cognovit, praemia amplum in modum ostentans Romam legatos ac litteras destinaverat, quibus necato eo frustratos se milites angebantur, - .

Capit. berichtet dieselben Vorgänge noch einmal in Gord. 7-9, wo auBer der Rede 7,4-8,4 ebenfalls alles auf Dexippos-Herodian zurïckgeht. Hier wird auch Herodians Notiz, daß Gordian gerade auf einem Ruhebett lay, vernerkt, und ebenso kehren die "Jünglinge" des Herod. wieder, ein Wort, das Dex. anscheinend bis dahin nicht gebraucht hatte, - ein weiteres Zeichen, das Capit. den Herod. nicht selbst kannte.

Während Zon. hier augenscheinlich zu einer anderen Quelle übergeht, folgt Capit. seinem bisherigen Vorbilde weiter:

$$
\begin{array}{ll}
\begin{array}{l}
\text { Max. } 14,4-15,1 \\
\text { Gord. } 10,5-8
\end{array} & \text { Herod. VII } 6,3-7,4, \\
\text { Max. } 15,2-5 & \text { Herod. VII } 7,5-6, \\
\text { Max. } 17 & \text { Herod. VII } 8,1-3 .
\end{array}
$$

Max. 18 gibt wie Herod. VII 8,4-8 eine Rede an die Soldaten, allerdings init a!)weicheinden Einzelheiten, wänrend die analoge Rede Gord. 14 einige Anklänge an Herod. zeigt.

$$
\left.\begin{array}{l}
\text { Max. } 19 \\
\text { Gord. } 14
\end{array}\right\}=\text { Herod. VII } 9
$$


der Bericht über den Aufstand des Capelianus, den auch Zon. XII 17 I $622 \mathrm{D}-623 \mathrm{~A}$ wieder übereinstimmend berichtet.

Max. 20,1-5 = Herod. VII 10,

Max. 20, $6 f$.

Gord. $22,7 \mathrm{f}$.

Max. et Balb. 9-10

$=$ Herod. VII $11-12$.

Endlich ist Herod. VIII vollständig von Capitolin ausgeschrieben worden: Max. 21-24; Max. et Balb. 11;12,1-3. Dabei geht die Übereinstimmung bis in so geringfügige Einzelheiten, wie die Angabe, daB die Soldaten sich nach den Quartieren am Albanerberge sehnten. Mit der feierlichen Einholung des Maximus setzt auch Zon. XII 17 I 622 B noch einmal ein und berichtet weiter über die anfänglich einträchtige

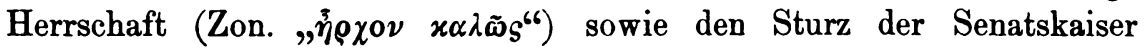
ebenfalls parallel zu Herod. und Capit.

Wir stehen vor der Entscheidung. Schon in den vorigen Kapiteln ergab sich, daB gerade die und nur die Teile der übrigen Quellen, die von Zos. abwichen, Anzeichen Dexippeischer Herkunft hatten; aber konnte ich bei den geringen Dexipposresten jener Zeiten nicht Opfer einer Selbsttäuschung geworden sein? Kann nicht, was dort falsch war, hier gelten? Diesmal bin ich umgekehrt von Dex. ausgegangen; diesmal steht ein ununterbrochener und unbestrittener Dexipposbericht zur Verfügung. Wenn nun trotzdem das Verhältnis dasselbe bleibt, wenn auch in diesen früheren Kapiteln Zos. mit den Teilen der verwandten Quellen und nur mit denen, die von Dex. abweichen, übereinstimmt, dann bleibt, so meine ich, kein Zweifel, daB Zos. von Dex. unabhängig ist. Und das ist wirklich der Fall; Zon., der ja natürlich auch hier wieder in erster Linie steht, zeigt engere Verwandtschaft mit Zos. nur gerade in den Abschnitten, die mit den Capitolinparallelen abwechseln, sich mit ihnen höchstens ganz entfernt berühren und selbst zu Herod. nur in weit loserer Beziehung stehen; ihm treten dann wenigstens hier und da auch die übrigen Verwandten zur Seite:

Da ist zunächst die erste Charakteristik Maximins Zos. I 13,3, Zon. XII 16 I $621 \mathrm{~A}$ (zu dem sich in einer Einzelheit Synk. stellt), Epit. 25. Auch diese Stellen stammen aus Herod., und zwar wesentlich aus VII 3. Einen AusfluB desselben Abschnittes bringt Zon. noch an anderer Stelle (XII 16 I 621 B), und zwar diesmal parallel zu Capit. Max. 13,5. Zon. geht also sichtlich durch Vermittlung zweier verschiedener Quellen auf Herod. zurück, die eine ist Dex., die andere die Zosimosquelle.

Den Aufstand in Afrika gibt Zon., wie wir sahen, parallel zu Capit., weicht demgemäB von Zos. I 14 ab; die Epit. 25 widerspricht 
Eutr.-Victor, was wir früher als Sympton der Abhängigkeit von der Zosimosquelle erkannten.

Zon. XII 16 I 621 D erwähnt, wie öfter, zwei widersprechende Angaben; nach der einen hätte der Senat den Maximus und Balbinus erhoben, nachdem er die Ermordung der Gordiane ${ }^{1}$ ) erfahren hatte, nach der anderen vorher. Die erste ist die von Herod.-Capit., also des Dex., die andere des Zos. DaB Zon., genau genommen, die erste Version nur voraussetzt, aber gar nicht ausdrücklich anführt, erklärt sich wieder nur aus seinem Quellenwechsel: eben geht er zur Zosimosquelle über und bringt aus ihr die von Dex. abweichende Notiz, vergibt aber dabei, daB er die betreffende Dexipposstelle noch gar nicht ausgeschrieben hatte, und zwar einfach deshalb nicht, weil sie dort erst weit später folgte. Der Quellenwechsel ist unverkennbar; denn auch der nächste Abschnitt gehört der Zosimosquelle an: Zos. I 15 und Zon. XII 16 I $621 \mathrm{D} ; 622 \mathrm{~A}$. Fast der ganze Abschnitt stammt aus Herod.; um so auffälliger ist, daB Zon. nicht eine der vielen Einzelheiten des Capit. gibt, sondern gerade im Kleinen - ich weise auf die Maurusier und die spezifische Darstellung der Ermordungsszene hin - zu Zos. steht. ${ }^{2}$ )

Mit XII 17 I 622 B geht Zon. zu Dex. über, doch erwähnt er D die Angabe des Zosimos (I 16,1), daB Gordian auf der Seefahrt gestorben sei. Und wieder stellt er dieser in I $622 \mathrm{D}-623 \mathrm{~A}$ die Erzählung des Dex. vom Ende der Gordiane als davon abweichende Version gegenüber.

Bis hierher ist das Ergebnis dasselbe wie in den früheren Kapiteln: Zon. hat außer Dex. noch eine andere Quelle benutzt, und diese andere ist die. Zosimosquelle. Alles, was diese mit Capit. gemein hat, stammt aus Herod. Nur für drei Punkte trifft das nicht zu: Das ist 1. die Erwähnung Valerians Zos. I 14, 1 und Gord. 9,7; da er bei Zos. Gesandter des Gordian ist, bei Capit. als Princeps senatus diese Gesandtschaft empfängt, so ist der Anklang nicht nur äußerst geringfügig, sondern nähere Betrachtung läßt sogar eher gegen als für Benutzung einer gemeinsamen Quelle schließen.

Punkt 2, die Nachricht von der Wahl der 20 Senatoren gegen Maximin, scheint um so schwerer zu wiegen, als Capit. diese Angabe selbst ausdrücklich auf Dex. zurückführt. Ist das Zitat genau, so hat

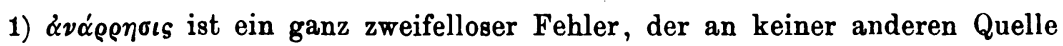

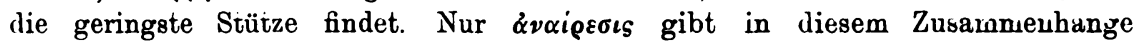
einen Sinn.

2) Für die Schlacht zwischen Maximus und Maximin vgl. die „Kaisergeschichte", die ja auch hier gewisse Einzelheiten der Zosimosquelle entnahm. 
Dex. die Wahl der Zwanzig nach dem Sturz der Gordiane erzählt, geht also doch nicht mit Zos., sondern widerspricht ihm. Andrerseits halte ich das Zitat nicht einmal für ganz einwandfrei. Die Wahl der Zwanzig wird bei Capit. dreimal berichtet. Gord. 22,1 läbt er zwar die Erhebung des Maximus und Balbinus ebenfalls nach dem Tode der Gord. vor sich gehen, verlegt aber die Konstituierung der Zwanzigerkommission schon in die Vergangenheit. Gord. 10,1 schaltet er sie direkt hinter der Gesandtschaft Gordians ein, also an derselben Stelle, wo sie bei Zos. steht. Und betrachtet man den Abschnitt etwas genauer, so kann man ihn deutlich als Einschiebsel erkennen; die Ermordung des Vitalianus nämlich, die nun folgt, hatte Dex. zweifellos, wie noch aus Capit. deutlich zu ersehen, ganz richtig nach Herod. wiedergegeben. Capit. dagegen hat den Zusammenhang vollständig verloren, läßt den Mord auf Befehl des Senats statt Gordians geschehen und weiB dann die Ausführung der Tat, die bei Herod. in Gordians Auftrage an die Gesandten gegeben war, nicht besser einzuleiten als durch den recht ungeschickten Flicksatz: „De cuius morte haec fabella fertur." Wie wir sahen, ist in Max. 14-16 die Erhebung Gordians und die in Rom darauf folgenden Ereignisse erzählt, also so, wie sie vermutlich auch Dex. berichtet hat; da ist von der ganzen Wahl der Zwanzig, von Maximus und Balbinus keine Rede, Gordians Briefe werden richtig erst nach der Ermordung des Vitalian dem Senat übergeben. Vergleichen wir damit Gord. 8,5ff., so sehen wir, daß eben nur die zu Zos. stimmenden Stücke abweichen, der ganze übrige Bericht genau mit Max. und Herod. parallel geht. Halten wir dazu, daB, wie erwähnt, in Max. 32 die Angaben des Dex. ausdrücklich auf die Zeit nach Gordians Tode beschränkt werden, so ergibt sich, daB Capit. die Wahl der Zwanzig entweder aus zwei verschiedenen Quellen entnahm - dann läßt sich daraus keine Beziehung zwischen Zos. und Dex. konstruieren --, oder daB jenes Zitat nicht ganz rein ist: Wie wir aus Herod. entnehmen können, wird auch bei Dex. von den VerteidigungsmaBregeln des Senates, den Instruktionen an die Provinzialbeamten u. a. m. die Rede gewesen sein. Sicher berichtete er die Wahl des Maximus und Balbinus nach Gordians Tod. Die Wahl der Zwanzigerkommission wäre dann dem Capit. mit in die Feder geflossen, trotzdem er sie in Wahrheit nicht aus Dex., sondern aus einer anderen Quelle kannte. Dafür spricht, daB in den reinen Herodianexzerpten Max. duo 20,1 und Max. et Balb. 1,1 auch nach Gordians Tode von jener Kommission keine Rede ist. Dazu kommt, daB Gord. 10,1 und 22,1, wo die Senatskaiser in Verbindung mit den Zwanzig genannt werden, wohl die eiuzigen Stellen sind, in denen der Name Pupienus neben Maximus gebraucht wird, ohne daB der Verfasser 
den Dex. gegen jene Namensform ins Feld führt. Daraus läBt sich schließen, daB er eben an diesen Stellen nicht dem Dex. folgte, sondern jener Quelle, die den Kaiser Pupienus nannte. Das war aber die von Eutr. und Aurel. Victor ausgeschriebene „Kaisergeschichte“. Diese benutzte ihrerseits, wenn auch für die von Dex. behandelte Zeit selten, die Zosimosquelle, so daB auf diesem Wege die Übereinstimmung des Capit. und Zos. ganz erklärlich wird.

Anders liegt die Sache bei Punkt 3. Auch die Angabe, daB Gordian III ein Sohn des zweiten sei, führt Capit. Gord. 23 ausdrücklich auf Dex. zurück. Daran läBt sich in diesem Falle nicht rütteln. Wieder einmal hilft uns die Epitome. Wir wissen, daB sie für die Daten, in denen sie von Victor abweicht, auf der Zosimosquelle beruht. Die Schrift De Caesaribus kennt wie Eutr. nur zwei Gordiane, Vater und Sohn; die Epitome nennt drei, und so werden die bezüglichen Angaben bei ihr der Zosimosquelle entsprechen. Da lesen wir Epit. 27: "Gordianus nepos Gordiani ex filia", und wir sehen, daB dies weiter

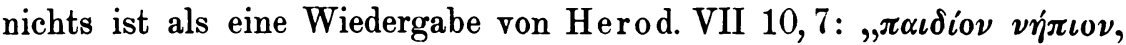

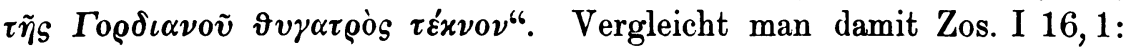

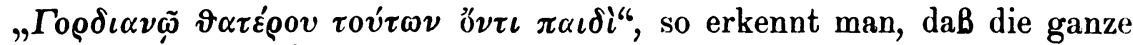
schwerwiegende Übereinstimmung zwischen Zos. und Dex. auf einen ganz gewöhnlichen Schreibfehler hinausläuft, der möglicherweise erst von einem Abschreiber des Zosimoswerkes herrührt.

Nach den bisherigen Ergebnissen scheint also kein stichhaltiger Grund vorhanden, Zos. mit Dex. in Verbindung zu bringen. Aber auch er heruht doch, wie Dex., auf Herod., wenn er ihn auch nicht so getreu ausschrieb wie jener. Doch selbst dieses Zugeständnis erfährt eine beträchtliche Einschränkung. Die einzige Periode, die Zos. vor den schon behandelten Kapiteln noch einigermaßen ausführlich behandelt, ist die Regierungszeit des Alexander Severus. Wie wir aus Zon. sahen, fuBt Dex. auch hier auf Herod. Anders Zos. und die ihm parallelen Stücke bei Zon.; das ist vor allem der erste Teil der Alexandervita:

$$
\text { Zos. I 11,2. }
$$

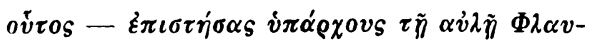

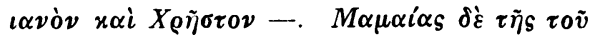

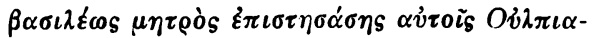

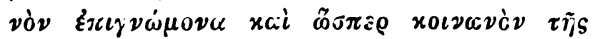
$\dot{\alpha} \varrho x \bar{\eta} / \varsigma-\dot{\alpha} v \alpha i \varrho \varepsilon \sigma \iota \nu \quad \alpha \dot{v} \tau \tilde{\omega} \quad \mu \eta \chi \alpha \nu \tilde{\omega} \nu \tau \alpha \iota \quad \lambda \alpha-$

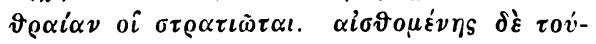

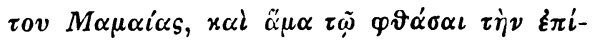

Zon. XII 15 I $618 \mathrm{~B}$.

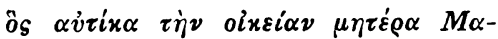

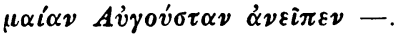

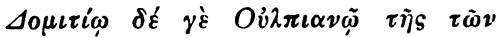

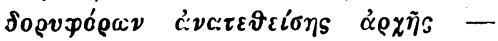
$\pi 0 \lambda \lambda \dot{\alpha}-\varepsilon \pi \pi \eta \nu \omega \rho \vartheta \dot{\sigma} \vartheta \eta$. ôs $\tau \dot{o} \nu \Phi \lambda \alpha$ -

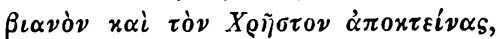

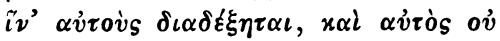




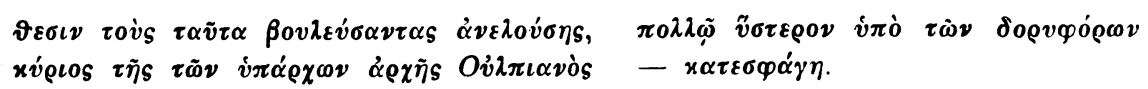

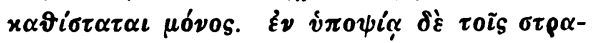

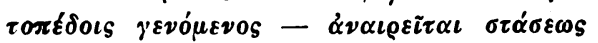

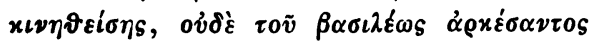

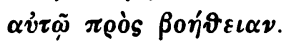

Wie ersichtlich, sind mit Ausnahme dessen, daB Zon. die fromme Mammaea in den Vordergrund rückt und ihr die Schuld an den Morde des Flavianus und Chrestus abnimmt, die Berichte ganz gleich. Auch Synk. erwähnt die Herrschaft des Ulpian und seine Ermordung , $\tau$, ṽ

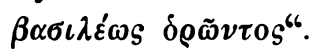

Von dieser ganzen Geschichte weiß Herod. nichts; dagegen übergeht Zos. wieder den ganzen Perserkrieg mit Stillschweigen, der bei Herod. reichlich die Hälfte eines Buches (VI 2-6) einnimmt, und ebensowenig erwähnt er den Zug gegen die Germanen. Das einzige, worüber er noch berichtet, sind die Empörungen des Antoninus und Uranius, die wieder Herod. durchaus fremd sind. Sie werden für die Zosimosquelle bestätigt durch die Erwähnung des Uranius als Gegenkaisers bei Synk. und in der Epit. (Taurinus).

Nimmt man hinzu, daB Alexanders Ende bei Zos. I 13,2 ebenfalls abweichend erzählt wird - besonders läBt er den Kaiser durch Selbstmord umkommen -, so ergibt sich, dab eigentlich nur eine ganz geringfügige Notiz über die Anfänge Maximins aus Herod. entnommen ist. Erst mit Alexanders Tode geht Zos. zu Herod. über, gibt allerdings, wie wir wissen, aus ihm wenig mehr als eine summarische Übersicht der Ereignisse, die er noch dazu verschiedentlich abändert und mit anderen Elementen versetzt.

Leider sind des Zos. erste Kapitel so knapp, daB sie einen weiteren Vergleich wohl kaum zulassen. Wir vermögen aus den zuletzt angeführten Stücken nur gerade zu erkennen, daB die vor Herod. herangezogene Vorlage Cassius Dio ist, worauf ja auch der Zeitpunkt des Quellenwechsels hinweist. So mag denn auch wenigstens ein großer Teil des Diobestandes bei Zon. nicht direkt von ihm, sondern aus der Zosimosquelle stammen. Erst nach dem Aufhören des Dio nahm der Verfasser dieser Quelle den Herod. zu Hilfe, um die Erzählung möglichst auf seine eigene Zeit herabzuführen. Für ihn wie für Dex. war Herod. das letzte größere Geschichtswerk, nach dessen Aufhören sie eigener Nachfrage, eigenem Gedächtnis vertrauen muBten. 
Oder ist etwa unser Autor, wie nach Dio auf Herod., so nach Herod. noch auf Dex. übergegangen? - Ein zeitlicher Zwang liegt ja nicht vor; wenn er siebzig Jahre alt wurde - gewiB kein übermäBiges Alter -, so konnte er mit zwanzig Jahren und darüber den Perserkrieg Gordians aus nächster Nähe mit angesehen haben, und man weiB, wie lebhaft Jugenderinnerungen zu bleiben pflegen. In der Tat enthält sein Bericht über diese Zeit nichts, was er nicht mit Leichtigkeit von jedem römischen Soldaten, mindestens von jedem Offizier erfahren konnte. Aber mahnend steigt der Text des Capit. vor uns auf, der doch nach meinem eigenen Urteil ganz auf Dex. beruht. In der Tat ist der Parallelismus nicht zu leugnen:

Zos. I 17; Zon. XII 18 I 633 D; Capit. Gord. 23, 4 f. Fast könnte man meinen, Zos. habe den Capit. ausgeschrieben, da das umgekehrte Verhältnis zeitlich unmöglich ist; also eine gemeinsame Quelle scheint doch sicher, und wer könnte das sein außer Dex.? $\left.{ }^{1}\right)$ Dazu kommt, daß Capit. überall die zu Zos. stimmenden Berichte mit Nennung der Konsuln einleitet, eine Erscheinung, die stets als sicherstes Zeichen Dexippeischen Ursprungs gegolten hat.

Freilich liefert es gerade an dieser Stelle keinen untrüglichen Beweis, da Capit. das Verfahren auch da beibehält, wo er von Zos. abweicht. Es zeigt deshalb doch nur, daB Capit. unter anderem auch Dex. vor sich hatte, was wir ohnehin wissen. Bei genauer Betrachtung will es sogar scheinen, als wäre der Text den Fasten ziemlich ungeschickt angefügt; so „G. iam iterum et Pompeiano conss. bellum Persicum natum est. quando et ..."; besonders sind aber Gord. 29,1 die Konsulnamen ganz offenbar in die fortlaufende Erzählung eingeflickt. - Dahei bleibt jedoch der enge Zusammenhang des Zos. mit Capit. unerschüttert. DaB dieser Zusammenhang über Dex. gehe, ist ja allerdings bisher unbewiesen; wie erinnerlich, kennen wir bereits einen anderen Verbindungsweg zwischen beiden Quellen: Capit. benutzte die „Kaisergeschichte“, die aus der Zosimosquelle schöpfte. Sollte sich da wider Erwarten ein Ausweg öffnen?

In der Tat läßt sich daran kaum zweifeln; so genau wie Zos. I 18-19, Zon. XII 18 I 623 D - 19 I 624 A, Kedr. P. 257 A und Synk.

1) Martin „De fontibus Zosimi“ Berol. 1866 hat sich denn auch besonders auf diese Kapitel gestützt; Boehme „Dexippi fragmenta ex Iulio Capit., Trebellio Pollione, Georgio Syncello collecta", Diss. Jena 1882, suchte die Berichte ebenfalls für Dex. zu retten, indem er diesem die Capitolinische Erzählung über Gordians Ende absprach und dagegen erklärte: „Zos. quae protulit omnia debet Dexippo" und weiter: Zos., Zon. und Sync. „Dexippi verba ipsa nobis reservarunt" (S. 45 u. 46). 
P. $361 \mathrm{D} ; 362 \mathrm{D}$ sich z. T. bis auf Wort gleichen ${ }^{1}$ ), ebenso einwandfrei bringen Capit., Eutr. und Victor dieselbe Erzählung in einer bestimmten, allen dreien gemeinsamen Form, wie aus einem Vergleich sofort einleuchten wird:

Gord. 26,3 f.

Praetextato et Attico conss. Gordianus aperto Iano gemino - profectus est contra Persas cum exercitu ingenti et tanto auro, ut -- Persas evinceret. per Syriam Antiochiam venit, quae a Persis iam tenebatur. Illic frequentibus proeliis pugnavit et vicit Sapore Persarum rege summoto, et post Artaxansem et Antiochiam recepit et Curras et Nisibin, quae omnia sub Persarum imperio erant.

28. - Misitheus - extinctus est -.

29. Quo mortuo Arriano et Papo conss. in eius locum praefectus praetorii factus est Philippus Arabs, humili genere natus -, - ut statim Gordiano - insidias per milites faceret, - . - artibus Philippi primum naves frumentariae sunt aversae, deinde in ea loca deducti sunt milites in quibus annonari non posset.

30. Philippus - Gordianum - iussit - occidi.

31, 1. Imperavit Gordianus annis sex. Philippus - Romam litteras misit, quibus scripsit Gordianum morbo periisse - .

34, 2. Gordiano sepulchrum milites apud Circesium castrum fecerunt in finibus Persidis.

31, 3. Senatus - G. adulescentem inter deos rettulit.

DaB Capit. unvergleichlich ausführlicher erzählt, als die beiden andern, und daB er auch in seinem ÜberschuB sich aufs engste an Zos. anschlieBt, ist nicht verwunderlich, da er ja auch wahrscheinlich oft wörtlich ausschrieb, während Eutr. und Victor selten ihre Quelle in extenso wiedergaben. Das Ende des Perserkrieges gibt Capit. nicht, wahrscheinlich weil es in der "Kirisergeschichte“ wie bei Victor 28,

1) Sotiriadis „Zur Krit. d. Joh. v. ¿nt.“, Jahrb. f. klass. Phil. XVI. Supplementband 1888 , S. 10 verquickt die aus zwei verschiedenen Quellen stammenden Leoberichte. 
Eutr. IX 3 erst unter Philippus erwähnt war. Eine Verkürzung des Zosimosberichtes durch den Autor der "Kaisergeschichte" liegt vor in dem Fehlen der gesamten Vorgeschichte des Perserkrieges, sowie der Angabe, da B Gord. in der Nähe von Ktesiphon ermordet wurde. Eine Spur der ausführlicheren Darstellung des Capit. findet sich z. B. bei Eutr. in der Nachricht von Gordians Vermählung, wo das „G. admodum puer cum Tranquillinam - duxisset uxorem" überdies so stark an das „adulescens G. - duxit uxorem filiam Misithei“ anklingt, daB leicht Tranquillinam erst eine Entstellung etwa aus "Misithei filiam" sein könnte. Mit Bestimmtheit läBt sich von der Quelle Capitolins dreierlei aussagen: erstens, sie war gegenüber Zos. stark verkürzt, sie hatte zweitens einige Zusätze und war drittens lateinisch geschrieben. All das geht aus dem einen Satz hervor "et post Artaxansem et Antiochiam recepit". Capit. liest post in der Bedeutung postea; das kann bei einem Manne, der imstande war, Dex. zu benutzen, nicht direkt aus $\mu \varepsilon \tau \alpha$ ü übersetzt sein. Er hält ferner das „Artaxerxem“ seiner Quelle für eine Stadt Artaxanses, die Gordian erobert, der Bericht von den Eroberungen Gordians muB also, um das Mißverständnis zu erklären, in seiner Vorlage dicht auf die Angaben über die Thronfolge in Persien gefolgt sein, entgegen Zos. Endlich hat nach dem übereinstimmenden Zeugnis aller übrigen Verwandten die Zosimosquelle eine Eroberung Antiochias nicht berichtet. Diese stark verkürzte, hier und da vermehrte lateinische Vorlage kann aber, wie die Öffnung des Janustempels, die „frequentia proelia“, die Regierungsjahre Gordians, dessen Grabmal bei Circesium und die Relatio inter divos auf den ersten Blick zeigen, nur die „Kaisergeschichte“ gewesen sein. ${ }^{1}$ )

Nun erklärt sich auch, warum Capit. nützlich fand, für Gordians Zeit die Fasten aus Dex. zu entnehmen, während er sie in seiner ganzen iibrigen Darstellung, die er z. T. wörtlich aus Dex. abschrieb, fortlieB. Wir wissen ja, daB er gelegentlich gegen die „Kaisergeschichte“, die den Maximus Pupienus nannte und nur zwei Gordiane erwähnte, starkes Mißtrauen äußerte. So mochte es ihm geraten scheinen, hier, wo er selbst aus dieser trüben Quelle schöpfte, ihren Angaben doch wenigstens durch die Dexippeischen Konsulnamen ein solideres Aussehen zu verleihen. Aber freilich, wie kam er dazu, gerade hier Dex. zu verlassen und sich der wenig geschätzten Vorlage zuzuwenden; weshalb hat selbst diese, für die doch ebenfalls Dex. Hauptquelle ist, hier die Zosimosquelle ausgeschrieben? Um hierüber ein Urteil zu gewinnen,

1) Man bemerke ïbrigens, daB Maximin, der bei Dex. als Thrax bezeichnet war, in dem hier zuständigen Synkellosbericht Mvøós genannt wird. 
müssen wir uns eine Anschauung davon zu schaffen suchen, wie der entsprechende Dexipposbericht ausgesehen haben mag.

Bei Zon. und Kedr. findet sich in der Vita Gordians eine umfangreiche Interpolation eingeschoben, die nicht aus der gemeinsamen Vorlage stammt, da Kedr. sie hinter, Zon. vor den gemeinsamen Bericht setzt. Bei Kedr. ist sie, mit weiteren Zutaten aus der „Kaisergeschichte“ versetzt, aus Georgios Monachos entnommen ${ }^{1}$ ), dessen mit Zon. übereinstimmende Daten zu Malalas in irgendeiner Beziehung stehen. ${ }^{2}$ ) $\mathrm{DaB}$ sie das Ende des älteren Gord. aus der Zosimosquelle enthält, erklärt den Einschub der Interpolation gerade hier, wo Zon. denselben Bericht ja auch sicher in seiner Hauptrorlage fand, die daran dann den entsprechenden Dexipposbericht anschloB (Zon. XII 17 I 622 D - 623 A). Dann folgt ein Bericht über den Perserkrieg des jungen Gord., der dabei infolge eines Schenkelbruches starb. AuBer der negativen Tatsache, daB diese Daten nicht aus der Zosimosquelle stammen, spricht noch die Beobachtung für Ableitung aus Dex., daB Gord. in der Inter-

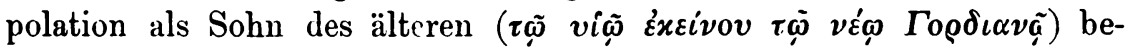
zeichnet wird. Endlich lassen sich auch einige andere Daten der Interpolation, wenn überhaupt, nur als Ausflüsse des Dex. erklären:

Bei Kedr. P. 257 B wird im AnschluB an die erwähnte Stelle noch ein angeblicher Sohn des Gord. erwähnt, der zwei Jahre herrschte und an der Wassersucht starb. Halten wir mit diesem Ausdruck, ,vं $\delta \rho\llcorner\alpha ́ \sigma \alpha S$

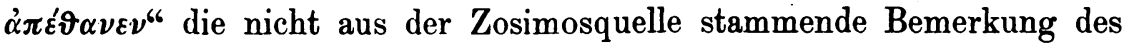
Capit. (c. 28) zusammen „cum effusione alui laboraret Misitheus", so erhellt die Möglichkeit, daß die Angabe bei Kedr. ein mißverstandener Überrest der Dexipposversion vom Tode des Timesikles ist, dessen maBgehender Finflu $B$ ja in der Tat etwa durch zwei Jahre dauerte. Der Name Oủvíoos dürfte dann ein entstellter Konsulname sein, etwa Arrianus, den Capit. als Konsul im Todesjahre des Misitheus angibt. DaB ein Konsul bei Kedr. (und Zon.) zum Kaiser avancierte, dafür gibt es anscheinend in dem fraglichen Textstück noch ein zweites Beispiel: In der Luft schweben bei Kedr. noch die ersten beiden Absätze von P. $257 \mathrm{~B}$; in dem zweiten davon könnten die Worte „rò $\tau \dot{\alpha} \gamma \mu \alpha$

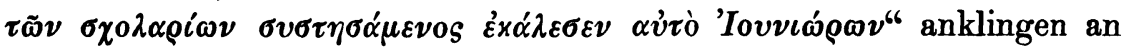
Aurel. Victor 26: „senatus - primo potestatum vices, mox con-

1) Vgl. De Boor Byz. Z. II S. 8.

2) Vgl. Patzig Byz. Z.V S. 40f. Dagegen würde es mir psychologisch unerklärlich scheinen, daB Zon. aus dem ganzen Text des Malalas nur gerade ein paar besonders unsinnige Sätze herausgesucht hätte; ich stehe deshalb der Annahme einer direkten Benutzung des Malalas selbst durch die Vorlage des Zon., wie Patzig will, skeptisch gegenüber. 
scriptis iunioribus Clodium Pupienum, Caecilium Balbinum Caesares constituit."1) Ebenfalls auf die „Kaisergeschichte“ mag es zurückgehen, daB Kedr. den Kaiser im ersten Absatze Puplianus nennt, statt Pompeianus bei Zon. Da aber eine Benutzung der „Kaisergeschichte“ durch Zon. nicht zu erweisen ist, so läBt sich der Name Pompeianus nicht überhaupt für eine Entstellung von Pupienus erklären. Bleibt eigentlich nur die eine Möglichkeit, daB sowohl jener Kaisername wie der sonst nicht unterzubringende Inhalt der beiden Absätze bei Kedr. und der entsprechenden Sätze bei Zon. aus Dex. stammen; dann ist aber jener Pompeianus sicher nichts anderes, als der Konsul des Jahres 241, und die übrigen Daten beziehen sich auf irgendwelche von Dex. zu den einzelnen Jahren erwähnten Gesetze oder Dekrete.

Bilden die oben besprochenen Abschnitte des Zos. und Kedr., besonders der über Gordian IU, wirklich den Bericht des Dex., so wird ohne weiteres erklärlich, warum Capit. für diese Zeit einer anderen Quelle folgte. Dex. wird eben so dürftig gewesen sein, daB sich aus der „Kaisergeschichte“ und Cordus eine weit reichhaltigere Erzählung zusammenschreiben lieB. ${ }^{2}$ ) Die Ursache davon ist leicht zu finden; wenn es wahr ist, daB der athenische Autor seine Chronika zuerst bis zur Millenniumsfeier geführt hat - die Feier wird bei Capit. und Eutr. Victor erwähnt -, so tat er das augenscheinlich deshalb, weil er von da ab Eigenes geben, vorher nur aus anderen Werken zusammenschreiben konnte. Das letzte von ihm benutzte reichhaltigere Werk ist aber das des Herod. Von dessen SchluB bis auf Philippus wird er auf dürftige Überlieferung angewiesen gewesen sein, so dab er sich begnügte, außer den Konsularfasten und einigen Notizen über neue Institutionen einen ganz kurzen Überblick ïher die politischen Ereignisse zu geben. Ein zweiter Grund für Capit., der „Kaisergeschichte“ hier zu trauen, mag gewesen sein, dab Cordus anscheinend das Ende Gordians ebenfalls gegen Dex. auf die Umtriebe Philipps zurückgeführt hat; wenigstens scheint die ganze von Zos. abweichende Darstellung, wie Philippus erst zum Mitherrscher erhoben und dann allmählich die Soldaten zur Ermordung des jungen Kaisers getrieben habe, auf ihn zurückzugehen.

1) Selbstverständiich lege ich auf diese Zusammenstellung nicht den geringsten Wert. Der Kedrenossatz kann ebensogut ganz andern Ursprungs sein und würde selbst in dem gegebenen Falle nur als eine Art Glosse zu dem unverstandenen Passus der „Kaisergeschichte“ anzusehen sein.

2) Der gleiche Grund gilt natürlich auch fü den Autor der „Kaisergeschichte“ selbst. DaB die Zosimosquelle hier reicher ist, erklärt sich einfach daraus, daB ihr Verfasser Orientale war. 
So spricht der Parallelismus der Quellen bei genauerer Betrachtung teils geradezu gegen die Benutzung des Dex. durch Zos., teils läBt er sich wenigstens ebensogut auch anders verstehen. Ich kann deshalb ruhig den Ring schließen und auch Zos. I 19,2 der Zosimosquelle zuschreiben. Hier wird ein Priscus erwähnt; sollte das derselbe sein wie der bei Dex. unter Decius genannte, so ist wieder der Gegensatz deutlich: den Bruder des Philippus, als welcher Priscus bei Zos. auftritt, konnte Decius unmöglich in so wichtiger Stellung lassen, in der ihn Dex. nennt. Das Ende ist: Zos. hat für sein ganzes erstes Buch mit Ausnahme zweier kurzer Abschnitte, die er Eunap entnahm, eine einzige Vorlage ausgeschrieben, auf die zum Teil auch Zonaras, Kedrenos, Synkellos, Trebellius Pollio, Vopiscus, Eutrop-Epitome und EutropVictor (daraus Capitolin) zurückgehen, eine Vorlage, die von Dexippos unabhängig ist und selbst Cassius Dio und Herodian benutzte.

\section{Das Verhältnis der Quellen zueinander.}

Das Bild wäre nicht vollständig, wollte ich nicht versuchen, die Stellung der angezogenen Geschichtswerke zueinander zu skizzieren. Da läBt sich denn zuerst erwarten, daB zwischen der Zosimosquelle und Dexippos, wenn anders sie wirklich in keinem Zusammenhange stehen, Unterschiede irgendwelcher Art erkennbar sein müssen. Nicht in der Sprache: Schon aus der durchgängig näheren Stellung der griechischen Chroniken zueinander im Wortlaut geht hervor, daB auch die Zosimosquelle griechisch abgefaBt war; wir besitzen aber auch ein direktes Zeugnis dafür: Vopiscus, der zuverlässigste der Scriptores historiae Augustae, hat bestimmt die Zosimosquelle, die „Kaisergeschichte" und Ephemeriden wenigstens des Aurelian benutat. Die „Kaisergeschichte“ war nach Capit. Maxim. duo 33, 2 lateinisch geschrieben; ihre Berichte gibt Vop. überdies stets erst an zweiter Stelle. Seine Hauptquelle war die mit Zos. gemeinsame Vorlage, und aus Aurel. I 9 "accepi libros Graecos et omnia mihi necessaria in manum sumpsi“ geht hervor, daB eben jene libri Graeci ihm den hauptsächlichen Stoff boten; daraus folgt, daB die Zosimosquelle ihm wenigstens in griechischer Sprache vorlag.

Nur Sache eines Fachgelehrten könnte es sein, über Stil und Diktion der Zosimosquelle etwas auszusagen, wenn überhaupt die Möglichkeit dazu vorhanden ist bei einem Werke, das, im Original völlig verloren, nur in mehr oder weniger freien Exzerpten erhalten blieb. Etwas günstiger sind wir gestellt, wenn wir die Wahl und Formung des Stoffes ins Auge fassen. Von den Skythika des Dexippos wissen wir aus den erhaltenen Fragmenten und Exzerpten, daB der Verfasser 
eine gewisse Freude an Reichtum des Stoffes hatte: Er flicht charakteristische Anekdoten ein, bei wichtigen Anlässen gibt er den handelnden Personen das Wort zu längerer Rede oder läßt sie Briefe schreiben; bei günstiger Gelegenheit greift er auch wohl in die Vergangenheit zurück, wie er denn bei Erwähnung einer Stadt ihre Gründungsgeschichte zu geben liebt. Aber auch die Chronika dürften doch nichts weniger als eine summarische Übersicht der politischen Begebenheiten gewesen sein. Die Worte Capitolins „docente Arriano - docente item Dexippo - qui etiamsi breviter, ad fidem tamen omnia persecuti sunt" können ja an sich nur für die von Capitolin behandelte Zeit gelten, also für die Zeit, deren Ereignisse Dex. nach älteren Quellen erzählte; wenn überdies Arrian, wie ich annahm, gleich Herodian ist, so stellt sich doch Capitolins Begriff von Kürze als etwas weitherzig heraus, und außerdem sehen wir ja aus Capitolins Viten selbst, welche Masse von Einzelheiten, kleinen Zügen Dex. aus Herodian herübergenommen hat, bei der Erhebung Gordians I, dem Verhalten der römischen Bevölkerung, dem Untergang Maximins - ich erinnere nur an die Sehnsucht der Soldaten nach den Albanerbergen -, wie er sogar die Rede Maximins an seine Soldaten nach dem Abfall von Afrika sich nicht entgehen lieB, trotzdem er sie anscheinend nicht einmal inhaltlich wiedergab, wie er sie bei Herodian fand, sondern ein wohldurchdachtes thukydideisches Meisterstück an ihre Stelle setzte. Dieselben Erscheinungen zeigen auch die späteren Texte, die ich dem Dex. glaubte zuweisen zu dürfen. $\mathrm{DaB}$ der tätige Staatsmann für politische und rechtliche Institutionen Interesse bewies, ist ganz natürlich; ich erinnere weiter an die Demosthenesepisode in den Perserkämpfen nach Valerians Gefangennahne und die Erzählung von der Gefahr, in die die Gemahlin des Gallienus während der Belagerung von Mailand geriet, bei Zonaras. Noch weiter würden wir in dieser Beziehung kommen, wenn wir wirklich die Geschichtchen des Anonymus auf Dex. zurückführen könnten, wie das ja bei fr. 1, fr. 2 und fr. 9, 1 wenigstens sehr wahrscheinlich ist. So viel läßt sich jedenfalls sagen, daß diese epische behagliche Breite nicht nur der Schreibweise des attischen Geschichtschreibers, soweit wir sie kennen, entspricht, sondern daB diese Behandlung bei der annalistischen Fassung, die er seinem Werke gab, sich vielleicht sogar als unvermeidlich herausstellte, wollte er sich nicht auf eine eine trockene Aufzählung von Daten beschränken. -Der Unterschied, der sich hier geliend macht, bildet eine starke Stütze für die Trennung, die ich besonders zwischen den Berichten des Zonaras von anderen Gesichtspunkten aus vorgenommen habe; denn sowie wir uns der Zosimosquelle zuwenden, weht eine ganz verschiedene Luft. 
Die fortlaufende Erzählung allein ermöglichte schon eine knappere Darstellung, ohne dürftig zu erscheinen; man darf es aussprechen, daB hier wirklich nur das gegeben wird, was zum Verständnis der politischen Vorgänge beiträgt. In der ganzen Zosimosquelle, soweit wir sie kennen, kommt nicht eine Rede vor, und aus ihren beiden ausführlichsten Berichten, dem über die Skythenzüge unter Gallienus und dem über Aurelians Feldzug gegen Zenobia, wird man sich - mit einer Ausnahme - vergebens bemühen, etwas wie eine Episode oder Anekdote herauszufinden. Dabei läBt sich auch nicht einwenden, daB wir ja nur Exzerpte des Werkes kennen; denn wie sich bei Zonaras das Bild ändert, wo er aus anderer Quelle schöpft, so auch bei Zosimos. Die beiden aus Eunap entnommenen Textstücke sind zwei umfangreiche Episoden. Ein recht nettes Beispiel für den Gegensatz der Darstellung. bietet der Doppelbericht des Zonaras über den Tod des Gallienus. Das Exzerpt aus der Zosimosquelle bringt nur ganz knapp das Wesentliche des Vorganges; das andere, das ich dem Dex. zuschrieb, gestaltet das Ereignis ungemein lebendig, mit dramatischer Bewegung, Rede und Gegenrede, auch hier weht ein Hauch von Thukydides.

Nicht ganz unter der Kategorie der Wahl des Stoffes läßt sich ein anderer Unterschied abhandeln, weil er eben nicht der freien Wahl, dem Interesse und Geschmack unterliegt, sondern auf dem Gradunterschiede der Kenntnis beruht, wie sie sich aus der Stellung und Heimat des Verfassers, sowie der Beschaffenheit seiner Quellen ergab. Der letzte Punkt ist bereits berührt; zum zweiten lassen sich einige Bemerkungen machen. Dexippos war Athener; das kommt nicht nur in seiner Erzählung von der Verteidigung Athens gegen die Skythen zum Ausdruck; daneben erscheinen auch Korinth, Argos, Sparta und die Provinz Achaia mit ihrem offiziellen Namen, Böotien und Epirus werden genannt. Außerdem sind natürlich die Vorgänge in Thrakien und den angrenzenden Landschaften eingehend behandelt, und weiter muBte Italien ein Hauptinteresse des Römers wecken. Aber selbst der äußerste Westen des Reiches fiel in seinen Gesichtskreis, wie er denn die Plünderung Spaniens durch die Franken berichtet. Nichts davon in der Zosimosquelle, die Spanien überhaupt nicht erwähnt und die Franken unter Probus zum ersten Male nennt; auch von den zahlreichen Gegenkaisern in Gallien kennt sie vor Probus nur die beiden wichtigsten, Postumus und Tetricus. Wie dem Verfasser die gesamten westlichen Barbaren noch nach altgriechischer Bezeichnung Kelten sind, so gehen ihm wohl auch die Markomannen und Alemannen etwas durcheinander. Besser bekannt war natürlich, was in Italien, dem Zentrum des Reiches, und besonders in Rom vor sich ging. Am nächsten 
kommen sich Dex. und die Zosimosquelle, wo es sich um den nördlichen Teil der Balkanhalbinsel handelt; ich erinnere an Aemilianus und die Belagerung von Thessalonike unter Gallienus. Dagegen ergibt sich das umgekehrte Verhältnis wie für den Westen, wenn wir uns dem Orient zuwenden. Vergleichen wir die Berichte über die Skythenzüge: die betroffenen Gegenden sind bei Dex. die Attika zunächstliegenden Inseln und die Westküste Kleinasiens, bei Zos. wird das ganze Innere der Halbinsel bis hindurch nach Cilicien geplündert. Odenathos, vielleicht der bedeutendste der Gegenkaiser unter Gallien, war zwar auch bei Dex. berücksichtigt; das Hauptgewicht in den Perserkämpfen scheint doch aber auf Ballista und Macrinus gefallen zu sein, die ihm erstens als Römer näher standen, deren Katastrophe dann in Illyrien sich entschied, so daB man wohl Gelegenheit hatte, aus ihrem Heer nähere Nachricht über die Vorgänge im Osten zu erlangen. Der Orient ist nun das Gebiet, auf dem der Verfasser der Zosimosquelle zu Hause ist; von den 39 Seiten bei Zosimos, die auf jener Vorlage beruhen, handeln gut 15 über orientalische Dinge; was in Kleinasien, Syrien, Mesopotamien und Ägypten spielt, wird ausführlich dargestellt. Schon daraus ließe sich schließen, daB der Verfasser in Syrien zu Hause war, wenn nicht außerdem diese Landschaft noch in eben dem Grade vor den übrigen des Orients bevorzugt würde, wie dieser vor dem Westen. In der Beschreibung der Schlacht bei Emesa und der damit zusammenhängenden Ereignisse spricht der Autor sicher als Zeitgenosse, der diese Nachrichten aus erster Quelle erhielt, vielleicht sogar als Augenzeuge. Zeitgenosse im besten Sinne ist er dann für die Regierung des Probus; jetzt erst erweitert sich sein Gesichtskreis bis über Gallien und Britannien hin, und man gowinnt den Eindruck, als müsse er sich damals in angesehener Stellung befunden haben, so daß ihm gute Meldungen von überall her zu Gebote standen.

Ich gehe nun zur Stellung der einzelnen Quellen zu Dex. und der Zosimosquelle über; die Hauptfrage dabei ist, zwischen welchen der Chroniken sich nähere Beziehungen erkennen lassen, die den SchluB gestatten, die betreffenden Autoren hätten nicht selbst die Originalquellen ausgeschrieben, sondern nur eine Vorlage benutzt, die ihrerseits auf der oder den Originalquellen beruhte. In solch näheren Beziehungen stehen:

1) Eutrop und Aurelius Victor de Caesaribus; Enmann hat gezeigt, daB ihre Übereinstimmungen sich aus gemeinsamer Benutzung einer verlorenen, lateinisch geschriebenen, biographisch gehaltenen 
Kaisergeschichte erklären; einzelne Schwierigkeiten, die dieser Annahme entgegenstehen, dürften durch die Ausführungen der vorliegenden Arbeit beseitigt sein. Ich konnte mehrfach darauf hinweisen, daB die „Kaisergeschichte" selbst auf Dexipps Chronika und die Zosimosquelle zurückgeht, und zwar, soweit Dex. reicht, diesem den Vorzug gibt; vorher sind nur einzelne Notizen und die Regierung Gordians III der Zosimosquelle entnommen.

2) Eutrop-Victor und Vopiscus. Auch hier hat Enmann wohl ohne Zweifel das Rechte getroffen, als er die bestehenden Beziehungen auf Benutzung der „Kaisergeschichte" auch durch Vopiscus zurückführte. Ich begnüge mich zur Erläuterung mit zwei Beispielen. Nachdem Vop. die Geschichte Aurelians bis Aur. c. 36 nach der Zosimosquelle erzählt hatte, bringt er zum Teil dieselben Nachrichten in c. 38-39 noch einmal aus der „Kaisergeschichte“, natürlich ohne zu ahnen, daB diese sie gleichfalls aus der Zosimosquelle hatte. Weiter sahen wir, daB er das Ende des Probus aus der Zosimosquelle wohl kannte; um aber Carus zu entlasten, gab er statt dessen den Bericht der "Kaisergeschichte“.

3) Eutrop-Victor und Capitolinus. DaB Capitolinus die „Kaisergeschichte“ gekannt habe, hat Enmann gesehen; denn davon geht seine ganze Darstellung aus. Dagegen glaubte er, da Cap. jene Quelle mehrfach kritisiere, habe er sie auch nicht benutzt. ${ }^{1}$ ) $\mathrm{DaB}$ dies doch der Fall ist, glaube ich im vorigen Kapitel nachgewiesen zu haben.

4) Aurelius Victor und die Epitome. Eine besonders überzeugende Parallele, weil ihr Inhalt in keiner weiteren Quelle, auch nicht bei Eutrop, zu finden ist, bietet sich in dem Bericht über den Tod des Kaisors Claudius III:

Caes. 34.

Nam cum pellere Gothos cuperet, quos diuturnitas nimis validos ac prope incolas effecerat, proditum ex libris Sibyllinis est primum ordinis amplissimi victoriae vovendum. Cumque is, qui esse videbatur, semet obtulisset, sibi potius id muneris competere ostendit - Ita nullo exercitus detrimento fusi barbari submotique, postquam imperator vitam rei publicae dono dedit.

\section{Epit. 34.}

Claudius vero, cum ex fatalibus libris - cognovisset, sententiae in senatu dicendae primi morte remedium desiderari, Pomponio Basso, qui tunc erat, se obferente, ipse vitam suam - dono rei publicae dedit -

Da die Übereinstimmungen mit Eutrop gegen Victor, soweit ich sehe, alle für nähere Beziehungen zur Zosimosquelle sprechen, so lassen Beispiele wie das vorstehende nur den SchluB auf unmittelbare Benutzung der Schrift De Caesaribus durch den Verfasser der Epitome zu.

1) Philologus IV. Supplementband S. 375. 
5) Eutrop und die Epitome. Wie oben erwähnt und in Kap. I näher ausgeführt, geht ihre nähere Verwandtschaft auf die Zosimosquelle zurück. Da aber die Epitome in manchen Fällen - ich erinnere an das Ende des Decius und an Hostilian - die Vorlage genauer wiedergibt als Eutrop, an anderen Stellen, wie bei Tacitus und Florian, Fehler macht, die ihr Verfasser nicht von Eutrop abschreiben konnte, so ist in ihr nicht Eutrop, sondern eine mit ihm gemeinsame Vorlage benutzt. Beide stimmen aber häufig auch in ganz kurzen Notizen so wörtlich überein, wie es weder bei selbständiger Übersetzung aus dem Griechischen, noch bei selbständigen Exzerpten aus einer weit umfangreicheren Quelle denkbar erscheint. Daraus ergibt sich als Postulat, daB beide nicht die Zosimosquelle selbst, sondern eine lateinische Epitome daraus benutzten; zu demselben Ergebnis führt die Bemerkung, daB Eutrop die „Kaisergeschichte“, der Epitomator gar den dürftigen Victor der Darstellung zugrunde legten, ein merkwürdiges Verfahren, wenn sie die reichhaltige Zosimosquelle vor Augen gehabt hätten. Endlich scheint die Annahme eines Vermittlers zur Erklärung einzelner beiden Schriften gemeinsamer Zusätze erforderlich.

Wenn ich im folgenden auch auf die näheren Beziehungen der späteren Byzantiner mit einigen Worten eingehe, so muB ich vorausschicken, daB ich mich in keiner Weise mit den verdienstrollen, von mir an einzelnen Punkten des öfteren zitierten Arbeiten von De Boor, Patzig und Praechter ${ }^{1}$ ) auseinandersetzen will, aus dem einfachen Grunde, weil ich für die von ihnen behandelten Fragen nicht kompetent bin. Trotzdem kann ich mich der Pflicht nicht entziehen, darzustellen, in welcher Mischung etwa nach den vorstehenden Untersuchungen das Nachrichtenmaterial der Primärquellen den späteren Werken zugeflossen sein mag. Nach allem kann es sich nur um einen Versuch handeln, um einen Versuch, der noch dazu auf Vollständigkeit von vornherein verzichtet; was ich im folgenden andeute, sind nähere Beziehungen, nicht aber die realen, nächsten Zusanmenhänge:

6) Zonaras und die Leo-Sippe. Kedrenos und seine Verwandten berichten sehr fragmentarisch, schließen sich aber überall, wo sie etwas ausführlicher werden, eng an Zonaras. Meist erzählt Zon. weit genauer, doch haben die übrigen immerhin auch Daten, die Zon. fehlen, geben selbst einzelne, sonst gemeinsame Berichte, wie den über die Tat des Victorinus, ausführlicher als jener. Und die aus diesen Tatsachen zu erschließende gemeinsame Vorlage beschrärkt sich, wie die Bücherverbrennungsanekdote beweist, nicht auf die Ausflüsse der Zosi-

1) Byz. Z. I $13 \mathrm{ff}$; II $1 \mathrm{ff}$. u. $195 \mathrm{ff}$; III $470 \mathrm{ff}$; V $24 \mathrm{ff}$. u. $484 \mathrm{ff}$. 
mosquelle. Die oben erwähnten Gelehrten haben bis zu einem gewissen Grade wahrscheinlich gemacht, daB nicht eine, sondern mehrere Quellen den fraglichen Geschichtswerken in verschiedener Mischung zugrunde liegen, andrerseits aber auch, daB diese Quellen selbst zuletzt zum großen Teil auf eine einzige, die von Patzig so genannte Epitome, zurückgehen. Die Ergebnisse der vorliegenden Arbeit jedenfalls führen mit Notwendigkeit nur auf die Annahme einer größeren Hauptquelle, die sowohl Zon. wie den Chroniken der Leo-Sippe die Nachrichten der beiden Primärquellen vermittelte. AuBerdem ist mit Sicherheit noch eine dürftige Nebenquelle zu erschlieBen, die zu Malalas ${ }^{1}$ ) in Beziehung steht und deren Daten Kedr. durch Vermittlung von Georgios Monachos erhielt. Auch die kirchengeschichtlichen Daten gehören wenigstens zum großen Teil der Hauptquelle wohl nicht an; sie gehen ja vermutlich bei allen in letzter Linie auf Eusebios zurück, erscheinen aber besonders bei Kedr. in sehr stark überarbeiteter Fassung und werden von Zon. und Kedr. völlig selbständig mit den Daten der politischen Geschichte zusammengeschmolzen.

7) Zonaras-Kedrenos und der Anonymus. Die Übereinstimmungen des Anon. mit Zon. sind im vierten Kapitel zusammengestellt, die Hauptparallele, die Bücherverbrennungsanekdote, findet sich auch bei Kedr., der überdies in Ausdruck und Satzbau z. T. näher zum Anon. steht als Zon.; die Verwandtschaft kam also schon der gemeinsamen Quelle zu. Wie weiter Zon. XII 27, I $636 \mathrm{BC}$-Anon. fr. 10, 1 zeigt, gehen die Parallelen über Dex. hinaus, sind also nicht auf ihn direkt zurückzuführen. Da Zon. und Kedr. den Text des Anon. nach verschiedenen Seiten variieren, scheint dieser selbst die Vorlage für die gemeinsame Quelle der beiden anderen gewesen zu sein, und zwar diejenige, durch deren Vermittlung ihnen die Dexipposberichte zukamen. ${ }^{2}$ )

8) Eutrop-Victor, Synkellos und Kedrenos. Schon im 2. Kapitel bemerkte ich, daB Synk. den Tod Aurelians parallel mit der Schrift

1) Für die Primärquellen des Malalas selbst wage ich nur eine Vermutung zu äuBern, daB nämlich ein Teil seiner Nachrichten auf die Script. hist. Aug. zurückgeht.

2) Ich beharre also in bezug auf den Anonymus noch bei einem "non liquet", trotz De Boor B. Z. I $13 \mathrm{ff}$. Nach meinen Ausführungen würde die These „Anon. = Petrus Patricins" erst dann gesichert sein, wenn wahrscheinlich gemacht wäre, daB entweder Petrus die Zosimosquelle nicht benutzt hätte, dafür aber von Dex. sowohl Chronika wie Skythika, oder daB auch der Anonymus von der Zosimosquelle abhängt. Da mir nun noch (vgl. S. 92) Petr. Patr. fr. 9 dem Zosimusbericht zu entsprechen scheint und ich beim Anon. keine Berührung mit Zosimos finde, so kann ich vorläufig trotz De Boors geistvollen Kombinationen nicht umhin, die beiden Autoren noch getrennt zu halten. 
De Caesaribus berichtet; dazu kommt die Aufgabe von Dacien, der Todesort des Probus und die Ermordung Apers durch Diokletian, die letzte in allen Einzelheiten. Die Regierungszeit des Tacitus stimmt nicht zu Victor, sondern nur zu Eutrop-Vopiscus; demnach ist nicht Victor, sondern die „Kaisergeschichte“ benutzt. Den Todesort Aurelians gibt übereinstimmend, als einziger griechischer Schriftsteller außer Synk., noch Kedren, und er zeigt noch eine weitere merkwürdige Parallele zu Victor ${ }^{1}$ ):

De Caes. 32.

(Valerianus) - Persarum regis - dolo circumventus, foede laniatus interiit.
Kedr. P. $258 \mathrm{D}$.

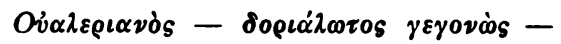

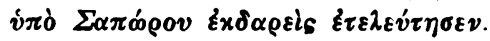

Nimmt man dazu auch noch die Erwähnung des Pupienus ${ }^{2}$ ), so bleiben die Anklänge doch zu gering, um anzunehmen, Synk. und Kedr. hätten beide die ganze Kaisergeschichte vor sich gehabt. Synk. bringt neben seinen wortgetreuen Eusebios-Exzerpten hier und da Parallelberichte, die wohl ebenfalls zum großen Teil Ausflüsse von dessen Kirchengeschichte sind, aber „mit Zusätzen, wie dem Martyrium des Cyprian und der Justina, und mit einer dogmatischen Umfärbung, indem an Stelle des vom Verfasser verdammten Origenes Gregor von Nazianz tritt, der bei Euseb nur ganz nebenbei Erwähnung findet. Da die gleichen Erscheinungen auch bei Kedr. auftreten, dürfte die Synk. und Kedr. gemeinsame Quelle eine kirchengeschichtliche Schrift mit Exzerpten aus der „Kaisergeschichte" gewesen sein. Man hat gemeint, Kedr. habe aus Synk. geschöpft. Er stimmt aber durchweg zu Zon. selbst gegen Synk. und über dessen Ende hinaus; in kirchengeschichtlichen Dingen gibt er bisweilen mehr als Synk., so das Martyrium der sieben Kinder und des Decius Schleierverbot; von den Exzerpten der „Kaisergeschichte" hat er nur den Todesort Aurelians mit ihm gemein. End-

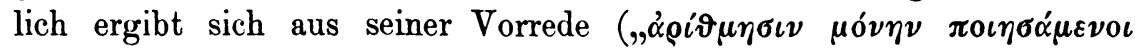

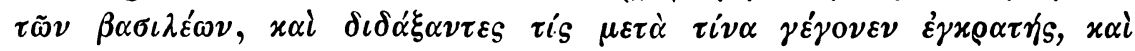

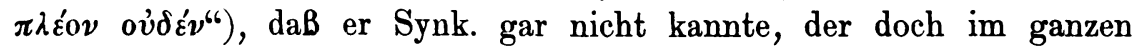
immer noch etwas mehr gibt als sein Kritiker. Auf die gleiche Folgerung führt denn auch die Angabe, daB Synk. mit Maximian und Maximin schlieBe, deren letzter in Wahrheit bei Synk. gar nicht vorkommt. Mir scheint daher sicher, daß Kedr. den Synk. ebenso wie Nikephoros nur bei einem seiner übrigen Gewährsmänner zitiert gefunden hat.

1) Diese Paralle übersieht De Boor B. Z. I 28.

2) Die aber vielmehr aus Georg. Monachos stammt, der ebenfalls Ausflüsse der „Kaisergeschichte" enthält. 
9) Zonaras und Synkellos zeigen gleichfalls eine Reihe genauerer Ubereinstimmungen. Gehen wir diese durch, so stellt Zon. bei dem Friedensschlusse des Philippus mit Sapor die Vorgänge ausführlicher dar als Synk.; ebenso steht sein Bericht über die Skytheneinfälle unter Gallienus - abgesehen von der engen Verbindung mit der aus dem Anonymus stammenden Bücherverbrennungsanekdote - Pollio näher als Synk. Bleibt die Erzählung der Skytheneinfälle unter Valerian, Aurelians Feldzug gegen Zenobia, das Ende Numerians, besonders aber Valerians Ausgang, die Eroberung Vorderasiens durch die Perser und die Taten des Kallistos. Davon erfordern die ersten drei die Annahme eines anderen als des bisher festgestellten Verwandtschaftsverhältnisses nicht, da sie alle sich aus gemeinsamer Benutzung der Zosimosquelle erklären lassen, und selbst der Bericht über Valerians Gefangennahme klingt beim Anonymus an. Anders steht die Sache in dem Abschnitt, in dem Kallistos die Hauptrolle spielt; wie kamen beide Quellen auf die falsche Namensform statt Ballista? Auch hier bringt Zon. für die Eroberung von Caesarea Einzelheiten, die Synk. fehlen, schweigt dagegen über Pompeiopolis und Lykaonien ganz, so dab wieder an Benutzung des Synk. durch Zon. nicht zu denken ist. - DaB Kallistos doch der richtige Name und ein ganz anderer Mann als der später auftauchende Ballista wäre, daB also Trebellius Pollio beide fälschlich zusammenwürfe, das wäre ja nicht unmöglich, hat aber doch nicht viel Wahrscheinlichkeit. Ein anderer Ausweg wäre die Annahme, daB Synk. ebenfalls für seine Dexippos-Exzerpte auf den Anonymus zurückginge. $\left.{ }^{1}\right) \mathrm{DaB}$ er den Dex. zitiert, ist kein Gegenbeweis; denn er zitiert auch den Dionysios in einem fort, trotzdem er dessen ganze Briefe nur wörtlich aus Eusebios abschrieb. Dagegen spricht nur, daB uns bei Synk. keine Spur der Skythika begegnet. Weiter könnten beide Autoren die ganze Geschichte von Valerians Ende, Macrianus und Ballista in ihrem Eusebioskommentar gefunden haben, da Eusebios VII 10 ausführlich über Valerian und Macrian handelt ${ }^{2}$ ); aber erstens

1) Wenn der Anonymus wirklich gleich Petrus Patricius wäre, so wäre diese Erklärung die gegebene. Damit würden sich die Quellenverhältnisse unendlich vereinfachen, indem dann tatsächlich Petrus die Grundquelle aller späteren Geschichtschreiber gewesen wäre. Leider scheint mir aber diese Annahme noch nicht zulässig (vgl. S. 148).

2) Die von De Boor B. Z. I $26 \mathrm{ff}$. angefübrten Parallelen bedürfen keiner weiteren Erklärung. Die profangeschichtlichen entstammen der Zosimosquelle, die kirchengeschichtlichen könnten, da beide Autoren doch wahrscheinlich keinen unkommentierten Eusebios benutzten, trotz allem auf diesen zurückgehen. Andrerseits ist ja gar nicht einzusehen, warum der orientalische Bearbeiter der Zosimosquelle (s. unten) nicht Christ gewesen und selbst kirchengeschichtliche Daten 
trennt Synk. die fragliche Erzählung ganz von der Eusebiosstelle, die er wörtlich abschreibt, und zweitens ist nicht abzusehen, warum der Kommentator sich dann über die Empörung des Macrian, auf die doch Euseb. anspielt, ausgeschwiegen hätte. Die einfachste Erklärung wäre ja, anzunehmen, daB der Anonymus und Synk. Dexippos-Handschriften derselben Familie benutzt hätten, in die eben jener Schreibfehler sich eingeschlichen hatte. Wahrscheinlicher ist mir aber doch eine andere Möglichkeit, da $B$ nämlich beide Autoren den ganzen Bericht von der Gefangennahme Valerians bis zu dem Abschnitt über Kallistos aus derselben Vorlage entnahmen wie den Text der Zosimosquelle. Dafür spricht erstens die enge Verbindung, in der er bei beiden mit den Odenath-Notizen der Zosimosquelle steht, was allerdings auch daran liegen könnte, daB Odenath und Ballista bei Dex. (vgl. Treb. Pollio) in Zusammenhang genannt waren. Jedenfalls ist das Ganze bei Zon. dadurch als zusammengehörig gekennzeichnet, daB er dahinter einen Abschnitt aus der Kirchengeschichte einschiebt, worauf dann ein Dexippos-Exzerpt folgt. Außerdem erwähnte ich schon, dab auch sonst in den Exzerpten der Zosimosquelle Zon. und Synk. sich besouders nahe stehen, und zwar nur in ihnen; so in dem auf S. 88 angeführten Bericht und der Erzählung vom Tode Numerians, wo sie stellenweise Wort für Wort übereinstimmen. Bemerkenswert ist noch, daB sie die einzigen Autoren sind, die den Feldzug der Zenobia gegen Ägypten bei Gelegenheit ihrer Besiegung durch Aurelian berichten. ${ }^{1}$ ) Erscheint es danach sicher, daB beide die zur Erörterung stehenden Abschnitte in derselben Vorlage fanden, wie die Nachrichten der Zosimosquelle, so ist doch der SchluB abzulehnen, daB diese Abschnitte der Zosimosquelle angehört hätten. Denn nicht nur wäre da das Schweigen des Zos. und der Epit. ganz unerklärlich, würde der Bericht der Epit. über Valerians Gefangennahme vollständig in der Luft schweben; da das Ende der Söhne des Macrian und also auch des Ballista durch die Quintus-Anekdote des Anonymus für Dex. belegt ist, müßten die verschiedenen Lebensabschnitte des Ballista in zwei ganz verschiedenen Quellen erzählt gewesen sein; und endlich spricht der Ansatz der Einnahme von Antiochia unter Gallienus statt unter Gallus, wie bei Zos., geradezu gegen Zugehörigkeit zur Zosimosquelle. Was Synk. und dem

eingefügt haben könnte. SchlieBlich stimmt ja auch die hier geäußerte Ansicht mit De Boors Annahme einer gemeinsamen kirchlich-weltlichen Vorlage überein, nur daB àer genannie Forscher nicht geneigi scineint, dieser Vorlage einen größeren Umfang zuzuschreiben.

1) Ich weise noch auf die ganz ungewöhnliche Kürze dieses und ähnlicher Parallelberichte hin. 
Gewährsmann des Zos. vorlag, war also eine Erweiterung jener Quelle, und diese Erweiterung erklärt sich leicht daraus, daB die zugefügten Dexippos-Exzerpte die einzigen diesem Autor eigentümlichen Abschnitte sind - wenigstens soweit uns bekannt - in denen er die Schicksale des Orientes in umfassender Weise darstellt. Ob der Exzerptor auch sonst noch dies oder jenes aus Dex. entnahm, entzieht sich natürlich unserem Urteil, wie wir denn überhaupt nicht wissen, welche Schicksale die einzelnen Geschichtswerke hatten, ehe sie den Verfassern der uns erhaltenen Chroniken zukamen, welchen Grad von Verstümmelung sie erreicht hatten, ehe jene sie mehr oder weniger genau abschrieben. ${ }^{1}$ )

10) Der Anonymus und Vopiscus. Anon. fr. 10, 4 enthält dieselbe Anekdote von der Einnahme von Tyana durch Aurelian, die Vop. Aur. 22,5 in den Palmyrenerkrieg der Zosimosquelle offenbar einschob (,multa eius magna et praeclara - facta - omnia libro innectere non possumus - sed ad intelligendos mores atque virtutem pauca libanda sunt"). Vielleicht besteht für fr. 10,3 ein ähnlicher Zusammenhang, und einen Brief, wie ihn fr. 10, 6 erwähnt, läßt auch Vop. Aur. 26, 7 den Kaiser an Zenobia richten, die allerdings etwas anders antwortet. Ich möchte glauben, daß diese Übereinstimmungen auf die Ephemeriden zurückgehen, die Vop. Aur. 1,6 als eine seiner Quellen anführt.

Über die Art, wie sich die einzelnen Autoren zu ihren Vorlagen stellten, mögen wenig Worte genügen. Zosimos folgt durchweg seiner einen Quelle und nimmt aus Eunap nur die Abschnitte auf, in denen dieser über die wahrscheinlich sonst ziemlich dürftigen Berichte seiner Gewährsmänner (wohl nur Futrop und Victor) hinaus interessante Einzelheiten gab, an denen besonders die Zeugnisse heidnischen Lebens seine Aufmerksamkeit in Anspruch nahmen. - Sehr einfach verfuhr auch der Anonymus; er exzerpierte wohl nur die beiden Werke des Dexippos, anscheinend nicht sehr sorgfältig, da sonst unklar bleibt, wie die Skytheneinfälle unter Gallienus bei Zonaras und Kedrenos in die Regierungszeit des Claudius geraten konnten. -- Von der „Kaisergeschichte" bemerkte ich bereits, daB ihr Verfasser, solange er Dexippos zur Verfügung hatte, im großen ganzen ihm folgte, daB er nur, wo Dex. zu dürftig wurde, die Zosimosquelle zu Rate zog, der er sonst nur einzelne Notizen (z. B. die Erwähnung Salonins und des Vertrages

1) Denkbar wäre, daB Zon. außer auf die erweiterte Zosimosquelle noch auf die reine Form zurückginge; dann würde ihm diese durch seine und des Kedrenos Vorlage, die andere, mit Synkellos gemeinsame, direkt zugeflossen sein. 
zwischen Gallienus und einem germanischen Könige) entnahm; erst nach dem Ende des Dex. wurde ihm jene Vorlage Hauptquelle. Trebellius Pollio macht in der ganz zerfahrenen Art, wie er die Brocken aus den beiden Quellen durcheinanderwürfelt, ohne sie doch zu verschmelzen, den Eindruck, als habe er, wenn nicht nach dem Gedächtnis, so doch nach kurzen Notizen gearbeitet, die or sich bei der Lektüre der großen Werke gemacht hatte. - Synkellos schrieb den Eusebios so wörtlich aus, und auch seine Parallelen zu Zon. und Eutr.-Victor sind z. T. so genau, daB er an seinen Vorlagen kaum bedeutende Kürzungen vorgenommen zu haben scheint. Wo er also Bruchstücke und Notizen gibt, wie im Ganzen der Dexippos-Exzerpte, erhielt er diese aus dritter Hand, vielleicht von Panodoros, dem er auch sein chronologisches Schema entnahm. DaB seine Zitate nicht eigene Einsicht in die zitierte Quelle beweisen, wurde bereits erwähnt. - In der Nachrichtenmasse bei Zonaras, mag er sie nun einem oder mehreren Gewährsmännern verdanken, sind gewisse Prinzipien der Auswahl zu erkennen: die Zosimosquelle bildet die unzweifelhafte Grundlage. Wo er die Quelle wechselt, gibt er aus der eben herangezogenen Vorlage nie eine einzelne Notiz, sondern stets einen längeren oder kürzeren Abschnitt. Alle Stellen endlich, wo er mit den verwandten Quellen irgend wörtlich übereinstimmt, sind von mäBiger Länge; bei zu kurzen Berichten wechselt er die Quelle, ebenso bisweilen bei zu langen, die er jedoch auch wieder in kurzen Auszug wiedergibt. Für die Autoren der Leo-Sippe, die, wie ich meine, mehr oder weniger direkt auf dieselbe Nachrichtenmasse zurückgehen, kann ich nicht umhin mehr eine Tätigkeit des Exzerpierens als des Kompilierens in Anspruch zu nehmen. - Vopiscus und Capitolinus ähneln sich darin, daB sie beide den Nachrichten ihrer Hauptquelle die ihrer Nebenquellen im ganzen ziemlich locker ein- und anfügen, wodurch sie eben für die Quellenuntersuchung besonders nützlich werden. - Aurelius Victor verwendet die „Kaisergeschichte" hauptsächlich als Substrat für seine gelehrten Bemerkungen und Charakterschilderungen. Eutrop und der Epitomator scheinen, obwohl der eine die „Kaisergeschichte“, der andere Victor zugrunde legte, doch im Zweifelsfalle ihrer Nebenquelle das größere Vertrauen geschenkt zu haben, wenn auch die Epit. zur Verherrlichung der Kaiserfamilie die mythische Geschichte vom Tode des Claudius aus Victor herübernahm. 
Von den folgenden Schematen enthält Nr. 1 die sich aus der vorstehenden Arbeit ergebenden, mir völlig real scheinenden Verwandtschaftsverhältnisse $-1^{2}$ stellt die Descendenz der Skythika der Übersichtlichkeit wegen gesondert dar. Schema 2 gibt Richtungslinien, auf denen sich die Mischung eines gröBeren Teiles der Berichte unserer Primärquellen mit einiger Wahrscheinlichkeit vollzogen hat, aber ohne den Anspruch auf absolute Sicherheit oder gar Vollständigkeit. ${ }^{1}$ ) Schema 3 endlich fügt den nachdiokletianischen Stammbaum der wichtigsten Quellen hinzu, soweit er für die Arbeit von Belang ist:

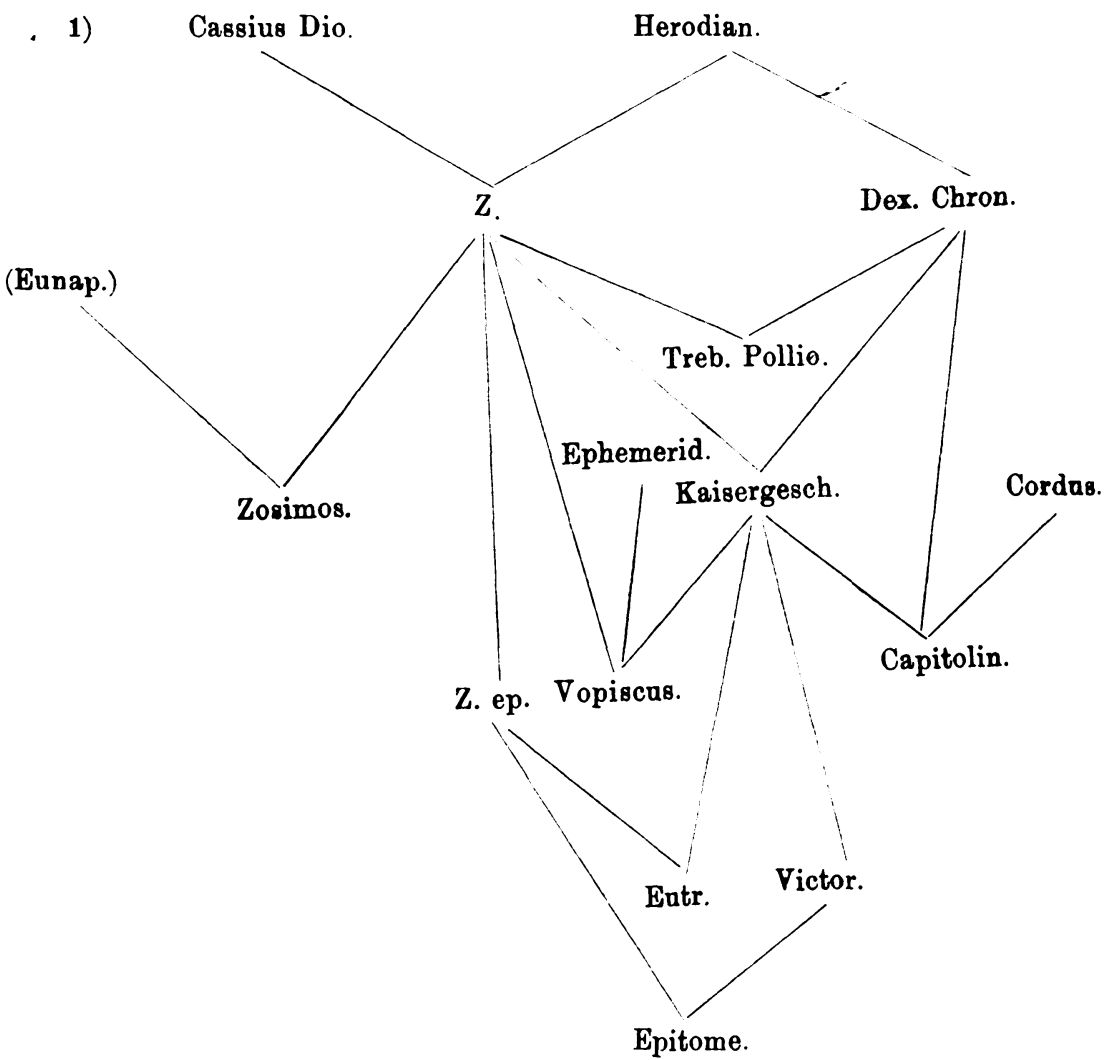

1) AuBerdem gebe ich die Quellen nur, soweit die Profangeschichte in Betracht kommt. 
1*) Z.

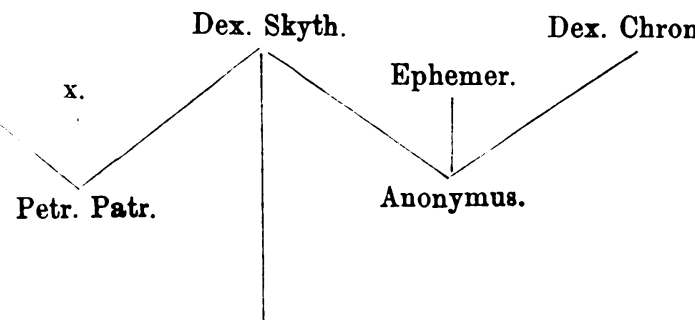

Ammian.?

J

Cassiodor.

2)

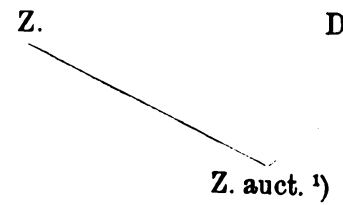

Dex. Chron.

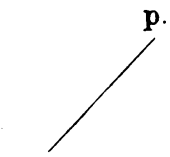

Anon.

Z. auct. ${ }^{1}$

Panodor.
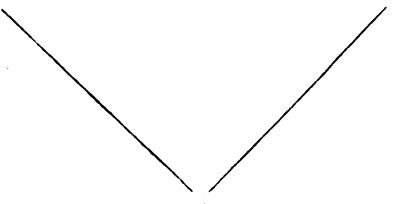

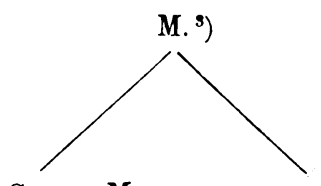

Georg. Mon.

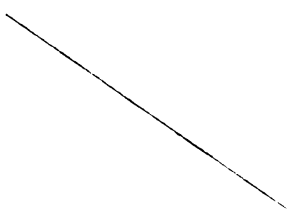

Kedrenos
K. E. ${ }^{2}$ )

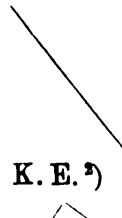


3) Kaisergesch. (cont.)

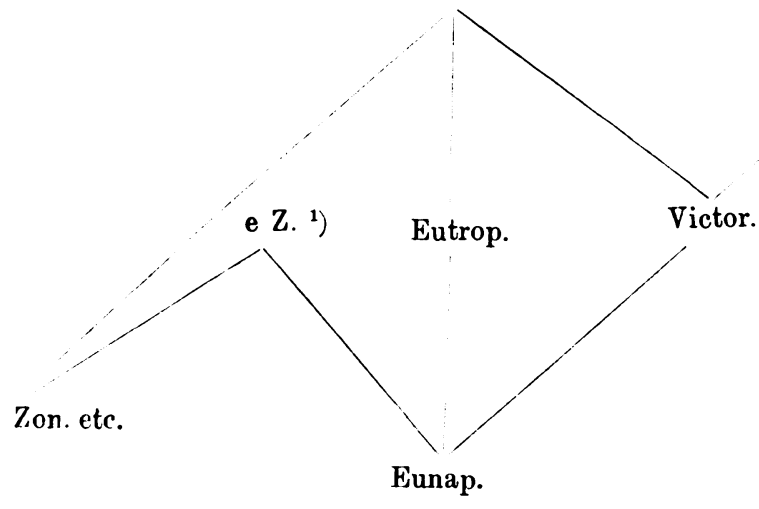

v.

SchluB.

Ich zeichne noch einmal kurz den Gang der Untersuchung: Im ersten Kapitel zeigte ich, daB Zosimos für sein erstes Buch mit mehreren anderen Geschichtschreibern eine gemeinsame Quelle benutzt hat, im zweiten, daB sämtliche Kapitel dieses Buches vom zwanzigsten an mit zwei Ausnahmen ihre Parallelen in den nach dem ersten Kapitel verwandten Quellen finden. Das dritte Kapitel legte dar, daB jene beiden Ausnahmen von Eunap stammen, dem Zosimos auch für die beiden nächsten Bücher hauptsächlich folgte, und daB von Diokletian, also dem Beginn des zweiten Zosimosbuches, an überhaupt ein anderes Verhältnis der Quellen zueinander hervortritt. Daraus folgte, daB Zosimos im ersten Buche im wesentlichen nicht Eunap folgt, sondern einer Quelle, die mit Diokletians erster Regierungszeit schlieBt. Da mit Ausnahme der Schrift De Caesaribus die Verwandtschaft der Quellen sich für den ganzen Zeitraum von Philippus Arabs bis Diokletian gleichbleibt, so hat auch die Vorlage den ganzen Zeitraum umfaBt, war also nicht gleich Dexippos, der mit Claudius resp. Aurelian abschlob. Bleiben noch zwei Möglichkeiten, nämlich daB die Zosimosquelle selbst Dexipp benutzt hätte, oder da $B$ gar nicht eine, sondern zwei gemeinsame Quellen vorhanden wären, die eine davon Dexippos; die letzte Ansicht könnte dadurch gestützt werden, daB tatsächlich die Zosimos verwandten Quellen zugleich Dexippos-Exzerpte aufweisen. Doch zeigt das 4. Kapitel, daB erstens die nachweislichen Dexipposberichte zum Teil keine klare Verwandtschaft mit Zosimos aufweisen, zum Teil ihm geradezu widersprechen, zweitens, daB der in den Quellen der Zosimosverwandt-

1) Zon. und. Zos. (aus Eunap) gemeinsam; vgl. S. 119. 
schaft nach Abzug der Zosimosparallelen übrig bleibende Bestand nicht wenig Beziehungen zu Dexippos erkennen läBt. Dazu kommt, daB die „Kaisergeschichte" ganz deutlich erst von da an, wo Dexippos aufhörte, sich enger an Zosimos anschlieBt. Bestätigt wird das Verhältnis durch Kapitel 5: der Vergleich mit dem einzigen Autor, der anerkannterweise einen zusammenhängenden Dexipposbestand aufweist, mit Capitolin, ergibt ebenfalls in den mit Zosimos verwandten Quellen zwei gesonderte Elemente, deren eines mit Dexippos, deren anderes mit Zosimos übereinstimmt. Außerdem zeigt sich, daB die Hauptbeweismomente für Abhängigkeit des Zosimos von Dexippos einer anderen Erklärung sehr wohl zugänglich sind, und daB überdies Dexippos und Zosimos in der Benutzung der vordexippeischen Quellen voneinander abweichen. Entbehrt nach allem die Annahme einer Beziehung beider Geschichtswerke zueinander der Begründung, so fällt auch jede Veranlassung, die Zosimosquelle auseinanderzureißen, fort. Das letzte, 6. Kapitel versucht dann noch, die inneren Unterschiede der Zosimosquelle von Dexippos zu skizzieren, die Verwandtschaftsverhältnisse der einzelnen Quellen festzustellen und ihr Verhalten bei Benutzung ihrer verschiedenen Vorlagen anzudeuten.

Dab eine Scheidung des Dexippos von der Zosimosquelle, ja allein schon deren Feststellung, wenn gelungen, für die politische Geschichte nicht nutzlos sein würde, liegt auf der Hand. Ich will mich mit. einigen Andeutungen begnügen: Die 320000 Goten unter Claudius sind in zweien unserer Quellen, bei Treb. Pollio und Zosimos, bezeugt. Durch Zurückführung auf die Zosimosquelle wird die Angabe auf eine Quelle beschränkt, und wenn sie auch den Ereignissen zeitlich näher rückt, so hat doch die Betrachtung ergeben, daB der syrische Verfasser wohl frühestens seit Aurelian in der Lage war, sich zuverlässige Zahlenangaben über so entfernte Vorgänge zu verschaffen. Besonders für das Verständnis der Goteneinfälle ist ein Nachweis der ersten Quellen wichtig. Ihre Darstellung bei Zosimos, die anscheinend ähnlich schon in dessen Vorlage sich fand, gibt den Hintergrund, auf dem sich die anderweit überlieferten Einzelheiten erst recht abheben. Sie läbt erkennen, da $B$ es sich nicht um einzelne groBe, planmäBig geleitete Züge handelt, wie etwa die bei Dexipp berichteten des Ostrogotha und Kniwa es waren, sondern um eine seit Gallus eintretende allmähliche Überschwemmung des Reiches durch zahllose kleine Scharen, die zuerst die Grenzgebjete, dann immer weitere Länder überfluteten, aber nur in den ihrer Heimat näheren Gegenden so dicht auftraten, daB sie selbst festeren Städten, wie Thessalonike und Trapezunt, gefährlich wurden. Von dieser Auffassung aus scheint denn auch der aphoristische Charakter 
unserer sicheren Dexippos-Exzerpte nicht nur auf das Konto der Ausschreiber zu kommen, sondern ist darauf zurückzuführen, daB hier zusammengezogen ist, was bei Dexipp auf eine Reihe von Jahren verteilt war. Endlich wird auch an den römischen Gegenmabregeln nun erst verständlich, daB sie neben einer Beobachtung der Grenze vor allem die Organisation der örtlichen Verteidigung bezweckten und daB Claudius nachher ein förmliches Kesseltreiben veranstaltete. Ich kann hier nur andeuten, da $B$ diese Feststellungen uns vielleicht auf die inneren Ursachen der ganzen Bewegung leiten: ich meine die Ausbildung des gotischen Gesamtkönigtums in dieser Zeit. Was uns vorher begegnet, sind Stammeskönige, und zwar sowohl Ostrogotha wie Kniwa vermutlich westgotische; unter Konstantin tritt uns mit Ariarich und Aorich zuerst das Gesamtkönigtum entgegen. Die Masse der plündernden Scharen von Gallus bis Claudius gehörte nicht den beiden Hauptstämmen, sondern Herulern, Boranern usw. an. Das Endergebnis war trotz dieser AbstoBung einer beträchtlichen Masse der Bevölkerung eine Ausdehnung des Volksgebietes: Carpen und Bastarner treten auf römischen Boden über. Das zwingt zur Annahme einer inneren Festigung, und diese vollzog sich durch die Ausbildung des Gesamtkönigtums. Die Stütze, die diese Auffassung in der Darstellung des Zosimos erhält, würde fortfallen, wenn wir gezwungen wären, dessen Bericht auf Dexipp zurückzuführen: Geht er auf die Skythika zurück, so ist die Einfügung in den historischen Gesamtverlauf nicht authentisch, wir verlieren insbesondere jedes Urteil über die kurzen eingestreuten Angaben, die den Beginn der Bewegung betreffen; entstammt er den Chronika, so ist auch er eine Zusammenfassung des bei Dexipp gegebenen und deshalb für eine Erfassung des Wesens der Goteneinfälle ohne Wert.

Am meisten Anteil hat an Untersuchungen, wie die vorliegende ist, natürlich die Quellenkunde selbst und damit die Literaturgeschichte. Leider wird diese Wissenschaft allen Grund haben, selbst wenn sie die Ergebnisse meiner Arbeit sich aneignen sollte, sich über einen Mangel zu beklagen. Ich habe - die Richtigkeit der Resultate immer vorausgesetzt - zu den vielen schon vorhandenen noch einen neuen Anonymus gefügt; ja ich fürchte, sogar mehrere; denn ich sehe noch keinen Modus, um etwa den Urquell des Zonaras und der Leo-Sippe mit dem salmasischen Johannes zu identifizieren. Am schwersten wiegt doch die Unkenntnis über den Verfasser der Zosimosquelle selbst, eines Werkes, das schon zu Diokletians Zeiten in Hofkreisen Beachtung gefunden haben muB, aber anscheinend nie weiter verbreitet und bald durch Kompendien, die z. T. auf ihm ruhten, verdrängt worden ist. 
Einige Jahrhunderte überdauerte es im Orient, der Heimat des Verfassers, um schlieBlich auch thier in seinen Ableitungen unterzugehen. Über diese Ableitungen, so hoffe ich, wird noch einmal volles Licht verbreitet werden; es wird auch wohl noch gelingen, sie mit den Namen und Resten der überlieferten Historiker in Verbindung $\mathrm{zu}$ bringen. Dabei soll mir nicht leid tun, wenn ein gut Teil meiner Ausführungen über Bord geworfen wird. Mögen sie nur ein weniges, und sei es auch lediglich durch Erregung von Widerspruch, durch Anregung der Diskussion, zur Förderung der Erkenntnis beigetragen haben.

Berlin.

F. Graebner. 